Predição de links em redes complexas utilizando informações de estruturas de comunidades

Jorge Carlos Valverde Rebaza 

SERVIÇO DE PÓS-GRADUAÇÃO DO ICMC-USP

Data de Depósito:

Assinatura:

\title{
Predição de links em redes complexas utilizando informações de estruturas de comunidades
}

\author{
Jorge Carlos Valverde Rebaza
}

Orientador: Prof. Dr. Alneu de Andrade Lopes

Dissertação apresentada ao Instituto de Ciências Matemáticas e de Computação - ICMC-USP, como parte dos requisitos para obtenção do título de Mestre em Ciências - Ciências de Computação e Matemática Computacional. VERSÃO REVISADA 
Ficha catalográfica elaborada pela Biblioteca Prof. Achille Bassi e Seção Técnica de Informática, ICMC/USP, com os dados fornecidos pelo(a) autor(a)

\begin{tabular}{|c|c|}
\hline \multirow[t]{3}{*}{ V289p } & $\begin{array}{l}\text { Valverde Rebaza, Jorge Carlos } \\
\text { Predição de links em redes complexas utilizando } \\
\text { informaços de estruturas de comunidades / Jorge } \\
\text { Carlos Valverde Rebaza; orientador Alneu de Andrade } \\
\text { Lopes. -- São Carlos, } 2013 \text {. } \\
\quad 108 \text { p. }\end{array}$ \\
\hline & $\begin{array}{l}\text { Dissertação (Mestrado - Programa de Pós-Graduação em } \\
\text { Ciências de Computação e Matemática Computacional) -- } \\
\text { Instituto de Ciências Matemáticas e de Computação, } \\
\text { Universidade de São Paulo, } 2013 .\end{array}$ \\
\hline & $\begin{array}{l}\text { 1. Redes Complexas. 2. Predição de Links. } 3 . \\
\text { Clusterização. 4. Inferencia Probabilística. 5. Redes } \\
\text { Sociais. I. de Andrade Lopes, Alneu, orient. II. } \\
\text { Título. }\end{array}$ \\
\hline
\end{tabular}




\section{Dedicatória}

A Deus.

Aos meus pais,

Jorge e Nidia.

$\mathrm{E}$ aos meus irmãos,

Cleydee, Joel e Luis. 



\section{Agradecimentos}

Antes de tudo, agradeço a Deus pela saúde, sabedoria e toda a força que me proveu para enfrentar com sucesso os caminhos da vida. Da sua mão consegui chegar onde hoje estou. E é graças a Deus que também tenho uma grande família, a quem gostaria de agradecer em espanhol.

A mis queridos padres, Jorge y Nidia, por la confianza que han depositado en mi, por su apoyo y comprensión, asi como por las enseñanzas que me han brindado y que hoy me sirven día a día. Gracias por ser mi inspiración y mis motivos.

A mis adorados hermanos, Cleydee, Joel y Luis, por permitirme ser su amigo y guia, por su confianza, por sus bromas y sonrisas, asi como por estar siempre junto a mi. Ustedes son también mis motivos.

A mis abuelos, Carlos y Felipa, a mis tios, en especial a Merces y Aurelio, Humberto e Isabel, Manuel y Flor, Higinio, Aleja, Miriam y Franklin, Carlos, Luz y German, Marco, Andrés y Teresa, Andrés Javier y Edgar, a mis primos, sobrinos y padrinos, por su apoyo y muestras de cariño, asi como por compartir conmigo tanto las dificultades como las alegrias de la vida.

Ao professor Alneu, pela dedicação e paciência que teve comigo. Agradeço a confiança em mim depositada na realização deste trabalho e outros que tive o privilégio de por ele ser orientado, bem como pelo direcionamento no curso da minha formação no mestrado.

Aos amigos e professores do LABIC: Newton, Rafael Rossi, Rafael Giusti, Everton, Igor, Thiago, Celso, Ricardo, Bruno, Diego, Vinicius, Fabiano, Pedro, Nils, Lilian, Nathalie, Merley, Tatiane, Carolina, Solange e Gustavo, pela sua amizade e ótimos momentos de convivência dentro e fora do laboratório.

Aos amigos que fiz em São Carlos: Laura, Gabriel, Fernando, Aurea, Oscar, Lucia, Jeaneth, Roni, Eduardo, Carlos, Maysa, Valéria, Ândrea, Murillo, Edimilson, Andrew, Leonardo, Rudison e Yuri, pelo seu companheirismo e as muitas conversas com grandes trocas de ideias.

Agradeço à Universidade de São Paulo (USP) e ao Instituto de Ciências Matemáticas e de Computação (ICMC) pela oportunidade de crescimento na minha carreira profissional. Também, ao Conselho Nacional de Desenvolvimento Científico e Tecnológico (CNPq), pelo apoio financeiro.

$\mathrm{E}$ a todos, que direta ou indiretamente, contribuíram para a realização deste trabalho. 



\section{Resumo}

Diferentes sistemas do mundo real podem ser representados por redes. As redes são estruturas nas quais seus vértices (nós) representam entidades e links representam relações entre essas entidades. Além disso, as redes caracterizam-se por ser estruturas dinâmicas, o que implica na rápida aparição e desaparição de entidades e seus relacionamentos. Nesse cenário, um dos problemas importantes a serem enfrentados no contexto das redes, é da predição de links, isto é, prever a ocorrência futura de um link ainda não existente entre dois vértices com base nas informações já existentes. A importância da predição de links deve-se ao fato de ter aplicações na recuperação de informação, identificação de interações espúrias e, ainda, na avaliação de mecanismos de evolução das redes. Para enfrentar o problema da predição de links, a maioria dos métodos utiliza informações da vizinhança topológica das redes para atribuir um valor que represente a probabilidade de conexão futura entre um par de vértices analisados. No entanto, recentemente têm aparecido métodos híbridos, caracterizados por usar outras informações além da vizinhança topológica, sendo as informações das comunidades as normalmente usadas, isso, devido ao fato que, ao serem grupos de vértices densamente ligados entre si e esparsamente ligados com vértices de outros grupos, fornecem informações que podem ser úteis para determinar o comportamento futuro das redes. Assim, neste trabalho são apresentadas duas propostas na linha dos métodos baseados nas informações das comunidades para predição de links. A primeira proposta consiste em um novo índice de similaridade que usa as informações dos vértices pertencentes a mesma comunidade na vizinhança de um par de vértices analisados, bem como as informações dos vértices pertencentes a diferentes comunidades nessa mesma vizinhança. A segunda proposta consiste de um conjunto de índices obtidos a partir da reformulação de algumas propostas já existentes, porém, inserindo neles informações dos vértices pertencentes unicamente à mesma comunidade na vizinhança topológica de um par de vértices analisados. Experimentos realizados em dez redes complexas de diferentes domínios demonstraram que, em geral, os índices propostos obtiveram desempenho superior às abordagens usuais. 



\section{Abstract}

Different real-world systems can be represented as networks. Networks are structures in which vertices (nodes) represent entities and links represent relationships between these entities. Moreover, networks are dynamic structures, which implies rapid appearance and disappearance of entities and their relationships. In this scenario, the link prediction problem attempts to predict the future existence of a link between a pair of vertices considering existing information. The link prediction importance is due to the fact of having different applications in areas such as information retrieval, identification of spurious interactions, as well as for understanding mechanisms of network evolution. To address the link prediction problem, many proposals use topological information to assign a value that represents the likelihood of a future connection between a pair of vertices. However, hybrid methods have appeared recently. These methods use additional information such as community information. Communities are groups of vertices densely connected among them and sparsely connected to vertices from other groups, providing useful information to determinate the future behavior of networks. So, this research presents two proposals for link prediction based on communities information. The first proposal consists of a new similarity index that uses information about the communities that the vertices in the neighborhood of a analyzed pair of vertices belong. The second proposal is a set of indices obtained from the reformulation of various existing proposals, however, using only the information from vertices belonging to the same community in the neighborhood of a pair of vertices analyzed. Experiments conducted in ten complex networks of different fields show the proposals outperform traditional approaches. 



\section{Sumário}

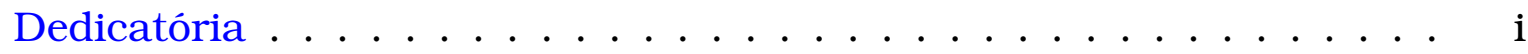

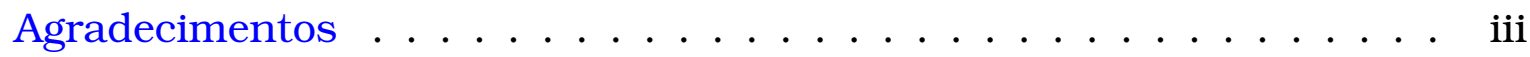

Resumo ....................... . .

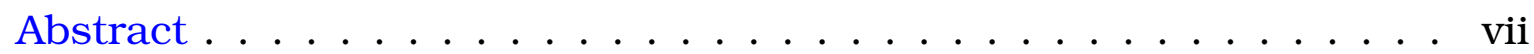

Sumário ..................... . . . . . . . . . .

Lista de Figuras . . . . . . . . . . . . . . . . . . xi

Lista de Tabelas . . . . . . . . . . . . . . . . . . $\mathrm{xv}$

Lista de Símbolos . . . . . . . . . . . . . . . . . xvii

Lista de Acrônimos . . . . . . . . . . . . . . . xix

1 Introdução 1

1.1 Contexto e Motivação . . . . . . . . . . . . . . . . 1

1.2 Problema Abordado . . . . . . . . . . . . . . . . . 2

1.3 Objetivos e Metodologia . . . . . . . . . . . . 5

1.4 Contribuições . . . . . . . . . . . . . . . 6

1.5 Organização........................ 7

2 Fundamentos $\quad 9$

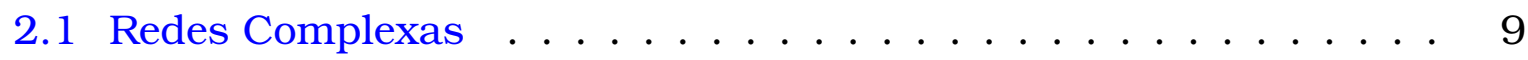

2.1.1 Representação . . . . . . . . . . . . . . 12

2.1.2 Propriedades ..................... 13

2.1.3 Modelos de Formação . . . . . . . . . . . . . . . 18

2.2 Mineração de Links . . . . . . . . . . . . . . . . . . . . 21

2.3 Considerações Finais . . . . . . . . . . . . . 25

3 Predição de Links 27

3.1 Definições e Fundamentos . . . . . . . . . . . . . . . 27

3.1.1 Princípios Teóricos . . . . . . . . . . . . 29

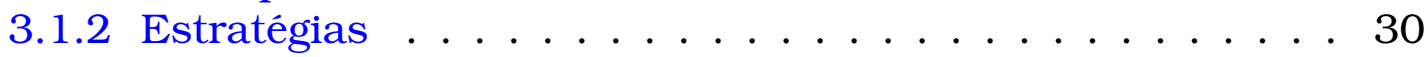

3.1 .3 Métricas de Avaliação . . . . . . . . . . . . . . . . . 32

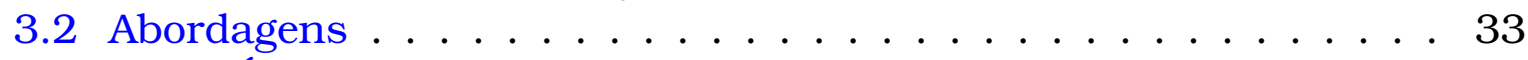

3.2.1 Índices Baseados na Similaridade . . . . . . . . . . . . 34

3.2.2 Métodos baseados na máxima verossimilhança . . . . . . . 38

3.2.3 Modelos probabilísticos . . . . . . . . . . . . . . 40

3.2.4 Métodos Híbridos . . . . . . . . . . . . . . . . . . 42 
3.3 Aplicações . . . . . . . . . . . . . . . . . . . . . . . . . 44 44

3.4 Desafios e Tendências . . . . . . . . . . . . . . . . . . 46

3.5 Considerações Finais . . . . . . . . . . . . . . . 48

4 Predição de Links baseada nas Informações das Comunidades 51

4.1 Fundamentos Teóricos da Proposta . . . . . . . . . . . . . . . 52

4.2 Obtenção das informações das comunidades . . . . . . . . . 53

4.3 Índice baseado nas Informações Intra e Inter Comunidades . . . . 55

4.4 Conjunto de Índices baseados nas Informações Intra-Comunidades 57

4.5 Considerações Finais . . . . . . . . . . . . . . 60

5 Avaliação Experimental 61

5.1 Redes Adotadas . . . . . . . . . . . . . . . . . . . 61

5.2 Metodologia Experimental . . . . . . . . . . . . . . 63

5.2.1 Detecção de Diferentes Estruturas de Comunidades . . . . 63

5.2.2 Subamostragem de Dados . . . . . . . . . . . . 64

5.2 .3 Experimentação . . . . . . . . . . . . . . . 67

5.2 .4 Medida do Desempenho . . . . . . . . . . . . . . 68

5.3 Resultados e Análise . . . . . . . . . . . . . . . . . . . . 70

5.3.1 Avaliação do Índice WIC e dos Índices da Forma W . . . . . 70

5.3.2 Avaliação dos Índices de Similaridade Estrutural e Baseados nas Informações das Comunidades . . . . . . . . . . 81

6 Considerações Finais 91

6.1 Conclusões e Principais Contribuições . . . . . . . . . . . . 91

6.2 Limitações do Trabalho . . . . . . . . . . . . . . . . . . 94

6.3 Trabalhos Futuros . . . . . . . . . . . . . . . . 95

$\begin{array}{ll}\text { Referências Bibliográficas } & 97\end{array}$ 


\section{Lista de Figuras}

2.1 Exemplo de uma rede social de coautoria em artigos científicos representada em grafo, no qual os vértices são os autores (indice e nome do cientista) e as arestas ligam autores que trabalharam juntos em um artigo. . . . . . . . . . . . . . . . . . . 12

2.2 Representação computacional do grafo da Figura 2.1 em forma de matriz de adjacência, com a primeira linha e a primeira coluna indicando o índice dos vértices. . . . . . . . . . . . . . . . . . 13

2.3 Representação computacional do grafo da Figura 2.1 em forma de lista de adjacência. As posições da lista de adjacência indicam os índices dos vértices do grafo. . . . . . . . . . . . . . . . 14

3.1 Esquema da tarefa de predição de links. Uma estrutura de rede $G$ no tempo $t$ evolui naturalmente no tempo chegando a uma estrutura diferente no tempo $t+1$. A tarefa de predição de links tenta prever os links que aparecerão nesse intervalo. Para a avaliação, é feita uma comparação entre os links preditos e os novos links reais. . . . . . . . . . . . . . . . . .

4.1 Exemplo de uma rede na qual são identificadas três comunidades diferençadas pela cor. Os vértices da mesma cor pertencem à mesma comunidade. .................

5.1 Exemplo da distribuição de dados para analise do resultados obtidos das métricas AUC e Precisão. Em (a) é mostrado um exemplo de histograma. Em (b) é mostrado um exemplo de gráfico de caixa. Os dados representados em (a) e (b) são apenas ilustrativos e não têm relação um com o outro. . . . . . . . . . . . . . 69

5.2 Exemplo de um gráfico de diferença estatística usado para representar o ranking do desempenho de diferentes métodos avaliados em diferentes conjuntos de dados. 
5.3 Resultados da predição de links para as redes adotadas quando se tem estruturas de comunidades diferentes detectadas pelos algoritmos FM (esquerda) e WT (direita). Cada ponto no gráfico indica o valor da média da AUC obtida por um dado índice em uma dada estrutura de comunidade de tamanho $M$ para (a) Airline, (b) Power e (c) Router. . . . . . . . . . . . . . . . . . . .

5.4 Resultados da predição de links para as redes adotadas quando se tem estruturas de comunidades diferentes detectadas pelos algoritmos FM (esquerda) e WT (direita). Cada ponto no gráfico indica o valor da média da AUC obtida por um dado índice em uma dada estrutura de comunidade de tamanho $M$ para (a) Industrypr, (b) Imdb-prodco e (c) PoolBlogs. . . . . . . . . . . . . . . . . .

5.5 Resultados da predição de links para as redes adotadas quando se tem estruturas de comunidades diferentes detectadas pelos algoritmos FM (esquerda) e WT (direita). Cada ponto no gráfico indica o valor da média da AUC obtida por um dado índice em uma dada estrutura de comunidade de tamanho $M$ para (a) Yeast, (b) Football e (c) Karate. . . . . . . . . . . . . . . . . . .

5.6 Resultados da predição de links para as redes adotadas quando se tem estruturas de comunidades diferentes detectadas pelos algoritmos FM (esquerda) e WT (direita). Cada ponto no gráfico indica o valor da média da AUC obtida por um dado índice em uma dada estrutura de comunidade de tamanho $M$ para NetScience.

5.7 Resultados da predição de links para as redes adotadas quando estruturas de comunidades diferentes foram detectadas pelos algoritmos FM (esquerda) e WT (direita). Cada ponto no gráfico indica o valor da média da Precisão (com $L=10 \%$ do número de links existentes, $|E|$, de cada rede) obtida por um dado índice em uma dada estrutura de comunidade de tamanho $M$ para (a) Airline, (b) Power e (c) Router. . . . . . . . . . . . . . . .

5.8 Resultados da predição de links para as redes adotadas quando estruturas de comunidades diferentes foram detectadas pelos algoritmos FM (esquerda) e WT (direita). Cada ponto no gráfico indica o valor da média da Precisão (com $L=10 \%$ do número de links existentes, $|E|$, de cada rede) obtida por um dado índice em uma dada estrutura de comunidade de tamanho $M$ para (a) Industry-pr, (b) Imdb-prodco e (c) PoolBlogs. . . . . . . . . . . . .

5.9 Resultados da predição de links para as redes adotadas quando estruturas de comunidades diferentes foram detectadas pelos algoritmos FM (esquerda) e WT (direita). Cada ponto no gráfico indica o valor da média da Precisão (com $L=10 \%$ do número de links existentes, $|E|$, de cada rede) obtida por um dado índice em uma dada estrutura de comunidade de tamanho $M$ para (a) Yeast, (b) Football e (c) Karate. . . . . . . . . . . . . . . . . . 
5.10 Resultados da predição de links para as redes adotadas quando estruturas de comunidades diferentes foram detectadas pelos algoritmos FM (esquerda) e WT (direita). Cada ponto no gráfico indica o valor da média da Precisão (com $L=10 \%$ do número de links existentes, $|E|$, de cada rede) obtida por um dado índice em uma dada estrutura de comunidade de tamanho $M$ para NetScience.

5.11 Distribuição estatística do desempenho em relação à AUC de todos os índices de predição avaliados. A linha dentro de cada caixa indica a mediana do desempenho nas dez redes avaliadas. .

5.12 Diferença estatística das dez primeiras posições do ranking da média do desempenho em relação à AUC dos índices avaliados sobre as dez redes adotadas. Para os índices de similaridade baseados nas informações das comunidades são considerados os resultados quando são usadas as informações fornecidas pelos algoritmos FM e WT. . . . . . . . . . . . . . . . . .

5.13Distribuição estatística do desempenho de todos os índices de predição avaliados. A linha dentro de cada caixa indica a mediana do desempenho respeito à Precisão com $L=10 \%$ do número de links existentes, $|E|$, de cada uma das dez redes avaliadas. . . 89

5.14 Gráfico de diferença estatística mostrando as dez primeiras posições de acordo ao ranking da média do desempenho em relação à Precisão com $L=10 \%$ do número de links existentes, $|E|$, de cada uma das dez redes avaliadas. 



\section{Lista de Tabelas}

4.1 Exemplo da computação do índice WIC. . . . . . . . . . . . . 57

5.1 Propriedades estruturais básicas de dez redes. . . . . . . . . . . 63

5.2 Informações das diferentes estruturas de comunidades obtidas usando o algoritmo Fast Modularity para cada rede adotada. . . . 65

5.3 Informações das diferentes estruturas de comunidades obtidas usando o algoritmo WalkTrap para cada rede adotada. . . . . . 66

5.4 Resultados da predição correspondentes à AUC das dez redes adotadas. Cada valor representa a média da AUC obtida pelos índices baseados nas informações das comunidades, tanto quando essas informações foram geradas pelo algoritmo FM quanto pelo algoritmo WT, e pelos índices de similaridade estrutural local e global. . . . . . . . . . . . . . . . . . . . . 83

5.5 Resultados da predição correspondentes à Precisão das dez redes adotadas, com $L=10 \%$ do número de links existentes de cada rede. Cada valor representa a média da Precisão obtida pelos índices baseados nas informações das comunidades, tanto quando essas informações são geradas pelo algoritmo FM quanto pelo algoritmo WT, e pelos índices de similaridade estrutural local e global. . . . . . . . . . . . . . . . . . 8 



\section{Lista de Símbolos}

$G \quad$ Grafo ou rede formada por um conjunto de vértices e links.

$V \quad$ Conjunto de $n$ vértices (nós) do grafo $G$.

$v_{i} \quad$ Vértice (nó) $i$ do conjunto $V$.

$E \quad$ Conjunto de $m$ arestas (links) do grafo $G$.

$e_{i, j} \quad$ Aresta (link) ligando os vértices $v_{i}$ e $v_{j}$.

$W \quad$ Conjunto de $m$ pesos correspondentes a cada aresta da rede $G$.

$A \quad$ Matriz de adjacência de tamanho $N \times N$.

$A_{i, j} \quad$ Entrada da matriz de adjacência $A$.

$k_{i} \quad$ Grau de um nó $v_{i}$.

$\langle k\rangle \quad$ Média dos graus dos vértices do grafo $G$.

$E_{i, j} \quad$ Número de links que ligam os vértices $v_{i}$ e $v_{j}$ da rede $G$.

E Matriz formada com os elementos $E_{i, j}$.

$\|\mathbf{E}\| \quad$ Soma de todos os elementos da matriz $\mathbf{E}$.

e Matriz de mistura normalizada.

$q_{k} \quad$ Distribuição de graus de uma rede $G$.

$\sigma_{q} \quad$ Desvio padrão da distribuição $q_{k}$.

$p_{k} \quad$ Probabilidade de escolher aleatoriamente um vértice de grau $k$.

$\operatorname{dist}(i, j) \quad$ Distância geodésica entre os vértices $v_{i}$ e $v_{j}$ da rede $G$.

$g_{i, j} \quad$ Número de caminhos geodésicos que ligam os vértices $v_{i}$ e $v_{j}$ da rede $G$.

$g_{j, k}\left(v_{i}\right) \quad$ Número de caminhos geodésicos do total $g_{j, k}$ que unem os vértices $v_{j}$ e $v_{k}$ passando pelo vértice $v_{i}$ em algum ponto.

$\triangle\left(v_{i}\right) \quad$ Número de 3 -cliques na vizinhança do vértice $v_{i}$ da rede $G$.

\# $\triangle \quad$ Número total de 3-cliques na rede $G$.

$\# v \quad$ Número máximo de vértices triplamente conectados na rede $G$.

$C C_{i} \quad$ Coeficiente de agrupamento local para o vértice $v_{i}$ da rede $G$.

C Coeficiente de agrupamento global para a rede $G$.

$\mathbf{r} \quad$ Coeficiente de assortatividade para uma rede $G$.

H Grau de heterogeneidade de uma rede $G$.

$|V| \quad$ Número de elementos do conjunto de vértices $V$.

$|E| \quad$ Número de elementos do conjunto de arestas $E$. 
$U \quad$ Conjunto universo de todos os possiveis links de uma rede $G$.

$s_{x, y} \quad$ Pontuação da similaridade entre dois nós $x$ e $y$ de um grafo $G$.

$\Gamma(x) \quad$ Conjunto de vizinhos do vértice $x$.

$D \quad$ Dendograma de uma rede $G$.

$\mathcal{L} \quad$ Verossimilhança de um dendograma $D$.

$H \quad$ Altura do dendograma $D$.

$L \quad$ Lista dos $L$ links com maior pontuação atribuída por um preditor.

$L_{r} \quad$ Número de folhas na subárvore à esquerda da folha raiz em um dendograma $D$.

$L_{d} \quad$ Número de folhas na subárvore à direita da folha raiz em um dendograma $D$.

Q $\quad$ Modularidade de uma rede $G$.

$M \quad$ Número de comunidades detetadas em uma rede $G$.

$C \quad$ Rótulo de uma comunidade.

$C_{x} \quad$ Comunidade de vértices contendo o vértice $x$.

$C_{x, y} \quad$ Comunidade de links contendo a aresta $e_{x, y}$.

$\sqcap_{x, y} \quad$ Conjunto de comunidades às quais os vértices $x$ e $y$ pertencem simultaneamente.

$\left|\sqcap_{x, y}\right| \quad$ Número de comunidades às quais os vértices $x$ e $y$ pertencem simultaneamente.

$x^{C} \quad$ Vértice $x$ da rede $G$ pertencente à comunidade de rótulo $C$.

$\Lambda_{x, y} \quad$ Conjunto de vizinhos comuns dos vértices $x$ e $y$.

$\Lambda_{x, y}^{W} \quad$ Conjunto de vizinhos comuns intra-comunidade dos vértices $x$ e $y$.

$\Lambda_{x, y}^{I} \quad$ Conjunto de vizinhos comuns inter-comunidade dos vértices $x$ e $y$.

$r \quad$ Proporção do total de links existentes e o total de vértices na rede $G$. 


\section{Lista de Acrônimos}

\begin{tabular}{|c|c|}
\hline AA & Índice de Adamic-Adar \\
\hline AA-W & Índice de Adamic-Adar intra-comunidade \\
\hline AM & Aprendizado de Máquina \\
\hline AUC & $\begin{array}{l}\text { Área sob a curva (Area Under the receiver operating characteris- } \\
\text { tic Curve) }\end{array}$ \\
\hline $\mathrm{CN}$ & Índice dos vizinhos comuns (Common Neighbors) \\
\hline $\mathrm{CN}-\mathrm{W}$ & $\begin{array}{l}\text { Índice dos vizinhos comuns intra-comunidade (Within-community- } \\
\text { Common Neighbors) }\end{array}$ \\
\hline DAPER & $\begin{array}{l}\text { Relacionamento de entidades probabilísticas acíclicas direciona- } \\
\text { das (Directed Acyclic Entity Relationship) }\end{array}$ \\
\hline $\mathrm{ECN}$ & $\begin{array}{l}\text { Indice dos vizinhos comuns melhorado (Enhaced Common Neigh- } \\
\text { bors) }\end{array}$ \\
\hline ERA & $\begin{array}{l}\text { Índice de alocação de recursos melhorado (Enhaced Resource A- } \\
\text { llocation) }\end{array}$ \\
\hline FM & Algoritmo Fast Modularity \\
\hline HDI & Índice do hub deprimido (Hub Depressed Index) \\
\hline HDI-W & $\begin{array}{l}\text { Índice do hub deprimido intra-comunidade (Within-community } \\
\text { Hub Depressed Index) }\end{array}$ \\
\hline HPI & Índice do hub promovido (Hub Promoted Index) \\
\hline HPI-W & $\begin{array}{l}\text { Índice do hub promovido intra-comunidade (Within-community } \\
\text { Hub Promoted Index) }\end{array}$ \\
\hline I & $\begin{array}{l}\text { Conjunto dos vizinhos comuns inter-comunidades (Inter-commu- } \\
\text { nity common neighbors set) }\end{array}$ \\
\hline IA & Inteligência Artificial \\
\hline IID & Independente e Identicamente Distribuído \\
\hline Jac & Índice de Jaccard \\
\hline Jac-W & Índice de Jaccard intra-comunidade \\
\hline LHN & Índice de Leicht-Holme-Newman \\
\hline LHN-W & Índice de Leicht-Holme-Newman intra-comunidade \\
\hline MD & Mineração de Dados \\
\hline ML & Mineração de Links \\
\hline NAG & Índice do Número de Amigos no Grupo \\
\hline
\end{tabular}


PA Índice de conexão preferencial (Preferential Attachment)

PAG Índice da Porção de Amigos no Grupo

PPI Interação proteína-proteína (Protein-Protein Interaction)

PRM Modelo probabilístico relacional (Probabilistic Relational Model)

RA Índice de alocação de recursos (Resouce Allocation)

RA-W Índice de alocação de recursos intra-comunidade (Within-community Resouce Allocation)

RBN Rede Bayesiana Relacional (Relational Bayesian Network)

RMN Rede de Markov Relacional (Relational Markov Network)

RPR Índice Rooted PageRank

Sal Índice de Salton

Sal-W Índice de Salton intra-comunidade

Sor Índice de $\mathrm{S} \phi$ rensen

Sor-W Índice de $\mathrm{S} \phi$ rensen intra-comunidade

SR Índice SimRank

$\mathrm{W}$ Conjunto dos vizinhos comuns intra-comunidade (Within-community common neighbors set)

WIC Índice intra e inter-comunidades (Within and Inter Community)

WT Algoritmo WalkTrap 


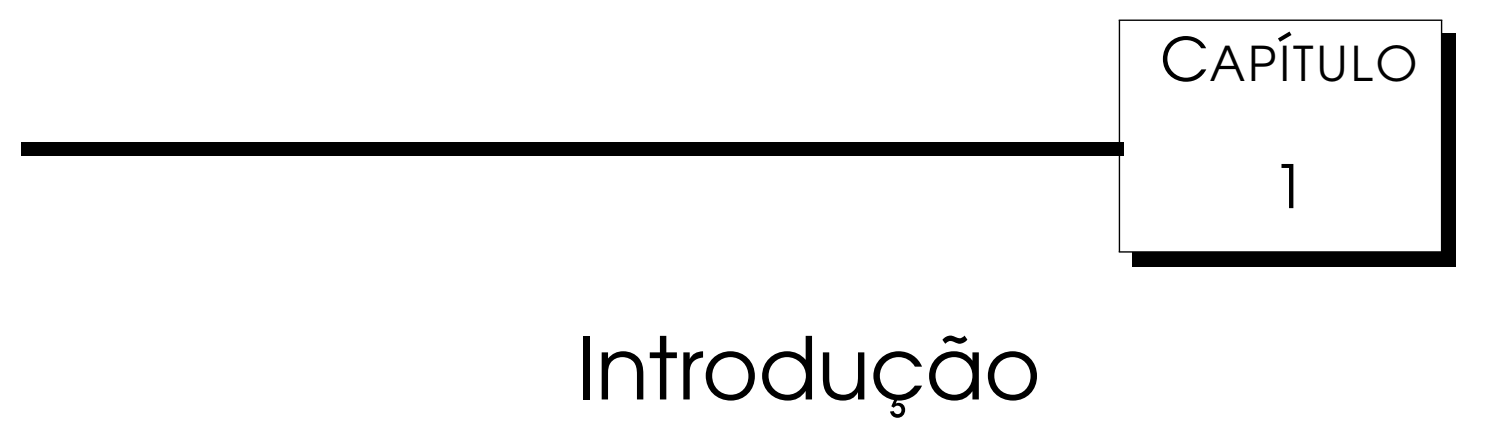

\subsection{Contexto e Motivação}

O Aprendizado de Máquina (AM) é um campo de pesquisa em Inteligência Artificial (IA) que está concentrado no desenvolvimento de algoritmos que melhorem automaticamente algum aspecto de seu desempenho através da experiência (Mitchell, 1997; Han et al., 2011). Além disso, AM apresenta aplicações bem sucedidas em inúmeras áreas, entre as quais destacam-se: visão computacional, processamento de linguagem natural, bioinformática, entre outras.

Grande parte das pesquisas em AM tem foco nos dados com estrutura "plana", ou seja, dados representados por um conjunto de pares atributovalor, e caracterizados por serem Independentes e Identicamente Distribuidos (IID). Porém, muitos conjuntos de dados que representam informações do mundo real têm uma estrutura relacional, a qual pode ser representada por redes, onde os vértices (nós) representam individuos, e os links (arestas) denotam as relações ou interações entre os vértices. Alguns exemplos de redes são: redes de páginas web ligadas por hiperlinks, redes sociais, redes de interações entre proteínas, redes de citações, entre outras (Newman, 2010; Washio et al., 2004).

Essas redes, ao modelarem sistemas naturais dinâmicos, são chamadas de redes complexas, e seu estudo tem recebido um grande interesse da comunidade científica, o qual se reflete nas pesquisas para o entendimento de sua 
evolução (Dorogovtsev e Mendes, 2002), das relações entre suas topologias e funções (Newman, 2003) e de suas propriedades (Costa et al., 2007). Parte do interesse no estudo dessas redes é devido à descrição mais expressiva que as redes fornecem na representação de diferentes domínios reais com estrutura relacional (Wang et al., 2007; Washio et al., 2004).

Dado esse crescente interesse, áreas de estudo focadas na análise das redes puderam constatar que, boa parte das redes complexas são governadas por regras não determinísticas devido ao seu comportamento naturalmente evolutivo (Barabási e Albert, 1999), isto é, ao longo do tempo, vértices e links tendem a aparecer e desaparecer, conforme um processo que não pode ser determinado com exatidão.

De maneira similar, constatou-se também que, a maioria das redes apresentam formação de grupos de vértices nos quais as conexões são densamente distribuídas internamente, mas são esparsamente distribuídas entre vértices de grupos diferentes (Granovetter, 1973; Girvan e Newman, 2002). Esses grupos de vértices, chamados também de comunidades, são importantes para descobrir diferentes comportamentos das redes bem como por fornecer informações que podem ser aproveitadas na solução de diferentes problemas em torno delas.

Assim, dada a grande dinâmica na qual as redes complexas estão inseridas, é de extrema importância entender os processos pelos quais a rede passa durante seu crescimento, para assim poder determinar com maior exatidão, como será sua estrutura no futuro. É neste contexto que o problema da predição de links se insere.

\subsection{Problema Abordado}

Predição de Links é uma das tarefas da Mineração de Links (ML), a qual procura estimar a probabilidade da existência futura de um link entre dois vértices com base nas informações dos links e dos vértices observados na rede (Getoor e Diehl, 2005). A definição formal do problema da predição de links, fornecida por Liben-Nowell e Kleinberg (2007), diz que: "dada uma rede de algum domínio, deve-se prever com precisão os links que serão adicionados à rede entre o tempo $t$ e um tempo futuro $t^{\prime \prime \prime}$.

A predição de links é uma das principais tarefas da ML e tem atraído ampla atenção das comunidades da Física e da Ciência da Computação pelo fato de ter uma grande aplicação na recuperação de informação (Bunescu e Mooney, 
2004), na identificação de interações espúrias (Kahanda e Neville, 2009), na avaliação dos mecanismos de evolução das redes (Liben-Nowell e Kleinberg, 2007; Potgieter et al., 2007), entre outras.

Assim, para resolver o problema da predição de links, diferentes métodos foram propostos, os quais, segundo Lü e Zhou (2011), podem ser divididos em três grupos: índices baseados na similaridade, métodos baseados na máxima verossimilhança e modelos probabilísticos.

As propostas pertencentes ao primeiro grupo são os chamados índices baseados na similaridade, os quais baseiam-se nas informações estruturais (topológicas) da rede. Esses índices podem ser do tipo local, nos quais são utilizadas somente as informações de um par de vértices, ou do tipo global, nos quais são utilizadas as informações de toda a rede. Uma comparação sistemática dos diferentes índices de similaridade local e global foi realizada por Liben-Nowell e Kleinberg (2007) e Zhou et al. (2009). Desse estudo concluiu-se que, entre os índices de similaridade local, o de alocação de recursos (Resource Allocation - RA) (Zhou et al., 2009) teve o melhor desempenho seguido pelos indices dos vizinhos comuns (Common Neighbors - CN) (Lorrain e White, 1971) e de Adamic-Adar (AA) (Adamic e Adar, 2003), enquanto que, entre os índices de similaridade global, destacou-se o índice Katz (Katz, 1953).

No segundo grupo são inseridos os métodos baseados na estimação da máxima verossimilhança. Esses métodos pressupõem alguns princípios de organização na estrutura da rede. Uma das propostas com maior destaque neste grupo é o modelo estrutural hierárquico, no qual, os vértices de uma rede são divididos em grupos e esses grupos, por sua vez, são divididos em sub-grupos, e assim por diante, formando uma estrutura de dendograma, no qual, os pares de vértices estreitamente relacionados são conectados antes de pares de vértices menos relacionados (Sales-Pardo et al., 2007). O modelo estrutural hierárquico foi utilizado no domínio das redes sociais e das redes biológicas (Krebs, 2002; Redner, 2008; Clauset et al., 2008).

O terceiro grupo é formado pelos modelos probabilísticos, os quais tentam abstrair a estrutura subjacente observada em uma rede complexa, para aumentar o desempenho da predição pelo uso de um modelo aprendido. Entre os modelos probabilísticos para predição de links destaca-se o modelo probabilístico relacional (Probabilistic Relational Model - PRM), o qual modela a distribuição de probabilidade conjunta e captura a influência probabilística entre os vértices e seus atributos em um domínio relacional (Poole, 1993; Koller e Pfeffer, 1998), e o modelo do Relacionamento de Entidades Probabilísticas 
Acíclicas Direcionadas (Directed Acyclic Entity Relationship - DAPER), o qual baseia-se no modelo entidade-relacionamento para a configuração de um modelo Bayesiano que fornece uma configuração específica das entidades e os relacionamentos existentes na rede (Heckerman et al., 2004b).

Ainda que as propostas pertencentes a esses três grupos tenham sido amplamente estudadas, elas apresentam algumas limitações sérias. No caso dos índices de similaridade estrutural, considerados como a abordagem mais usual, tem-se que (Zhou et al., 2009): i) os índices de similaridade local, mesmo tendo um baixo custo computacional, têm baixa acurácia na predição; ii) os índices de similaridade global têm uma maior acurácia de predição, mas ao utilizar toda a informação topológica da rede, possuem um alto custo computacional. Os métodos baseados na estimação da máxima verosimilhança apresentam também a grande desvantagem de ter uma alta complexidade computacional na geração do dendograma, a qual é quadrática no caso médio (Clauset et al., 2008). Da mesma maneira acontece com as propostas pertencentes ao terceiro grupo, os quais ao abstrair diferentes informações da rede para criar modelos mais complexos, precisam de uma maior quantidade de recursos computacionais, o que faz que seu uso seja pouco viável no domínio de redes de grande escala (Getoor e Taskar, 2007).

Dessa maneira, diferentes propostas tentaram melhorar o desempenho das medidas de similaridade estrutural para fazê-las comparáveis às propostas que têm um maior desempenho mas sem precisar de um alto custo computacional para isso. Assim, apareceram propostas que utilizam informações externas às normalmente usadas, essas propostas, chamados de métodos híbridos, utilizam as informações dos atributos dos vértices ou links (Gong et al., 2012), as informações das comunidades da rede (Zheleva et al., 2008; Soundarajan e Hopcroft, 2012), entre outras.

Contudo, a informação das comunidades tem demonstrado ser um aspecto importante que deveria ser considerado na predição de links. Os poucos trabalhos publicados baseados na predição de links com uso de informações das comunidades obtiveram resultados promissores, melhorando notavelmente a qualidade das predições (Zheleva et al., 2008; Soundarajan e Hopcroft, 2012; Valverde-Rebaza e de Andrade Lopes, 2012a,b). Mesmo assim, todavia não se buscou compreender que aspectos estão diretamente envolvidos na dinâmica das conexões dada as estruturas de comunidades das redes. Trata-se, portanto, de uma linha de pesquisa em crescimento, com muitos fundamentos a serem explorados e compreendidos, o que estimula e demanda de uma maior 
quantidade de pesquisas.

\subsection{Objetivos e Metodologia}

Com base no problema abordado, o presente trabalho tem como principal objetivo propor um método que faça uso das informações das comunidades detectadas em uma rede na predição de novos relacionamentos em redes complexas.

Para alcançar o objetivo principal de maneira satisfatória, alguns objetivos especificos foram estabelecidos:

- realizar um levantamento teórico e uma análise dos estudos mais relevantes do estado da arte da predição de links, contribuindo assim para melhor entendimento dos fundamentos, aplicabilidade, limitações e tendências da área;

- modelar uma dada rede complexa como um objeto de múltiplas estruturas de comunidades, no qual seja possível explorar características em diferentes configurações de agrupamentos de vértices ao longo da evolução do sistema;

- utilizar os conceitos referentes à qualidade das estruturas de comunidades, bem como as métricas já consolidadas na abordagem clássica da predição de links para verificar os casos nos quais as informações das comunidades melhoram o desempenho da predição;

- avaliar o desempenho das predições geradas pela abordagem baseada nas informações das comunidades frente aos resultados da abordagem tradicional baseada na similaridade estrutural.

Para avaliar a viabilidade e o desempenho dos métodos propostos, experimentos foram realizados em dez redes complexas de diferentes domínios. Assim, para cada rede avaliada, utilizaram-se dois algoritmos para detecção das comunidades, dos quais se obtiveram diferentes estruturas de comunidades diferentes. Depois disso, seguindo a metodologia de subamostragem aleatória, gerou-se dez conjuntos de treino e de teste. Com isso, para realização dos experimentos, cada conjunto de treino é adicionado às estruturas de comunidades previamente geradas. Sobre esses conjuntos de dados, são executados os índices de similaridade estrutural local e global, pertencentes à abordagem tradicional, bem como os índices propostos nesta dissertação. 
Para avaliação do desempenho, foram usadas duas métricas: AUC (área sob a curva) e Precisão. Dos resultados obtidos dessas métricas foram realizadas a análise da tendência central e da diferença estatística significativa. Finalmente, em termos gerais, os resultados mostraram que os índices propostos obtiveram um desempenho superior aos índices de similaridade estrutural da abordagem tradicional.

\subsection{Contribuições}

Para alcançar os objetivos traçados, neste trabalho foram desenvolvidas duas propostas para predição de relacionamentos inseridas nos contexto dos métodos híbridos. A primeira proposta consiste no uso das informações das comunidades às quais pertencem os vértices na vizinhança topológica de um par de vértices analisados. Essas informações são inseridas na abordagem probabilística baseada no teorema de Bayes, do qual é obtido um novo índice para predição de links. Assim, esse novo índice, caracterizado pelo uso das informações de similaridade estrutural dos vértices pertencentes à mesmas comunidades bem como dos que pertencem a comunidades diferentes, chamado de índice WIC (Within and Inter Community index), destaca-se pela sua simplicidade e bom desempenho frente aos índices de similaridade estrutural, local e global, pertencentes à abordagem tradicional.

A segunda proposta consiste de um conjunto de índices, obtidos a partir da reformulação dos índices de similaridade estrutural local com base na fundamentação teórica do índice WIC. Esse conjunto de índices, chamados de índices dos vizinhos comuns intra-comunidade, ou simplesmente índices da forma $\mathrm{W}$ (Within-community form indices), caracterizam-se pelo uso das informações de similaridade estrutural local de cada um de seus índices base bem como das informações dos vértices pertencentes às mesmas comunidades na vizinhança analisada. Cada um dos índices da forma W obtêm um melhor desempenho que seus respectivos índices de similaridade local usados como sua base, e em alguns casos, têm um melhor desempenho que índices de similaridade global.

Os resultados obtidos na aplicação das propostas foram apresentados na forma de artigos completos, sendo submetidos e aceitos para sua publicação em duas importantes conferências internacionais da área.

1. Valverde-Rebaza, Jorge e de Andrade Lopes, Alneu (2012). Link prediction in complex networks based on cluster information. Em Advances in 
Artificial Intelligence, SBIA 2012, 21th Brazilian Symposium on Artificial Intelligence, volume 7589 de Lecture Notes in Computer Science, páginas 92-101. Springer (Valverde-Rebaza e de Andrade Lopes, 2012a): Neste artigo são mostrados os resultados preliminares da pesquisa desenvolvida e apresentados nesta dissertação.

2. Valverde-Rebaza, Jorge e de Andrade Lopes, Alneu (2012). Structural Link Prediction Using Community Information on Twitter. Em Proceedings of the 2012 Fourth International Conference on Computational Aspects of Social Networks, CASON 2012, páginas 132-137. IEEE (Valverde-Rebaza e de Andrade Lopes, 2012b): Neste artigo são apresentados os resultados obtidos na aplicação do índice WIC para predição de links em uma rede social online de grande escala, como é Twitter, caracterizada por ser uma rede direcionada.

\subsection{Organização}

Em função da proposta de pesquisa e dos objetivos levantados, esta dissertação esta organizada da seguinte maneira.

- Capítulo 2: apresenta os principais conceitos teóricos relacionados ao tema de pesquisa e que serão relevantes para o desenvolvimento da dissertação em questão.

- Capítulo 3: apresenta a fundamentação, técnicas e metodologias do problema da predição de links, bem como suas aplicações práticas e tendências futuras.

- Capítulo 4: apresenta em detalhe a formulação teórica dos métodos propostos para predição de relacionamentos.

- Capítulo 5: expõe os experimentos realizados nas redes complexas adotadas e apresenta uma análise dos resultados obtidos.

- Capítulo 6: apresenta as considerações finais deste trabalho, apresentando as conclusões e contribuições de nossa pesquisa bem como as limitações e algumas sugestões de trabalhos futuros que podem ser feitos como continuação de nossa pesquisa. 



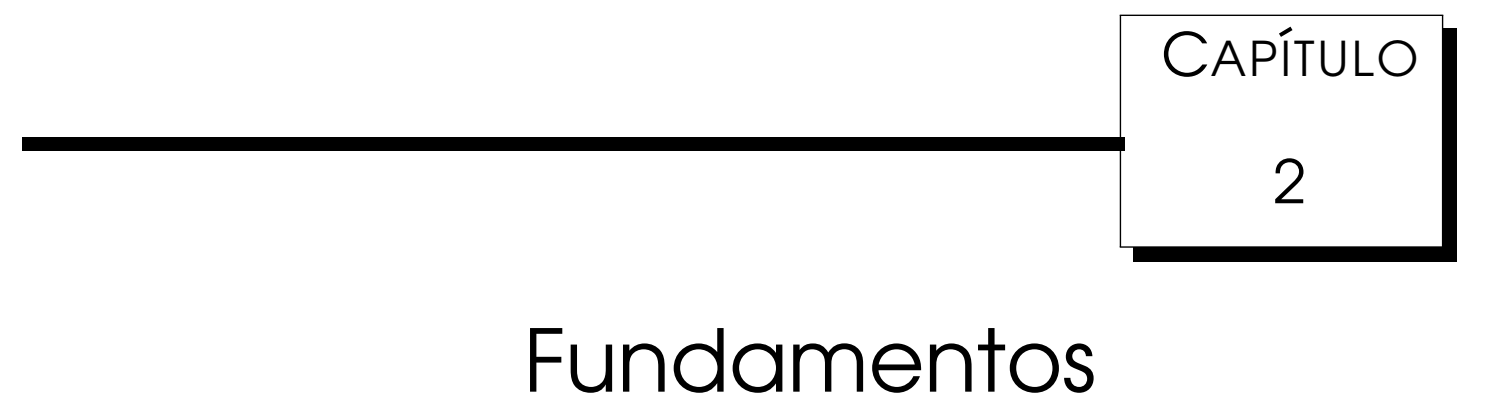

s redes complexas modelam sistemas naturais dinâmicos os quais
têm uma diversidade de propriedades e características que têm sido
o foco de estudo da comunidade científica, especialmente pelo grande impacto que suas aplicações têm no mundo real. Entre essas aplicações destacam-se aquelas relacionadas com a aparição de novos relacionamentos entre os indivíduos que formam parte de uma dada rede.

Neste capítulo são apresentados os principais conceitos das redes complexas e da mineração de links, os quais são relevantes para o desenvolvimento da dissertação em questão.

\subsection{Redes Complexas}

As redes complexas são especialmente caracterizadas pelo estudo do comportamento de vários sistemas naturais dinâmicos modelados através de grafos. Tais grafos podem ter milhares, milhões ou bilhões de vértices e arestas que representam interações entre esses vértices. A pesquisa em redes complexas é multidisciplinar e engloba conceitos de teoria dos grafos, estatística e sistemas complexos para apoiar a caracterização, análise e modelagem dos mais variados fenômenos (Newman, 2010).

Uma rede ${ }^{1}$ pode ser definida como um conjunto de itens conectados por relações existentes entre si, nos quais os itens são os vértices (nós) e suas

\footnotetext{
${ }^{1}$ Nesta dissertação vai-se usar os termos grafo e rede como sinônimos.
} 
conexões são os links (arestas). Formalmente, uma rede $G=(V, E)$ contém um conjunto de $n=|V|$ vértices, $V=\left\{v_{1}, v_{2}, \ldots, v_{n}\right\}$, e um conjunto de $m=|E|$ links, $E=\left\{e_{1}, e_{2}, \ldots, e_{m}\right\}$ (Newman, 2004a).

Com relação à forma como os vértices e links armazenam informações importantes ao entendimento da rede como um todo, uma rede pode ser classificada como multimodal, quando as informações estão presentes nos vértices, diferenciando-os entre si; multirrelacional ou multidimensional, quando as informações estão presentes nas ligações, o que permite a existência de diferentes tipos de links (Wasserman e Faust, 1994); ou ainda heterogênea quando é multimodal, multirrelacional ou ambos (Han, 2009).

Os links ainda apresentam duas propriedades importantes que devem ser consideradas, pois variam dependendo do tipo de rede em questão. Essas propriedades são o direcionamento e a valoração (Newman, 2010; Soares, 2012).

O direcionamento é a propriedade que indica o tipo de relacionamento entre os vértices participantes. Relacionamentos são direcionais quando um de seus vértices atua como transmissor e outro como receptor. Quando as relações de uma rede são direcionadas, a rede é chamada de direcionada, orientada ou dígrafo, e as arestas são representadas graficamente por meio de setas, as quais indicam a direção do link. Em contrapartida, quando a relação entre os vértices participantes de um relacionamento é recíproca, a rede é chamada de não direcionada ou não orientada, e os links são representados graficamente por meio de linhas, indicando a ausência de direcionamento na conexão .

Uma relação é chamada de valorada quando um peso, seja discreto ou contínuo, pode ser atribuído a ela. Dessa maneira, quando os links de uma rede são valorados, além da rede ser formada pelos conjuntos $V$ e $E$, ela possui ainda um conjunto $W=\left\{w_{1}, w_{2}, \ldots, w_{m}\right\}$ representando o peso de cada link. Desse modo, a rede passa a ser representada por $G=(V, E, W)$. Na Figura 2.1, é apresentado um exemplo de rede não direcionada e não valorada.

Além disso, considerando que diferentes sistemas dinâmicos podem ser categorizados em um contexto de redes complexas, para facilitar seu entendimento, Newman (2010) apresenta uma divisão das redes em quatro categorias: redes tecnológicas, redes de informação, redes biológicas e redes sociais.

Redes Tecnológicas: As redes tecnológicas são redes construídas pelo homem com o objetivo de melhorar a distribuição de algum recurso. Um exemplo é a rede de energia elétrica, que é uma rede de alta tensão com linhas de transmissão que se estendem por um país ou parte dele. Outros exemplos são as redes de rotas de companhias aéreas, redes telefônicas 
e a rede de conexões entre computadores (Internet).

Redes de Informação: As redes de informação, ou também chamadas redes de conhecimento, caracterizam-se por armazenar certo tipo de informação ou conhecimento em seus vértices. Um dos exemplos clássicos é a rede de citações entre artigos acadêmicos, na qual, os vértices representam artigos acadêmicos e uma aresta direcionada do artigo $A$ ao artigo $B$ indica que A está citando B. Outro importante exemplo de rede de informação é a rede mundial de computadores (World Wide Web) que contém informações de páginas web ligadas umas as outras por meio de hiperlinks.

Redes Biológicas: As redes biológicas representam sistemas biológicos como redes. O exemplo clássico dessas redes é a rede de via metabólica, que é uma representação de substratos e produtos metabólicos com arestas direcionadas que os juntam caso uma reação metabólica conhecida atue sobre um determinado substrato e produza um determinado produto. Outras importantes redes biológicas são as redes de interação entre proteínas (PPI) e as redes de regulação genética.

Redes Sociais: As redes sociais modelam um conjunto de indivíduos ou grupos de indivíduos com algum padrão de contatos ou interações entre si. Esses padrões de contato podem ser de amizade entre indivíduos, de negócios entre empresários, de colaboração entre cientistas, entre outros. Um exemplo de rede social de colaboração é a rede de coautoria (ver Figura 2.1), na qual cientistas são representados nos vértices do grafo e as arestas ligam os cientistas que colaboraram entre si para publicação de um artigo. A análise das redes sociais tem sido o foco de diferentes pesquisas devido ao grande impacto que seu estudo tem na vida real, por exemplo: para a análise de doenças e epidemias (Christakis e Fowler, 2007), para a análise de conteúdo da Web 2.0 (Tang et al., 2009), para melhorar o desempenho de aplicações do comércio eletrônico (eCommerce) (Swamynathan et al., 2008) e do governo eletrônico (eGovernment) (Maciel et al., 2009), para melhorar a acurácia nos sistemas de recomendação de usuários e itens (Xiang et al., 2010), para a medição de fatores na economia (Mayer, 2009), entre outros. 


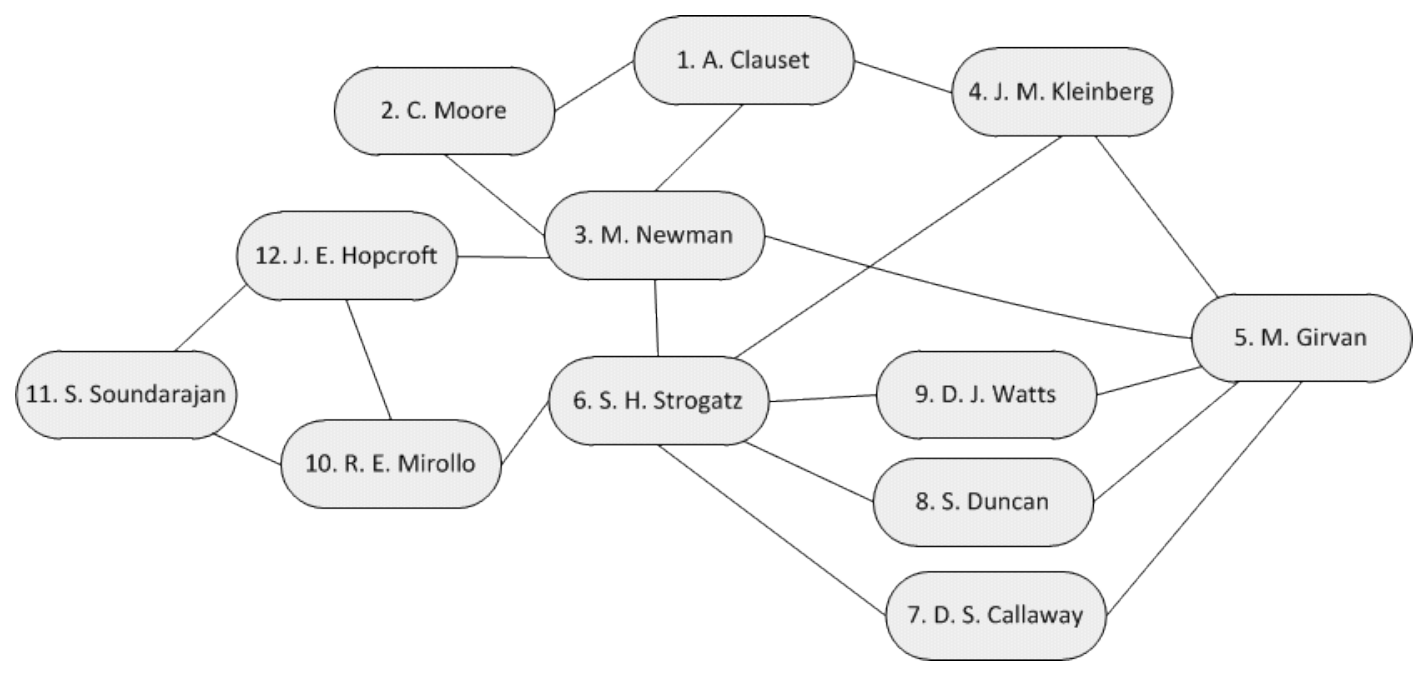

Figura 2.1: Exemplo de uma rede social de coautoria em artigos científicos representada em grafo, no qual os vértices são os autores (indice e nome do cientista) e as arestas ligam autores que trabalharam juntos em um artigo.

\subsubsection{Representação}

A representação gráfica é útil para o entendimento e visualização de algumas propriedades de um grafo. Porém, quando o grafo é muito grande e complexo, esse tipo de representação não é muito adequada. Além disso, devido ao processamento das redes serem através de programas de computador, tornaram-se necessárias o uso de outras representações (Soares, 2012). Assim, considerando o grafo $G=(V, E)$, a seguir são apresentadas as principais representações utilizadas para os grafos.

Matriz de Adjacência: Representação na qual os vértices da rede são dispostos nas linhas e colunas de uma matriz em uma ordem predefinida, o que se faz é numerar os vértices arbitrariamente de 1 até $n$.

Assim, teria-se uma matriz $A$, com número de linhas e colunas igual ao número de vértices. No caso de uma rede não direcionada, se dois vértices $v_{i}$ e $v_{j}$ estão ligados, as entradas $A_{i, j}$ e $A_{j, i}$ na matriz são iguais a 1 , caso contrário são iguais a 0 , isto é, tem-se uma matriz simétrica. No caso de uma rede direcionada, se o vértice $v_{i}$ possui uma ligação direcionada ao vértice $v_{j}$ então somente a entrada $A_{i, j}$ é igual a 1 , caso contrário é igual a 0 . O valor do elemento $A_{i, j}$ poderia ser o peso $w_{k}$ do link $e_{i, j}$, se o link é valorado.

Na Figura 2.2 é apresentada a representação computacional do grafo da Figura 2.1 na forma de uma matriz de adjacência. A primeira linha 
e a primeira coluna, dessa matriz de adjacência, indicam o índice dos vértices do grafo.

\begin{tabular}{|c|c|c|c|c|c|c|c|c|c|c|c|c|}
\hline & 1 & 2 & 3 & 4 & 5 & 6 & 7 & 8 & 9 & 10 & 11 & 12 \\
\hline 1 & 0 & 1 & 1 & 1 & 0 & 0 & 0 & 0 & 0 & 0 & 0 & 0 \\
\hline 2 & 1 & 0 & 1 & 0 & 0 & 0 & 0 & 0 & 0 & 0 & 0 & 0 \\
\hline 3 & 1 & 1 & 0 & 0 & 1 & 1 & 0 & 0 & 0 & 0 & 0 & 1 \\
\hline 4 & 1 & 0 & 0 & 0 & 1 & 1 & 0 & 0 & 0 & 0 & 0 & 0 \\
\hline 5 & 0 & 0 & 1 & 1 & 0 & 0 & 1 & 1 & 1 & 0 & 0 & 0 \\
\hline 6 & 0 & 0 & 1 & 1 & 0 & 0 & 1 & 1 & 1 & 1 & 0 & 0 \\
\hline 7 & 0 & 0 & 0 & 0 & 1 & 1 & 0 & 0 & 0 & 0 & 0 & 0 \\
\hline 8 & 0 & 0 & 0 & 0 & 1 & 1 & 0 & 0 & 0 & 0 & 0 & 0 \\
\hline 9 & 0 & 0 & 0 & 0 & 1 & 1 & 0 & 0 & 0 & 0 & 0 & 0 \\
\hline 10 & 0 & 0 & 0 & 0 & 0 & 1 & 0 & 0 & 0 & 0 & 1 & 1 \\
\hline 11 & 0 & 0 & 0 & 0 & 0 & 0 & 0 & 0 & 0 & 1 & 0 & 1 \\
\hline 12 & 0 & 0 & 1 & 0 & 0 & 0 & 0 & 0 & 0 & 1 & 1 & 0 \\
\hline
\end{tabular}

Figura 2.2: Representação computacional do grafo da Figura 2.1 em forma de matriz de adjacência, com a primeira linha e a primeira coluna indicando o índice dos vértices.

Lista de Adjacência: Considerando que uma representação matricial não é uma das mais eficientes quando tem-se um grafo muito grande, pois precisa-se de uma grande quantidade de espaço de armazenamento. $\mathrm{O}$ problema torna-se ainda mais crítico quando o grafo é esparso, pois, ao apresentar poucas conexões, a maioria das entradas da matriz indicarão a inexistência de links, desperdiçando recursos computacionais.

Assim, usando uma lista cujas posições são indexadas apenas pelos vértices do grafo, e cada uma dessas posições, por sua vez, contém uma lista composta pelos vértices adjacentes ao vértice que indexa a posição em questão. Com a lista de adjacência, o uso de memória torna-se mais eficiente.

Na Figura 2.3 é apresentada a representação computacional do grafo da Figura 2.1 na forma de uma lista de adjacência. Cada posição da lista é indexada por um índice dos vértices do grafo.

\subsubsection{Propriedades}

As redes do mundo real são geralmente estruturas complexas, isto é, não são governadas por fórmulas determinísticas (redes regulares), nem são geradas por processos puramente randômicos (Soares, 2012). Baseado nos conceitos apresentados por Newman (2001, 2003, 2010) e Costa et al. (2007), uma breve descrição de algumas propriedades das redes complexas, usadas no desenvolvimento deste trabalho, são apresentadas a seguir. 


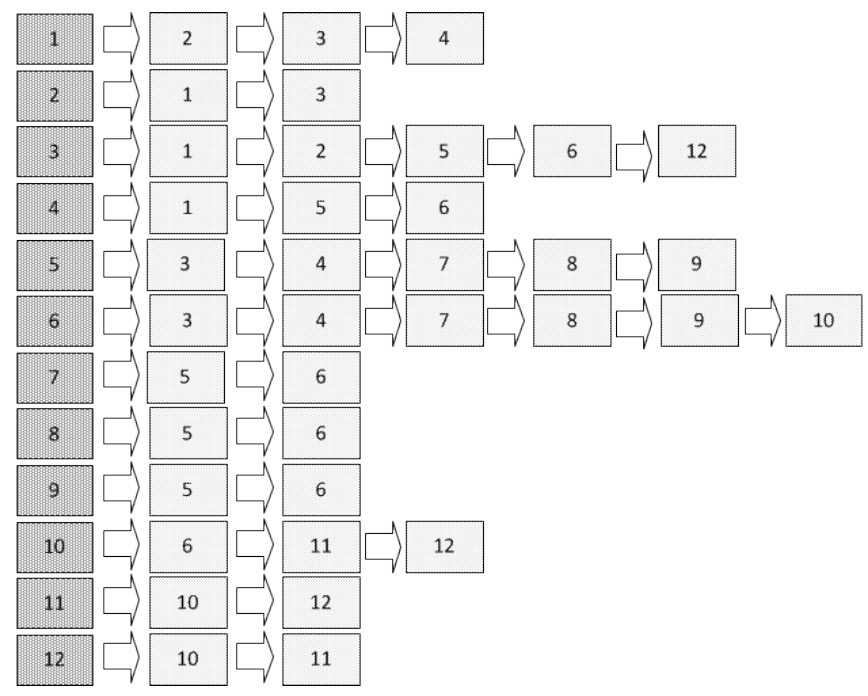

Figura 2.3: Representação computacional do grafo da Figura 2.1 em forma de lista de adjacência. As posições da lista de adjacência indicam os índices dos vértices do grafo.

Centralidade: A análise da centralidade ajuda a identificar quais vértices são importantes dentro de uma rede, ou seja, quais vértices são relevantes para o fluxo de informação ${ }^{2}$ na rede desde um ponto de vista topológico. Três características levam a três diferentes conceitos de centralidade: de grau, de proximidade, e de intermediação.

- Grau de um vértice: O grau de um vértice representa o número de arestas incidentes nele. No caso de um dígrafo, o grau pode ser determinado de duas maneiras: i) a partir do número de arestas que chegam ao vértice (grau de entrada); ii) a partir do número de arestas que saem do vértice (grau de saída). Assim, o grau de um vértice indica o número de vértices diretamente ligados a ele, conforme a Equação 2.1.

$$
k_{i}=\left|\Gamma\left(v_{i}\right)\right|
$$

Onde $\Gamma\left(v_{i}\right)$ representa o conjunto de vértices vizinhos ao vértice $v_{i}$, e $\left|\Gamma\left(v_{i}\right)\right|$ mede a cardinalidade desse conjunto, ou seja, representa o número de vizinhos do vértice $v_{i}$.

- Proximidade: A proximidade de um vértice indica quão próximo ele está de todos os demais vértices da rede. Para seu cálculo, pri-

\footnotetext{
${ }^{2}$ Fluxo de informação em uma rede é entendido como a maneira que uma mensagem poderia ser espalhada dentro dela.
} 
meiro deve-se obter a soma das distâncias geodésicas ${ }^{3}$ do vértice em relação aos demais vértices da rede. Assim, o grau de proximidade é definido na Equação 2.2.

$$
\text { proximidade }_{i}=\frac{1}{\sum_{v_{j} \in V, v_{j} \neq v_{i}} \operatorname{dist}\left(v_{i}, v_{j}\right)}
$$

Onde $\operatorname{dist}\left(v_{i}, v_{j}\right)$ representa a distância geodésica entre os vértices $v_{i}$ e $v_{j}$. Quanto mais próximo de 1 for o valor de proximidade, mais próximo está o vértice analisado dos demais.

- Intermediação (Betweenness): O grau de intermediação analisa a frequência com que um vértice aparece no caminho geodésico entre dois outros vértices quaisquer, ou seja, este grau tenta identificar vértices com grande potencial de controle do fluxo de informação na rede. O grau de intermediação é definido na Equação 2.3.

$$
\text { intermediacao }_{i}=\sum_{i \neq j \neq k} \frac{g_{j, k}\left(v_{i}\right)}{g_{j, k}}
$$

Onde $g_{j, k}$ é o número de caminhos geodésicos que ligam os vértices $v_{j}$ e $v_{k}$, e $g_{j, k}\left(v_{i}\right)$ é o número de caminhos geodésicos do total $g_{j, k}$ que unem os vértices $v_{j}$ e $v_{k}$ passando pelo vértice $v_{i}$ em algum ponto.

Densidade: Indica o grau de coesão entre os membros de uma rede, isto é, o quão conectadas estão as entidades com relação ao número máximo de possíveis conexões na rede. Assim, a densidade representa a proximidade de seus membros. Segundo Wasserman e Faust (1994), quanto mais densa é uma rede, melhor o fluxo de informação entre as entidades que a compõem. A equação da densidade para um grafo $G$ é dada pela Equação 2.4 .

$$
\operatorname{densidade}(G)=\frac{2 \cdot|E|}{|V| \cdot(|V|-1)}
$$

Caso o grafo seja direcionado, as arestas só são contabilizadas em uma direção, por isso, não é feita a multiplicação por 2 no numerador da Equação 2.4 .

\footnotetext{
${ }^{3}$ Distância geodésica corresponde ao tamanho de um caminho geodésico, o qual é o menor caminho possivel entre um par de vértices, sendo o tamanho do caminho a quantidade de links existentes entre o vértice de origem e de destino.
} 
Clique: Um clique é um grafo de densidade máxima, isto é, todos os seus membros estão conectados entre si. Mesmo que não seja um clique, um grafo pode conter diversos subgrafos que são cliques, caracterizando um distinto grupo de vértices (altamente conectados) do restante da rede. Um clique composto por $n$ vértices é chamado de $n$-clique.

Coeficiente de Agrupamento Local: Introduzido por Watts e Strogatz (1998), mede o quão próximo os vizinhos de um vértice estão de formar um clique. Em outras palavras, mede a transitividade ${ }^{4}$. Assim, o coeficiente de agrupamento local para um vértice $v_{i}$ é dado pela proporção entre o número de triângulos, 3-clique, dos quais $v_{i}$ faz parte, dividido pelo número de ligações que poderiam existir na vizinhança de $v_{i}$. Sua representação matemática é apresentada na Equação 2.5.

$$
C C_{i}=\frac{2 \cdot \triangle\left(v_{i}\right)}{\left|\Gamma\left(v_{i}\right)\right| \cdot\left(\left|\Gamma\left(v_{i}\right)\right|-1\right)}
$$

Onde $\triangle\left(v_{i}\right)$ é o número de triângulos na vizinhança do vértice $v_{i}$. Quando nenhum dos vizinhos de um vértice estão conectados entre si, o vértice apresenta um coeficiente de agrupamento local nulo. Em contrapartida, se todos os seus vizinhos apresentam conexões unindo-os uns aos outros, formando um triângulo, o valor de seu coeficiente de clusterização é 1, o qual é o máximo valor possível.

Coeficiente de Agrupamento Global: O coeficiente de agrupamento global, também conhecido como coeficiente de aglomeração, é baseado na contagem de triângulos presentes na rede, da mesma forma que o coeficiente de agrupamento local, diferindo apenas pelo fato de ser uma medida global referente à rede como um todo e não unicamente a um vértice específico. O coeficiente de agrupamento global é definido na Equação 2.6 .

$$
\mathbf{C}=\frac{3 \times \# \triangle}{\# v}
$$

Onde $\# \triangle$ é o número de triângulos na rede, e \#v refere-se ao número máximo de vértices triplamente conectados. Deve-se considerar que, na

\footnotetext{
${ }^{4} \mathrm{~A}$ transitividade ocorre quando um vértice $v_{i}$ está ligado a um vértice $v_{j}$, e este, por sua vez, está conectado a um vértice $v_{k}$, aumentando as chances de $v_{i}$ também estar conectado a $v_{k}$. No caso particular de uma rede direcionada, deve-se ter em conta a orientação das arestas.
} 
Equação 2.6, o fator 3 no numerador é necessário para garantir que o valor deste coeficiente seja um valor entre 0 e 1 .

Coeficiente de Assortatividade: Este coeficiente baseia-se na correlação entre graus de vértices adjacentes. Seja $E_{i, j}$ a quantidade de links na rede que ligam os vértices $i$ e $j$, e seja $\mathbf{E}$ a matriz formada com os elementos $E_{i, j}$, define-se a matriz de mistura normalizada e, como:

$$
\mathbf{e}=\frac{\mathbf{E}}{\|\mathbf{E}\|}
$$

Onde $\|\mathbf{E}\|$ é a soma de todos os elementos da matriz E. Considerando-se que $p_{k}$ é a probabilidade de escolher aleatoriamente um vértice de grau $k$, define-se a distribuição de graus como:

$$
q_{k}=\frac{(k+1) \cdot p_{k+1}}{\sum_{k} k \cdot p_{k}}
$$

Considerando esses conceitos, o coeficiente de assortatividade para uma rede não direcionada, é:

$$
\mathbf{r}=\frac{\sum_{j, k} j \cdot k \cdot\left(\mathbf{e}_{j, k}-q_{j} \cdot q_{k}\right)}{\sigma_{q}^{2}}
$$

Onde $\sigma_{q}$ é o desvio padrão da distribuição $q_{k}$.

Média do Grau: A média do grau é obtida a partir dos graus de cada vértice da rede, descrita pela Equação 2.10. Com seu cálculo é possivel identificar vértices com alto grau em relação a média, os quais são conhecidos como hubs. Esses vértices, além de seu destaque individual, têm importante papel na formação da estrutura das redes complexas, representando importantes conexões.

$$
\langle k\rangle=\frac{1}{|V|} \cdot \sum_{i=1}^{|V|} k_{i}
$$

Grau de Heterogeneidade: Indica quão sensível é uma rede em relação aos graus de seus vértices. É definida na Equação 2.11.

$$
\mathbf{H}=\frac{\left\langle k^{2}\right\rangle}{\langle k\rangle^{2}}
$$


Resiliência: Indica a capacidade de uma rede para tolerar a perda de membros sem que haja deficiência no fluxo de informação. A perda de vértices implica na perda de ligações, o que por sua vez pode ocasionar um aumento significativo no menor caminho entre dois vértices distintos, ou ainda partir a rede em diversos componentes não conectados entre si.

Formação de Comunidades: A formação de comunidades é uma propriedade presente nas redes que possuem grupos de vértices nos quais as conexões são densamente distribuídas internamente e esparsamente distribuídas entre vértices de grupos distintos, ou seja, os elementos de cada grupo são fortemente conectados entre si e fracamente conectados com os elementos de outros grupos. Essa propriedade é chamada de estrutura de comunidade, módulo ou agrupamento (Newman, 2001; Girvan e Newman, 2002; Brandes et al., 2003; Fortunato, 2010; Newman, 2010).

No contexto social, a sociedade oferece de maneira natural uma grande variedade de possíveis formas de agrupamentos: famílias, círculos de amizade ou de contatos profissionais, cidades, países, entre outros. A difusão da Internet e a existência de redes sociais online levou à criação de comunidades virtuais. No contexto biológico, micro-organismos se organizam de maneira natural, formando agrupamentos entre aqueles que têm certa compatibilidade ou com aqueles com cuja interação garantem sua sobrevivência. Isso acontece com todos os diferentes sistemas dinâmicos que podem ser representados mediante redes, ou seja, indivíduos buscam sempre uma maneira de se agrupar.

Assim, uma comunidade é um agrupamento de vértices que têm uma alta probabilidade de compartilhar propriedades comuns e/ou ter papeis similares na rede. As comunidades existentes nas redes reais caracterizamse por, em geral, permitir a coexistência de muitos vértices de baixo grau com outros vértices de alto grau (Fortunato, 2010; Newman, 2010).

\subsubsection{Modelos de Formação}

Diferentes autores tentaram explicar o processo de formação das redes, propondo diferentes modelos matemáticos, dos quais, nesta seção são apresentados três deles: modelo de rede aleatória, modelo do mundo pequeno, e modelo da rede de livre escala. 
Rede Aleatória

O modelo de rede aleatória é o modelo de formação de redes mais simples, foi proposto por Solomonoff e Rapoport (1951) e, de maneira independente, por Erdös e Rényi (1959). Nesse modelo, a formação da rede segue um processo aleatório, onde partindo de um conjunto de $n$ vértices, as conexões que ligam os vértices uns aos outros ocorrem com probabilidade $p$.

A distribuição de graus segue uma distribuição binomial $b(n, p)$. Portanto, em uma rede aleatória, a probabilidade de que haja $m$ arestas é dada por $p^{m}(1-p)^{|U|-m}$, onde $|U|=\frac{n(n-1)}{2}$ é o máximo número de arestas possíveis no grafo $^{5}$. Assim, tem-se que o grau esperado $\lambda$ de um vértice é $p(n-1)$ (Newman, 2003).

A medida que o número de vértices aumenta, a distribuição aproxima-se de um processo de Poisson devido à presença ou ausência de arestas serem considerados como eventos independentes. Assim, a probabilidade de que um vértice possua grau $k$, é dada pela Equação 2.12.

$$
p_{k}=\left(\begin{array}{l}
n \\
k
\end{array}\right) p^{k}(1-p)^{n-k} \simeq \frac{\lambda^{k} e^{-\lambda}}{k !}
$$

Assim, quando a quantidade média de links por vértice extrapola o valor crítico de 1 , o número de vértices que não são alcançáveis por outros vértices dentro da rede decresce exponencialmente. Outra implicação deste modelo é que para uma rede grande, ainda que os links estejam dispostos de maneira aleatória, boa parte dos vértices terão aproximadamente o mesmo grau, o que significa que a longo prazo, nenhum vértice será favorecido ou isolado (Newman, 2003, 2010).

Rede Mundo Pequeno

Com base no conceito de Seis Graus de Separação, Granovetter (1973) propõe que, dentro de uma rede de relacionamentos sociais, a informação é eficientemente espalhada pelas ligações de fraca relevância (links fracos) do que por sólidos relacionamentos.

Assim, segundo o estudo de Granovetter, a sociedade seria composta por grupos altamente conectados, existindo apenas poucos vínculos externos (liga-

\footnotetext{
${ }^{5}|U|$ é a cardinalidade do conjunto $U$, o qual é o conjunto universal de todas as possiveis arestas no grafo.

${ }^{6}$ Conceito apresentado por Stanley Milgram em 1967, o qual diz que existe um número muito pequeno que separa um individuo de outro em uma rede. Stanley verificou que o grau médio de separação entre dois vértices de uma rede aproxima-se de 6 .
} 
ções fracas) que conectam esses grupos a outros, evitando o isolamento deles com o resto da rede. Em outras palavras, Granovetter observou a presença de estruturas de comunidades, as quais foram melhor conceitualizadas por Girvan e Newman (2002).

Dada a existência de grupos de vértices e da importância das ligações fracas que os unem, o processo de formação de uma rede com essas características não pode ser modelado por um modelo puramente randômico, dado que seguindo essa abordagem, a probabilidade de que dois indivíduos próximos se conheçam é a mesma que dois completos estranhos possuam um vínculo (Soares, 2012).

Assim, Watts e Strogatz (1998) propuseram uma alternativa ao modelo randômico de Erdös e Rényi, com o intuito de explicar a ocorrência de grupos na maioria das redes reais. Seu modelo proposto, conhecido como modelo mundo pequeno, consiste inicialmente em criar grupos densos (grupos de vértices altamente conectados) na rede, para depois inserir novos links ligando vértices aleatoriamente escolhidos. Esses links oferecem atalhos cruciais entre vértices distantes, evitando o isolamento dos grupos e diminuindo o grau de separação entre os vértices da rede. Por fim, o modelo consegue reproduzir o efeito mundo pequeno, o que é compatível com as descobertas de Stanley e Ganovetter.

\section{Rede de Livre Escala}

Ao estudar as propriedades da Web como uma rede, Barabási e Albert (1999) descobriram uma característica não observada pelos modelos anteriormente apresentados. Esses autores verificaram a existência de vértices altamente conectados, os quais chamaram de hubs, e caracterizam-se por estarem presentes em diversas redes complexas e exercerem um papel importante na disseminação de informações dentro de um sistema.

Barabási e Albert verificaram que para comportar a existência de tais hubs, a distribuição de links na rede deveria seguir uma lei de potência, conforme à Equação 2.13.

$$
p_{k} \sim k^{-\gamma}
$$

Onde $\gamma$ é o expoente do grau, que para a maioria dos sistemas varia em torno de 2 e 3. Essa distribuição consegue comportar o fato de que, em muitas redes, grande parte dos vértices possuem poucos links, e coexistem com poucos vértices com alto poder de associação (hubs). Essa característica fez que a 
distribuição dos graus dos vértices tenha uma curva exponencial que permite uma contínua hierarquia de vértices, desde os hubs aos numerosos vértices pouco conectados. Pela ausência de uma escala, esse modelo foi chamado de livre de escala ou sem escala.

O entendimento dos conceitos das leis de potência e dos hubs que emergem do modelo livre de escala, Barabási e Albert demonstraram que grande parte das redes reais apresenta como uma característica bem específica, a conexão preferencial, fenômeno conhecido como rico fica mais rico. Assim, o que acontece no processo de crescimento das redes é que não são os vértices mais antigos os mais propensos a adquirirem links ao longo do tempo, senão, são os novos membros os mais favoráveis a se conectarem com aqueles que apresentam mais conexões na rede. Logo, os vértices mais bem conectados serão escolhidos com mais frequência e crescerão mais rapidamente que outros vértices menos conectados.

\subsection{Mineração de Links}

Como mencionado anteriormente, grande parte das pesquisas em Aprendizado de Máquina (AM) têm foco nos dados com estrutura "plana", isto é, representados por um conjunto de pares atributo-valor. Porém, muitos conjuntos de dados que representam informações do mundo real têm uma estrutura relacional, na qual os dados são multirrelacionados e interdependentes (Newman, 2010).

Os dados relacionais, como por exemplo as redes, consideram os links como ligações entre as instâncias de dados bem como indicadores de sua importância. Sendo assim, a Mineração de Links (ML) é uma área de estudo que emprega técnicas da Mineração de Dados (MD) que consideram explicitamente os links no desenvolvimento de modelos preditivos ou descritivos de dados de natureza relacional (Getoor e Diehl, 2005).

Getoor e Diehl (2005) identificam diversas tarefas relacionadas com a ML. Essas tarefas são divididas em três grupos: tarefas relacionadas com os objetos, tarefas relacionadas com os links, e tarefas relacionadas com os grafos. A seguir, algumas dessas tarefas são brevemente descritas, focando na tarefa de detecção de comunidades, a qual é uma tarefa relacionada com os objetos.

Classificação de Vértices: Considerada como uma tarefa relacionada com os objetos, consiste em atribuir rótulos de classe aos vértices de uma rede. A principal característica desta tarefa e que se difere da classificação 
tradicional é que, em muitos casos, os rótulos dos vértices relacionados tendem a estar correlacionados. Assim, o desafio nesta tarefa é o desenvolvimento de algoritmos de classificação coletiva, os quais atribuem rótulos aos vértices considerando suas correlações, ou seja, como dado vértice é afetado por outros vértices ao seu redor. Algumas das propostas com maior destaque foram feitas por Hummel e Zucker (1983), Lafferty et al. (2001), e Lu e Getoor (2003).

Ranking de Vértices: Considerada como uma tarefa relacionada aos objetos, consiste na ordenação de um conjunto de vértices considerando sua priorização com base na análise das ligações que possuem. Este problema está associado à área de recuperação de informação, onde a partir de um conjunto de documentos, deseja-se encontrar aqueles mais relevantes para uma dada consulta. O PageRank (Page et al., 1998) e o HITS (Kleinberg, 1999) são os algoritmos com maior destaque nesta categoria.

Detecção de Grupos: Considerada também como uma tarefa relacionada aos objetos, consiste na detecção automática dos agrupamentos dos vértices que compartilham características similares. Esses agrupamentos, também chamados comunidades, atuam como um resumo da rede e fornecem informações que permitem melhorar a visualização das redes bem como revelar características importantes, dificilmente detectadas através da análise das redes como um todo (Fortunato, 2010).

Diferentes algoritmos para detecção de comunidades foram propostos. Dois dos algoritmos de detecção de comunidades caracterizados por utilizar estratégias diferentes e por terem um grande destaque na literatura, são descritos a seguir.

Algoritmo Fast Modularity (FM) : Clauset et al. (2004) apresentaram um algoritmo para detecção de comunidades baseado na identificação de grupos de vértices que tenham um alto valor de modularidade. A modularidade, apresentada por Newman e Girvan (2004), é uma das medidas mais usadas para avaliar quão rica é a estrutura de comunidades de uma rede. Uma estrutura de comunidade é mais rica quando existe uma grande quantidade de arestas entre os vértices pertencentes às mesmas comunidades e poucas arestas entre as diferentes comunidades. Assim, a modularidade $Q$ é definida pela Equação 2.14. 


$$
Q=\frac{1}{2 m} \sum_{x, y}\left[A_{x, y}-\frac{k_{x} k_{y}}{2 m}\right] \delta\left(C_{x}, C_{y}\right)
$$

Onde $A_{x, y}$ é a entrada na matriz de adjacência para os vértices $x$ e $y$, $k_{x}$ e $k_{y}$ são seus respectivos graus, e $C_{x}$ e $C_{y}$ são as comunidades às quais esses vértices pertencem. Além disso, $\delta\left(C_{x}, C_{y}\right)$ é uma função cujo valor é 1 no caso que a comunidade à qual pertence $x$ é a mesma à qual pertence $y$, e 0 no caso contrário.

Assim, Clauset et al. (2004) propuseram o uso de estruturas de dados ótimas que forneçam um melhor desempenho nas operações de busca das estruturas de comunidades ricas ${ }^{7}$. Tomando como base a proposta de Newman (2004b), Clauset et al. (2004) utilizam uma matriz esparsa de variações de modularidade, um max-heap para armazenar os maiores elementos de cada linha da matriz esparsa bem como os rótulos das respectivas comunidades, e um simples vetor cujos elementos são a soma dos elementos de cada linha da matriz de adjacência da rede.

O uso dessas três estruturas de dados faz com que o algoritmo FM tenha uma complexidade de $O(m H \log n)$, onde $H$ é a altura do dendograma, $m=|E|$ e $n=|V|$. Embora se tenha esse bom desempenho computacional, mesmo quando executado em redes reais caracterizadas por serem esparsas e terem uma hierarquia bem definida, tem-se que $m \sim n$ e $H \sim \log n$. Nesse caso, FM tem uma complexidade de $O\left(n \log ^{2} n\right)$.

Algoritmo WalkTrap (WT): Pons e Latapy (2006) focam-se na detecção de comunidades considerando que uma estrutura de comunidade é rica se a proporção de arestas em uma comunidade (arestas internas) é muito grande comparada com a proporção de arestas entre as diferentes comunidades (Brandes et al., 2003). Assim, Pons e Latapy (2006) propuseram o uso da caminhada aleatória até uma certa distância percorrida no dendograma da rede. Essa distância captura informações topológicas e hierárquicas da rede.

O uso da caminhada aleatória permite que a complexidade compu-

\footnotetext{
${ }^{7}$ Quanto maior for o valor de modularidade de uma rede, melhor, pois isso indica o quão rica é sua estrutura de comunidade. O maior valor que pode-se obter para $Q$ é 1 no caso trivial que todos os vértices pertencem a uma única comunidade. Porém na prática, valores acima de 0.3 são indicadores de uma estrutura de comunidade significativamente rica (Clauset et al., 2004).
} 
tacional do algoritmo WT seja $O(m n H)$, onde $H$ é a altura do dendograma, $m=|E|$ e $n=|V|$. Dessa maneira, no pior caso tem-se uma complexidade de $O\left(m n^{2}\right)$. Porém, como mencionado, as redes reais são esparsas $(m \sim n)$ e $H$ é geralmente pequeno, o que é favorável quando o dendograma é balanceado $(H \sim \log n)$. Nesse caso, a complexidade computacional chega a ser $O\left(n^{2} \log n\right)$.

É importante destacar que tanto os algoritmos FM e WT, quanto outros (Girvan e Newman, 2002; Donetti e Muñoz, 2005; Blondel et al., 2008; Rosvall e Bergstrom, 2008) pertencem a uma abordagem chamada detecção de comunidades de vértices. Existe também outra abordagem chamada de detecção de comunidades de arestas, a qual caracteriza-se por formar grupos de links ao invés de vértices (Ahn et al., 2010).

Predição de Links: Considerada como uma tarefa relacionada aos links, consiste em prever a futura existência de um link entre dois vértices com base nos atributos dos outros vértices e dos links observados. O problema da predição de links também pode ser visto como um problema de classificação, isto é, atribuir 1 como rótulo binário de existência de um dado link ou 0 no caso contrário. Liben-Nowell e Kleinberg (2007) e Lü e Zhou (2011) apresentam uma revisão completa de diferentes algoritmos para predição de links.

Classificação de Grafos: Considerada uma tarefa relacionada aos grafos, consiste em categorizar um grafo inteiro com base na ocorrência ou não de determinadas propriedades do grafo. Ao contrário da classificação de vértices, a classificação de grafos não requer classificação coletiva devido ao fato que os grafos são, geralmente, gerados de forma independente. Algumas das técnicas usadas nestas tarefa são as baseadas na programação lógica indutiva (King et al., 1996) e em kernels de grafos (Gärtner, 2002).

Descoberta de Subgrafos: Considerada uma tarefa relacionada aos grafos, consiste em encontrar subgrafos relevantes ou recorrentes em um conjunto de grafos. A partir desses subgrafos podem ser identificados padrões que, por sua vez, podem ser posteriormente utilizados para representar atributos úteis para outras tarefas. Algumas das propostas com maior destaque são Subdue (Cook e Holder, 1994) e GBI (Yoshida et al., 1994). 
Nesta dissertação, duas das tarefas da ML têm um maior destaque: a detecção de grupos e a predição de links. Porém, a tarefa de detecção de grupos é utilizada para geração de estruturas de comunidades que forneçam informações úteis para melhorar o desempenho da tarefa da predição de links. Sendo assim, nesta seção foi dado um maior foco à tarefa de detecção de grupos, no entanto, a tarefa de predição de links será apresentada com profundidade no capítulo a seguir.

\subsection{Considerações Finais}

Neste capítulo apresentou-se os principais conceitos relacionados com o estudo das redes complexas, bem como da Mineração de Links. Com relação às redes complexas viu-se que, geralmente são modeladas por grafos e que sua representação tem fortes embasamentos matemáticos. Vários pesquisadores propuseram modelos e teorias que tentam explicar o comportamento das redes com base na análise de sua estrutura topológica.

Apesar da existência de diferentes propriedades das redes complexas, um comportamento comum nelas é que rara vez possuem uma estrutura determinística, isto é, redes nem sempre têm um crescimento regular. Porém, a auto-organização dinâmica que caracteriza às redes, as torna mais complexa com o decorrer do tempo.

Com isso, diferentes modelos tentaram explicar a formação das redes, sendo que as quatro categorias nas quais foram agrupadas as redes complexas, apresentam, em geral, características de mundo pequeno e de modelos livre de escala, mas sem descartar o modelo de aleatoriedade, o qual ainda explica alguns aspectos importantes das redes.

Quando áreas do conhecimento como Aprendizado de Máquina e Mineração de Dados são focadas no estudo e análise de dados com estrutura relacional, como as redes, são identificadas um conjunto de tarefas, as quais são associadas a uma área emergente, chamada de Mineração de Links. Mineração de Links é caracterizada por empregar explicitamente as informações fornecidas pelos links, bem como da estrutura geral das redes analisadas, para o desenvolvimento de modelos preditivos ou descritivos.

As tarefas associadas à Mineração de Links estão longe de serem triviais, dado que, como visto, redes podem estar formadas por dados heterogêneos, e muitos desses ainda podem nem estar disponiveis. Mesmo assim, diferentes algoritmos têm sido propostos para afrontar os desafios impostos por cada 
uma dessas tarefas.

No próximo capítulo será discutido uma das principais tarefas da Mineração de Links: predição de links, a qual, por sua vez, é o foco da pesquisa desenvolvida e apresentada nesta dissertação. Assim, será apresentado o fundamento teórico do problema que tenta resolver esta tarefa bem como as principais abordagens do estado da arte, suas principais aplicações, e por fim, seus desafios e tendências futuras. 


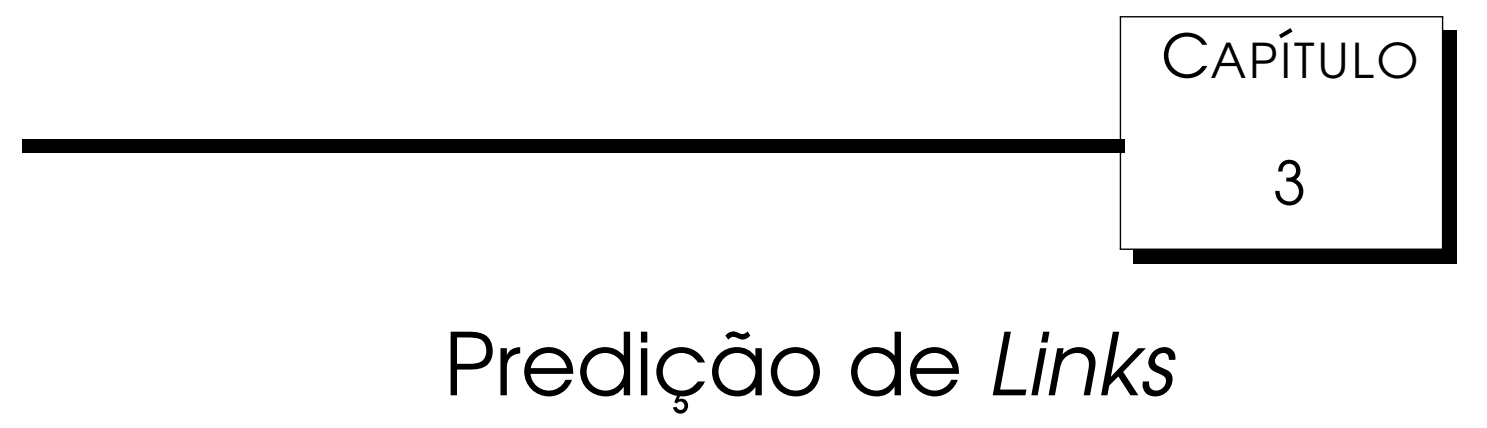

$\mathcal{E}$ ste capítulo está focado na fundamentação do problema da predição de links e como esse problema é tratado pelas principais abordagens atuais. São apresentadas também algumas aplicações do problema bem como os desafios e tendências futuras da área.

\subsection{Definições e Fundamentos}

A predição de links é um importante problema para se resolver no contexto das redes complexas e, portanto, nas redes sociais, motivo pelo qual tem atraído amplamente a atenção das comunidades da Física e da Ciência da Computação (Lü e Zhou, 2011). Nesta última, como discutido no capítulo anterior, Getoor e Diehl (2005) enxergam a predição de links como uma tarefa da Mineração de Links (ML).

A predição de links tem como objetivo estimar a probabilidade da existência de um link entre dois nós com base nas informações dos atributos dos nós e dos links presentes na rede (Getoor e Diehl, 2005). Segundo Lü et al. (2009), esse objetivo pode ser encarado de duas maneiras. A primeira é a predição de links faltantes que poderiam ter sido perdidos durante o processo de construção da rede (Appel e Hruschka Junior, 2011; Zhou et al., 2009), o que em geral é aplicável nas redes da cadeia alimentar, redes criminosas e na World Wide Web. A segunda, foco deste trabalho, é a predição de links que poderão existir no futuro devido à evolução da rede no tempo, como acontece, 
por exemplo, nas redes sociais.

Nesse último contexto, a definição da predição de links dada por LibenNowell e Kleinberg (2007) e que tem sido bastante utilizada na literatura ao servir como referência para diversos trabalhos é: dada uma rede de algum domínio, a predição de links tenta prever com precisão quais links serão adicionados à rede no intervalo entre o tempo $t$ e um tempo futuro $t+1$. Na Figura 3.1 é apresentado o esquema da tarefa da predição de links seguindo a definição anterior.
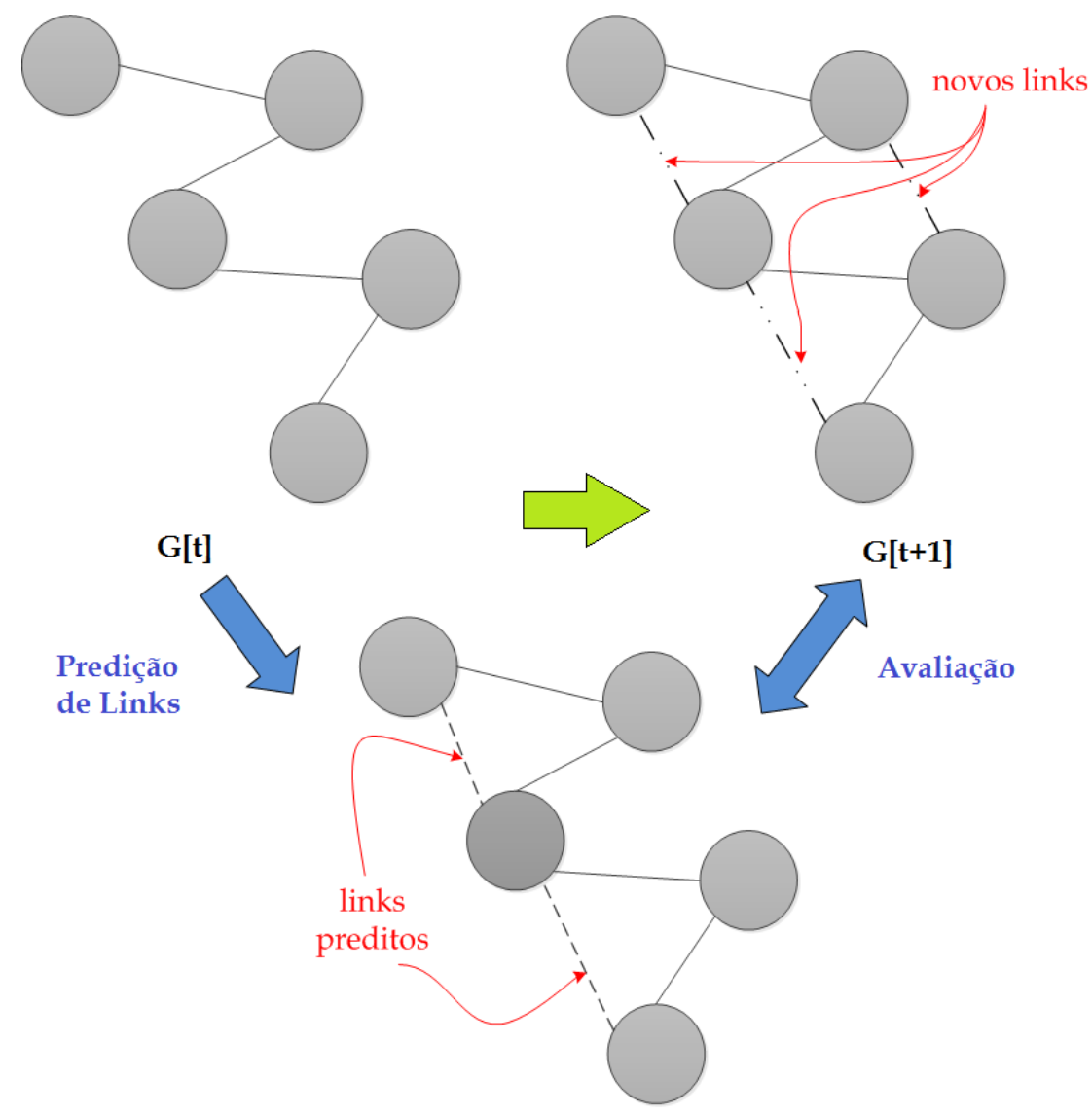

Figura 3.1: Esquema da tarefa de predição de links. Uma estrutura de rede $G$ no tempo $t$ evolui naturalmente no tempo chegando a uma estrutura diferente no tempo $t+1$. A tarefa de predição de links tenta prever os links que aparecerão nesse intervalo. Para a avaliação, é feita uma comparação entre os links preditos e os novos links reais.

O processo da predição de links pode-se basear em duas fontes de dados: as características dos membros das redes (conteúdo ou semântica), e as informações estruturais (topológicas) da rede. Embora sejam distintas, essas fontes de dados muitas vezes estão implicitamente relacionadas. Assim, diferentes métodos de predição de links utilizam tais fontes de dados para o 
cálculo de métricas que possam representar padrões de associação ou características dos elementos de uma rede de forma mensurável (Soares, 2012).

$\mathrm{Na}$ tarefa de predição de links, as métricas servem para estimar o grau de proximidade entre dois indivíduos da rede mediante a atribuição de uma pontuação (score). Essa pontuação é aplicada a pares de vértices (díades) que não têm uma ligação em um dado estado ${ }^{1}$ da rede. Guanto maior é o valor da pontuação para um dado par de vértices, maior é a probabilidade de que esses vértices serão conectados em um estado futuro (Liben-Nowell e Kleinberg, 2007). As pontuações são computadas para todos os pares de vértices não ligados seguindo um processo de aprendizado não supervisionado ou supervisionado. Depois disso, diferentes métodos de avaliação de resultados podem ser usados para determinar o desempenho das métricas empregadas.

A seguir, são apresentados os princípios teóricos nos quais se baseiam as métricas para predição de links, bem como as estratégias para enfrentar o problema da predição de links e as métricas de avaliação usadas na literatura.

\subsubsection{Princípios Teóricos}

As propostas que enfrentam o problema da predição de links têm como princípios teóricos diferentes formulações baseadas nas teorias fornecidas pela Sociologia ${ }^{2}$. Esse fato tem fundamento no apontado por Newman (2003), quem identifica às Ciências Sociais, especialmente à Sociologia, como uma das primeiras áreas do conhecimento que realizaram estudos em redes reais, especialmente em redes sociais, destacando os trabalhos de Moreno (1934), Davis et al. (1941), Rapoport (1957), e Fararo e Sunshine (1964). Assim, alguns dos conceitos sociológicos que são usados na predição de links foram elencados por Yin et al. (2010b), e são descritos sucintamente a seguir.

Homofilia: Permite notar que pares de indivíduos com fortes laços estão propensos a apresentar maior similaridade que aqueles com laços fracos, do qual se supõe que, tratar todos os relacionamentos com um peso igual pode levar à degradação no desempenho de algum algoritmo para resolver alguma tarefa da ML (McPherson et al., 2001).

Raridade: Determina que gostos e características raras tendem a ser mais relevantes do que outros atributos comuns, o qual supõe que indivíduos

\footnotetext{
${ }^{1}$ Considera-se como estado de uma rede a sua estrutura em termos de vértices e links em um tempo $t$.

${ }^{2}$ A Sociologia é a área de estudo do comportamento humano em função do meio em que está inserido e dos processos que regem a interação entre os indivíduos (Soares, 2012).
} 
que são minoria na preferência por alguma atividade específica têm uma maior chance de se relacionar.

Influência Social: Os atributos compartilhados por grande parte dos indivíduos ligados a um outro indivíduo são importantes para identificar relacionamentos em potencial que esse indivíduo possa vir a ter com novos indivíduos.

Amizades em comum: Permite notar que, quantos mais indivíduos ligados em comum dois indivíduos possuem, mais chances eles têm de se conhecerem. Assim, os relacionamentos em comum atuam como elementos de intermediação entre dois indivíduos, fazendo com que a informação flua entre eles e que eventuais novos vínculos surjam.

Proximidade social: Possiveis pessoas com que se pode ter um relacionamento tendem a estar próximos em um grafo social.

Conexão Preferencial: Pessoas tendem a se relacionar com outras mais populares, isto é, aquelas que possuem uma maior quantidade de vínculos sociais do que com as menos populares.

Exclusividade: É o conceito oposto ao de conexão preferencial. Poucos vínculos podem indicar relacionamentos mais fortes e relevantes, enquanto que a alta popularidade, apesar de agregar muitas ligações, pode ser composta por laços fracos e poucos duradouros.

É importante destacar que esses conceitos são inerentes e ubíquos nas redes, e que sua maior ou menor presença caracterizam de maneira especial uma dada rede.

\subsubsection{Estratégias}

A maneira como uma dada proposta de predição de links é aplicada sobre uma dada rede, implica a maneira como vai ser avaliado seu desempenho, bem como também é um indicador de quanto sobreajustados estão os dados avaliados (overfitting ${ }^{3}$ ). Assim, duas estratégias podem ser utilizadas: estratégia não supervisionada e estratégia supervisionada.

\footnotetext{
${ }^{3}$ Sobreajuste ou overfitting é o fenômeno que acontece quando um dado modelo preditivo se ajusta em demasiado ao conjunto de dados utilizado para formação desse modelo, apresentando assim, uma alta precisão quando testado com esses mesmos dados porém obtendo um pobre desempenho quando testado com outros dados.
} 


\section{Estratégia Não Supervisionada}

Nesta estratégia, o problema de predição de links, de acordo com Lü e Zhou (2011) é caracterizado por usar diretamente as pontuações atribuídas pelos métodos computados e pode ser formalmente descrito como a seguir. Considere uma rede não direcionada $G(V, E)$, onde $V$ é o conjunto dos vértices e $E$ é o conjunto dos links. Não é permitida a existência de múltiplos links entre um par de vértices nem autoconexões.

Denota-se por $U$ ao conjunto universal contendo todos os possiveis links. A cardinalidade desse conjunto é definida na Equação 3.1.

$$
|U|=\frac{|V|(|V|-1)}{2}
$$

Onde $|V|$ é o número de elementos no conjunto $V$. Então, o conjunto de links ainda não existentes na rede é $U-E$. Assume-se que os links faltantes ou que vão aparecer no futuro estão no conjunto $U-E$, e a tarefa da predição de links é encontrar esses links.

Como já comentado, na estratégia não supervisionada podem ser usadas dois tipos de amostragem de dados: validação de sub-amostragem aleatória e validação cruzada.

Na validação de sub-amostragem aleatória os links observados, $E$, são aleatoriamente divididos em duas partes: o conjunto de treino, $E^{T}$, tratado como a informação conhecida, e o conjunto de avaliação, $E^{P}$, usado para avaliar o desempenho da predição. Nenhuma informação nesse conjunto é usada para predizer. É facilmente observável que $E^{T} \cup E^{P}=E$ e $E^{T} \cap E^{P}=\varnothing$. A vantagem da validação de sub-amostragem aleatória é que a parte do conjunto de treino utilizada não depende do número de iterações. Embora, neste método, alguns links poderiam nunca ser utilizados no conjunto de avaliação, o que poderia levar à ocorrência de overfitting.

Essa limitação presente na validação de sub-amostragem aleatória é superada pela validação cruzada usando $k$-folds, na qual os links observados na rede são particionados aleatoriamente em $k$ sub-conjuntos. Um sub-conjunto é selecionado por vez como conjunto de avaliação, e os restantes $k-1$ subconjuntos formam o conjunto de treinamento. Então o processo da validação cruzada é repetido $k$ vezes, com cada um dos $k$ sub-conjuntos usados como dados de avaliação. Assim, todos os links são usados tanto como dados de treinamento como de avaliação e cada link é usado somente uma vez para a predição. 


\section{Estratégia Supervisionada}

Em uma estratégia supervisionada, a tarefa de predição de links é tratada como uma tarefa de classificação binária, na qual as duas condições possiveis para um par de vértices são ligados ou não ligados ou, o que é o mesmo, para dizer se um link é existente ou não existente, o que corresponde à classe positiva e negativa, respectivamente.

É importante destacar que cada link que forma o conjunto de treinamento é representado de diferentes maneiras, sendo uma das mais usadas a representação por vetor de características composto por diferentes índices de similaridade. De maneira similar à estratégia não supervisionada, a validação de subamostragem aleatória e a validação cruzada podem ser usadas na estratégia supervisionada. Assim, o conjunto de treinamento é usado para gerar um modelo e treinar um classificador, tal como árvores de decisão, rede neural, máquina de vetores de suporte, entre outros (Hasan et al., 2006; Benchettara et al., 2010). O classificador treinado serve para rotular novos exemplos de links como existentes ou não existentes.

\subsubsection{Métricas de Avaliação}

Quando a estratégia não supervisionada é aplicada em uma rede, duas métricas padrões são usadas para quantificar o desempenho dos métodos de predição: a área sob a curva (area under the receiver operating characteristic curve - AUC) e a precisão. Deve-se considerar que um dado método de predição de links fornece uma lista de todos os links não observados (i.e., $U-E^{T}$ ). Assim, dado o par de vértices $x, y \in U-E^{T}$, é computada sua pontuação $s_{x, y}$, a qual quantifica a probabilidade da existência de um futuro link entre esse par de vértices. A AUC avalia o desempenho dos algoritmos de acordo com as pontuações na lista completa de links não observados, enquanto a precisão somente tem foco nos L links no topo do ranking, ou seja, nos links com as maiores pontuações dessa lista (Zhou et al., 2009). Uma breve descrição dessas duas métricas é apresentada a seguir.

Área sob a curva (AUC): Uma vez obtida a lista das pontuações de todos os links não observados, o valor da AUC pode ser interpretado como a probabilidade que um link faltante escolhido aleatoriamente (i.e., um link de $E^{P}$ ) ter uma alta pontuação em comparação à escolha aleatória de um link não existente (i.e., um link de $U-E$ ). 
$\mathrm{Na}$ implementação dos algoritmos de predição de links, usualmente é calculada a pontuação de cada link não observado ao invés de criar uma lista ordenada, pois isso pode necessitar de maior tempo de processamento. A cada vez que escolher aleatoriamente um link faltante e um link não existente, serão comparadas suas pontuações. Se entre $n$ comparações independentes, há $n^{\prime}$ comparações, onde os links faltantes têm uma maior pontuação e $n^{\prime \prime}$, comparações onde ambos têm a mesma pontuação, então, o valor da AUC é:

$$
A U C=\frac{n^{\prime}+0.5 n^{\prime \prime}}{n}
$$

Se todas as pontuações são geradas considerando que são IID, o valor da AUC deve-se aproximar de 0,5 . Portanto, o grau em que o valor excede 0.5 indica quanto o desempenho do algoritmo de predição avaliado é melhor em comparação com um de predição por simples aleatoriedade.

Precisão: Dada a lista ordenada descendentemente das pontuações dos links não observados, a precisão é definida como o proporção de links relevantes que foram selecionados para o número de links selecionados. Isto é, se tomamos os $L$ links do topo da lista como os links preditos, entre os quais $L_{r}$ são links preditos corretamente (i.e., os $L_{r}$ links pertencem ao conjunto de avaliação $E^{P}$ ), então a precisão é dada por:

$$
\text { Precisao }=\frac{L_{r}}{L}
$$

Claramente, uma maior precisão significa um maior desempenho na predição.

No caso de ser usada uma estratégia supervisionada, para quantificar o desempenho dos métodos de predição de links são usadas as mesmas métricas de desempenho usadas pelas técnicas supervisionadas de AM como revocação, cobertura, medida F, etc. (Powers, 2011; Han et al., 2011).

\subsection{Abordagens}

Segundo Lü e Zhou (2011), as diferentes propostas existentes na literatura para resolver o problema da predição de links podem ser divididas em três categorias: índices baseados na similaridade, métodos baseados na máxima 
verossimilhança e modelos probabilísticos. Porém, existem também um grupo de métodos, chamados de métodos híbridos, caracterizados pela combinação das propostas anteriores ou pelo uso de informações diferentes das usadas tradicionalmente. A seguir, são apresentadas propostas pertencentes a cada uma dessas categorias.

Antes, contudo, as propostas a serem apresentadas consideram apenas arestas não valoradas, existem, porém, variações que levam em consideração o peso das arestas quando estas os possuem (Murata e Moriyasu, 2008). Apesar disso, existe uma certa discordância na área se o uso do peso nos links pode melhorar ou não a tarefa de predição de links (Murata e Moriyasu, 2007, 2008; Lü e Zhou, 2010).

\subsection{1 Índices Baseados na Similaridade}

Uma das primeiras ferramentas utilizadas para a predição de links, e uma das mais simples, foram os índices baseados na similaridade, onde para cada par de vértices $\left(x, y\right.$, é atribuída uma pontuação $s_{x, y}$, a qual é definida como a similaridade (ou proximidade) entre $x$ e $y$. Os pares de vértices com maior pontuação são tidos como links com alta probabilidade de existência.

A similaridade estrutural existente entre os vértices de uma rede é aproveitada para criar um grupo de índices chamado índices de similaridade estrutural (ou topológica). Esses índices baseiam-se unicamente na estrutura da rede e, por sua vez, podem ser divididos em índices de similaridade local e global.

Índices de Similaridade Local

Os índices de similaridade local caracterizam-se por usarem informações só de um par de vértices. Isso permite que o cálculo desses índices tenha um baixo custo computacional, embora o desempenho da predição possa muitas vezes não ser melhor. Diferentes índices locais foram propostos. A seguir alguns deles são apresentados.

Vizinhos Comuns (Common Neighbors - CN): Proposto por Lorrain e White (1971) diz que dois vértices $x$ e $y$ têm maior probabilidade de ter um futuro relacionamento se eles têm muitos vizinhos em comum. Assim, a pontuação é calculada da seguinte maneira:

$$
s_{x, y}^{C N}=|\Gamma(x) \cap \Gamma(y)|
$$


O índice de CN foi utilizado por Newman (2001) no estudo de redes sociais de colaboração, apresentando uma correlação positiva entre o número de vizinhos comuns e a probabilidade de que dois cientistas possam colaborar no futuro.

Índice de Salton (Sal): Apresentado por Salton e McGill (1986). Definido como:

$$
s_{x, y}^{S a l}=\frac{|\Gamma(x) \cap \Gamma(y)|}{\sqrt{k_{x} \times k_{y}}}
$$

O índice de Salton é também chamado similaridade do cosseno.

Índice de Jaccard (Jac): Um índice muito utilizado na recuperação de informação (Jaccard, 1901). É definido como:

$$
s_{x, y}^{J a c}=\frac{|\Gamma(x) \cap \Gamma(y)|}{|\Gamma(x) \cup \Gamma(y)|}
$$

Índice de Adamic-Adar (AA): O índice de AA (Adamic e Adar, 2003) refina a simples contagem dos vizinhos comuns atribuindo um maior peso aos vizinhos com menor quantidade de conexões. É definido como:

$$
s_{x, y}^{A A}=\sum_{z \in \Gamma(x) \cap \Gamma(y)} \frac{1}{\log k_{z}}
$$

Índice de alocação de recursos (Resource Allocation - RA): Considerando o par de vértices $(x, y)$, os quais não estão diretamente conectados, tem-se que o vértice $x$ pode enviar algum recurso para $y$ usando seus vizinhos como transmissores. No caso simples, assume-se que cada transmissor tem uma unidade de recurso e vai distribuí-lo igualmente para todos os seus vizinhos. Assim, a similaridade entre $x$ e $y$ pode ser definida como a quantidade de recursos que $y$ tem recebido de $x$ como:

$$
s_{x, y}^{R A}=\sum_{z \in \Gamma(x) \cap \Gamma(y)} \frac{1}{k_{z}}
$$

O índice RA (Zhou et al., 2009) é uma medida simétrica, isto é, $s_{x y}=s_{y x}$. Além disso, o índice RA tem uma grande semelhança com o índice AA.

Índice de $\mathbf{S} \phi \mathbf{r e n s e n ~ ( S o r ) : ~ P r o p o s t o ~ p o r ~} \mathbf{S} \phi$ rensen (1948), é um índice comu- 
mente usado em dados de comunidades ecológicas. É definido como:

$$
s_{x, y}^{S o r}=\frac{2|\Gamma(x) \cap \Gamma(y)|}{k_{x}+k_{y}}
$$

Índice do hub promovido (Hub Promoted Index - HPI): Proposto por Ravasz et al. (2002) para quantificar as sobreposições topológicas de pares de substratos em redes metabólicas. É definido como:

$$
s_{x, y}^{H P I}=\frac{|\Gamma(x) \cap \Gamma(y)|}{\min \left\{k_{x}, k_{y}\right\}}
$$

Índice do hub deprimido (Hub Depressed Index - HDI): É um índice considerado oposto ao índice HPI. É definido como:

$$
s_{x, y}^{H D I}=\frac{|\Gamma(x) \cap \Gamma(y)|}{\max \left\{k_{x}, k_{y}\right\}}
$$

Índice de Leicht-Holme-Newman (LHN): É um indice proposto por Leicht et al. (2006) e definido como:

$$
s_{x, y}^{L H N}=\frac{|\Gamma(x) \cap \Gamma(y)|}{k_{x} \times k_{y}}
$$

Índice de Conexão Preferencial (Preferential Attachment - PA): Índice proposto por Newman (2001) e Barabási et al. (2002), que verificaram que a probabilidade de um link entre dois vértices é proporcional ao produto do número de vizinhos que cada um possui, isto é:

$$
s_{x, y}^{P A}=k_{x} \times k_{y}
$$

É importante notar que este índice não precisa de informação da vizinhança de cada vértice. Consequentemente, este índice tem uma complexidade computacional muito menor que os outros.

Liben-Nowell e Kleinberg (2007) e Zhou et al. (2009) realizaram uma comparação sistemática dos diferentes índices de similaridade local. Dos resultados obtidos desses estudos, os índice RA, AA e CN obtiveram o melhor desempenho, constituindo o estado da arte na predição de links com esse tipo de abordagem. 
Índices de similaridade global

Os índices de similaridade global caracterizam-se por envolver o uso de toda ou quase toda a informação topológica presente na rede. Isso permite que a eficácia desses métodos seja alta, embora o custo de processamento seja maior. A seguir alguns deles são apresentados.

Índice de Katz: Proposto por Katz (1953), computa o resultado da soma do tamanho de todos os caminhos possíveis entre dois vértices, ponderando com maior intensidade os caminhos mais curtos segundo a expressão matemática seguinte:

$$
s_{x, y}^{K a t z}=\sum_{x y}^{\infty} \beta^{l} \cdot\left|p a t h s_{x y}^{\langle l\rangle}\right|=\beta A_{x y}+\beta^{2}\left(A^{2}\right)_{x y}+\beta^{3}\left(A^{3}\right)_{x y}+\ldots
$$

Onde $\operatorname{paths}_{x y}^{\langle l\rangle}$ é o conjunto de todos os caminhos de tamanho $l$ que têm $x$ como vértice inicial e $y$ como vértice final. $\beta \in(0,1)$ é o parâmetro livre que controla os pesos dos caminhos de acordo com seus tamanhos.

O alto custo computacional que demanda o cálculo do índice Katz pode ser minimizado mediante o cálculo da respectiva matriz de pontuações. Uma matriz de pontuações é um array bidimensional cujas linhas e colunas são indexadas pelos vértices de um grafo e que as posições de dito array contêm os resultados da aplicação de determinado índice (pontuação) sobre dois vértices do grafo. A matriz de pontuações para o índice Katz pode ser obtida pela fórmula:

$$
K A T Z=(I-\beta A)^{-1}-I
$$

Onde $A$ e $I$, são a matriz de adjacência e de identidade, respectivamente, do grafo analisado.

Rooted PageRank (RPR): Proposto por Page et al. (1998), é uma métrica muito popular em problemas de recuperação de informação. $O$ índice RPR consiste em uma adaptação da PageRank para uso em problemas de predição de links. Para seu cálculo, executa-se uma caminhada aleatória entre os vértices $x$ e $y$. A cada passo, com probabilidade $\alpha$, o processo de caminhamento pode ser reiniciado (retorna ao vértice $x$ ) e com probabilidade $1-\alpha$ o processo continua selecionando de forma aleatória um 
vizinho do vértice referente ao passo atual. A matriz de pontuações do RPR é dada por:

$$
R P R=(1-\alpha) \times(I-(\alpha \dot{T}))^{-1}
$$

Onde $T$ é igual a $D^{-1} A$, sendo $A$ a matriz de adjacência do grafo, e $D$ é a matriz diagonal, tal que $D_{i, j}=\sum_{j} A_{i, j}$.

SimRank (SR): Proposto por Jeh e Widom (2002), utiliza a ideia de que dois vértices são similares se possuem vizinhos similares. A noção de vizinhança considerada por SR é mais ampla; estende-se por todos os vértices alcançáveis a partir dos vértices em análise. Pode ser calculado usando uma fórmula recursiva, na forma:

$$
s_{x, y}^{S R}=\gamma \cdot \frac{\sum_{a \in \Gamma(x)} \sum_{b \in \Gamma(y)} s_{a, b}^{S R}}{|\Gamma(x)| \cdot|\Gamma(y)|}
$$

Onde $\gamma \in(0,1)$ e $s_{x, x}^{S R}=1$, isto é, a similaridade entre um vértice e ele mesmo é máxima (caso base).

Comparados com os índices de similaridade local, os índices de similaridade global consideram as informações topológicas de toda a rede. Ainda que os índices de similaridade global possam obter uma alta acurácia na predição, eles têm duas grandes desvantagens: i) o cálculo dos índices globais precisa de um alto custo computacional devido a que muitas vezes precisam da obtenção da matriz inversa para obter a matriz de pontuações, a qual é inviável no domínio de redes complexas de grande escala; ii) algumas vezes, as informações topológicas globais não estão totalmente disponíveis.

\subsubsection{Métodos baseados na máxima verossimilhança}

Algumas propostas para resolver o problema da predição de links baseiamse na estimativa da máxima verossimilhança. Esses algoritmos pressupõem que alguns princípios da estrutura da rede geram regras e parâmetros específicos que podem ser usados para determinar os links que poderão existir no futuro.

Segundo Sales-Pardo et al. (2007), muitas redes reais têm uma organização hierárquica, na qual os vértices podem ser divididos em grupos e esses grupos por sua vez são divididos em sub-grupos e assim por diante. Dessa maneira, o modelo de estrutura hierárquica é um dos mais representativos neste grupo de métodos baseados na máxima verossimilhança. 
O modelo de estrutura hierárquica de uma rede pode ser representado por um dendograma com $n$ folhas (correspondentes aos vértices da rede) e $n-1$ vértices internos. Clauset et al. (2008) apresentam um modelo simples onde cada vértices interno $r$ é associado com uma probabilidade $p_{r}$ e a probabilidade de ligar dois vértices (folhas) é igual a $p_{r^{\prime}}$, onde $r^{\prime}$ é o mais baixo ancestral comum desses dois vértices. Dada uma rede real $G$ e um dendograma $D$, seja $E_{r}$ o número de links em $G$ cujas terminações têm $r$ como seu mais baixo ancestral comum em $D$, e dados $L_{r}$ e $R_{r}$ sendo o número de folhas na subárvore esquerda e direita, respectivamente, que tem sua raiz em $r$. Então, a verossimilhança do dendograma $D$ junto com o conjunto de $p_{r}$ é:

$$
\mathcal{L}\left(D, p_{r}\right)=\prod_{r} p_{r}^{E_{r}}\left(1-p_{r}\right)^{L_{r} R_{r}-E_{r}}
$$

A verossimilhança $\mathcal{L}\left(D, p_{r}\right)$ pode ser maximizada com:

$$
p_{r}^{*}=\frac{E_{r}}{L_{r} R_{r}}
$$

Com isso, um algoritmo para predição de links tem o seguinte procedimento: i) amostrar um grande número de dendogramas com probabilidades proporcionais à suas verossimilhanças; ii) para cada par de vértices não ligados $i$ e $j$ calcular a probabilidade média de conexão $\left\langle p_{i j}\right\rangle$ mediante a média da probabilidade correspondente $p_{i j}$ sobre todos os dendogramas amostrados; iii) classificar esses pares de vértices em uma lista em ordem decrescente de $\left\langle p_{i j}\right\rangle$, os primeiros elementos dessa lista são considerados como os elementos preditos. Tendo como base esse procedimento, Krebs (2002) obteve bons resultados no desempenho da predição em comparação com o índice de vizinhos comuns (CN) no domínio de uma rede social de organizações terroristas. Redner (2008) e Clauset et al. (2008) utilizaram também o modelo de estrutura hierárquica para predição de links em diferentes domínios de redes biológicas e redes sociais.

Assim, o modelo de estrutura hierárquica é uma proposta para predizer links e tem uma grande importância pelo fato de também ajudar na descoberta da organização hierárquica, muitas vezes oculta nas redes. Uma grande desvantagem desse modelo é que seus algoritmos necessitam de muito tempo de execução devido ao fato que o processo de amostragem do dendograma usualmente tem uma complexidade computacional quadrática, quando se usa algoritmos ótimos como as cadeias de Markov (Clauset et al., 2008), sendo que, no pior caso, essa complexidade pode chegar até ser exponencial (Mossel 
e Vigoda, 2005).

Dada essa grande dificuldade, alguns autores como Pons e Latapy (2011) propõem um método para gerar de maneira ótima um dendograma a partir do uso das estruturas de comunidade presentes nas redes complexas. Ainda assim, tendo em consideração os avanços dos computadores modernos, um algoritmo de predição de links baseado no modelo de estrutura hierárquica vai ser capaz de trabalhar só com redes de uns poucos milhares de vértices em um tempo computacionalmente aceitável ${ }^{4}$, mas não vai ser capaz de trabalhar com redes que têm milhões de vértices como são, por exemplo, as redes sociais online. Outra importante consideração é o fato que o modelo de estrutura hierárquica pode ter um pobre desempenho nas redes que não têm uma estrutura hierárquica bem definida.

\subsubsection{Modelos probabilísticos}

Das abordagens apresentadas anteriormente, pode-se notar que para tentar melhorar o desempenho na predição elas fazem uso das informações estruturais ou organizacionais da rede analisada. Os modelos probabilísticos abstraem as diferentes informações relevantes dos membros da rede, de suas ligações e de sua estrutura como um todo. Com essas informações é gerado um modelo que vai ser aprendido para depois ser utilizado na predição de novos links (Getoor e Diehl, 2005; Yu et al., 2010; Lü e Zhou, 2011).

Entre os modelos probabilísticos com maior destaque, as redes Bayesianas (Potgieter et al., 2007) e as redes de Markov (Wang et al., 2007) têm sido utilizadas para modelar a estrutura de uma rede para resolver o problema da predição de links. Embora o uso das redes Bayesianas e das redes de Markov tenham um ótimo desempenho na predição de links, elas ainda não aproveitam todas as informações relacionais que são inerentes nas redes.

Assim, para um melhor aproveitamento das informações presentes nos dados com estrutura relacional, dois frameworks foram propostos: i) O Modelo Probabilístico Relacional e ii) O Relacionamento de Entidades Probabilísticas Acíclicas Direcionadas.

Modelo Probabilístico Relacional: O modelo probabilístico relacional (Probabilistic Relational Model - PRM) foi apresentado por Poole (1993) e Koller

\footnotetext{
${ }^{4}$ Dependendo do problema que esta sendo tratado, a definição de tempo computacionalmente aceitável pode variar, mas para problemas complexos em geral considera-se aceitável se uma solução demanda um tempo logarítmico ou quadrático com relação à quantidade de dados processados.
} 
e Pfeffer (1998). PRM representa uma distribuição de probabilidade conjunta sobre os atributos da rede, assim, as propriedades de um objeto dependem probabilisticamente das propriedades dos objetos relacionados.

PRM pode ser classificado como redes Bayesianas relacionais (Relational Bayesian Network - RBN) ou redes de Markov relacionais (Relational Markov Network - RMN), se utilizam as redes Bayesianas ou de Markov, respectivamente, como base para geração do modelo que abstrai a rede analisada.

Friedman et al. (1999), Taskar et al. (2001) e Getoor et al. (2003) utilizam a RBN na predição de links em diferentes domínios de redes obtendo um bom desempenho. No entanto, a RBN tem duas grandes limitações. A primeira é que seu uso está restrito às redes direcionadas, também chamadas redes causais (i.e., redes de informação como são as redes de páginas web ligadas por hiperlinks). A segunda limitação é mais significativa pelo fato que a RBN necessita especificar um modelo completo da rede analisada, isto é, para cada atributo de cada classe presente na rede, o que pode ser muito custoso computacionalmente.

Devido às limitações da RBN, Taskar et al. (2002) propõem a rede de Markov relacional (Relational Markov Network - RMN) como ferramenta para superar as limitações presentes na RBN. Primeiro, as RMN ao terem base em um modelo probabilístico gráfico não direcionado como são as redes de Markov, têm uma representação mais apropriada para o modelado de redes não causais. Segundo, as RMN não necessitam especificar um modelo completo da rede analisada devido ao uso do template de cliques relacional. O template de cliques relacional é uma ferramenta que fornece uma forma de classificação coletiva que permite melhorar a qualidade predição bem como reduzir consideravelmente o custo computacional dos cálculos a serem realizados.

Relacionamento de Entidades Probabilísticas Acíclicas Direcionadas: Este framework (Directed Acyclic Entity Relationship - DAPER) está baseado no modelo entidade-relacionamento. O DAPER é capaz de manipular a representação de parâmetros e hiperparâmetros usando a abordagem Bayesiana como seu fundamento. Assim, o DAPER fornece uma personalização das entidades e os relacionamentos do grafo (Heckerman et al., 2004b). 
O DAPER está constituído por seis tipos de classes: i) classes de entidades, as quais especificam os membros da rede; ii) classes de relacionamento, as quais representam as ligações entre membros; iii) classes de atributos, que indicam os atributos das entidades e relacionamentos; iv) classes de arco, que representam as dependências probabilísticas entre atributos; v) classes de distribuição local, as quais geram as distribuições locais de um atributo; e vi) classes de restrição, as quais especificam como gerar o grafo de inferência.

O DAPER é usualmente usado em situações nas quais a estrutura relacional encontra-se em um estado de incerteza. O modelo DAPER é mais expressivo que os PRMs (Heckerman et al., 2004a).

\subsubsection{Métodos Híbridos}

As abordagens até aqui apresentadas utilizam diretamente as informações topológicas que capturam para enfrentar o problema da predição de links. Porém, com o intuito de melhorar o desempenho da predição, recentemente tem sido apresentadas propostas caracterizadas pelo uso de mais de uma técnica ou tipo de informação. Essas propostas são inseridas em um grupo chamado de métodos híbridos.

Os métodos híbridos podem ser divididos em dois grupos: i) os que combinam diferentes algoritmos de predição de links em um ensemble e, assim, criam um único algoritmo que aproveita as vantagens de seus preditores base (Polikar, 2006); ii) os que utilizam informações externas às usadas nos preditores mas que estão presentes na rede, por exemplo, informações que descrevem como são os atributos dos vértices e dos links (Gong et al., 2012) ou informações das comunidades das quais os vértices são membros (Zheleva et al., 2008; Soundarajan e Hopcroft, 2012).

Dado que as comunidades são uma estrutura onipresente nas redes, os métodos híbridos com base nas informações das estruturas de comunidades apresentam um importante destaque, dado seu desempenho na tarefa da predição de links.

Assim, considerando que as diferentes comunidades existentes em uma rede foram identificadas por um dado algoritmo de detecção de comunidades, os métodos híbridos baseados nas informações das estruturas de comunidades capturam certo tipo de informação das comunidades e as combinam com outras informações topológicas. A seguir, são apresentadas duas propostas que utilizam esta metodologia. 
Relações de Amizade e Círculos Familiares: Zheleva et al. (2008) estudaram redes sociais de animais, nas quais estão presentes os relacionamentos entre os membros de diferentes árvores genealógicas (relações de amizade), bem como os relacionamentos entre os membros de uma mesma árvore genealógica (círculos familiares). Dessa maneira, os grupos existem de maneira natural e são definidas pelas árvores genealógicas às quais pertencem os animais.

Considerando que $C_{x}$ é o conjunto dos vértices que pertencem ao mesmo grupo do vértice $x$, dois índices são definidos por Zheleva et al. (2008):

- Número de amigos no grupo (NAG): Apresenta o número de amigos que $x$ tem na família de $y$, permitindo saber como um ator se relaciona nos grupos de outros atores. É definido como:

$$
s_{x, y}^{N A G}=\left|\Gamma(x) \cap C_{y}\right|
$$

- Porção de amigos no grupo (PAG): Apresenta a razão entre o número de amigos que o vértice $x$ tem no grupo do vértice $y$ e o tamanho do grupo de $y$. É definida como:

$$
s_{x, y}^{P A G}=\frac{\left|\Gamma(x) \cap C_{y}\right|}{\left|C_{y}\right|}
$$

Índices estruturais melhorados: Com a intuição de que um vértice que pertence ao mesmo grupo e que tem uma similaridade topológica com um par de vértices analisados pode contribuir ainda mais na computação da similaridade, Soundarajan e Hopcroft (2012) propõem melhorias nos índices baseados em similaridade topológica.

Considerando que em uma rede as comunidades são desconhecidas, primeiramente deverá ser executado um algoritmo de detecção para identificá-las. Os autores dessa proposta consideram a existência de dois tipos de algoritmos de detecção de comunidades: i) algoritmos que detectam comunidades de vértices (Blondel et al., 2008; Rosvall e Bergstrom, 2008), e ii) algoritmos que detectam comunidades de arestas (Ahn et al., 2010). Assim, da mesma maneira que $C_{x}$ é o conjunto dos vértices contendo o vértice $x$ quando usado um algoritmo de detecção de comunidades de vértices, $C_{x, y}$ é o conjunto dos links contendo o link formado pelos vértices $x$ e $y$ quando usado um algoritmo de detecção de comunidades de arestas. Finalmente, os seguintes índices são definidos: 
- Índice de Vizinhos Comuns Melhorado (Enhanced Common Neighbors - ECN): Adiciona um ponto ao índice de CN para cada comunidade compartilhada com cada vértice ou link comum. Quando se tem informação de comunidades de vértices, este índice é definido como:

$$
s_{x, y}^{E C N V}=s_{x, y}^{C N}+\sum_{w \in \Gamma(x) \cap \Gamma(y)}\left|C_{w} \cap C_{x} \cap C_{y}\right|
$$

Quando se tem informação de comunidades de arestas, este índice é definido como:

$$
s_{x, y}^{E C N L}=s_{x, y}^{C N}+\sum_{w \in \Gamma(x) \cap \Gamma(y)}\left|C_{x, w} \cap C_{y, w}\right|
$$

- Índice de Alocação de Recursos Melhorado (Enhanced Resource Allocation - ERA): Considerando que $\sqcap_{x, y, w}$ é o conjunto de comunidades às quais os vértices $x, y$ e $w$ pertencem e $\left|\sqcap_{x, y, w}\right|$ é o número de elementos desse conjunto. Assim, quando se tem informação de comunidades de vértices, este índice é definido como:

$$
s_{x, y}^{E R A V}=\sum_{w \in \Gamma(x) \cap \Gamma(y)} \frac{\left|C_{w} \cap C_{x} \cap C_{y}\right|}{\left|\Pi_{x, y, w}\right|}
$$

Quando se tem informação de comunidades de arestas, este índice é definido como:

$$
s_{x, y}^{E R A L}=\sum_{w \in \Gamma(x) \cap \Gamma(y)} \frac{\left|C_{x, w} \cap C_{y, w}\right|}{\left|\cap_{x, y, w}\right|}
$$

Soundarajan e Hopcroft (2012) apontam que, da mesma maneira feita para CN e RA, outros índices, como Jac, LHN e Sor, também podem ser modificados para obter sua versão melhorada.

\subsection{Aplicações}

A capacidade de prever as mudanças na estrutura de uma rede antes que elas ocorram pode ser muito interessante para diferentes organizações, por isso, a predição de links vem atraindo bastante atenção da comunidade de 
pesquisa (Lü e Zhou, 2011). A grande variedade de propostas feitas vem sindo aplicadas para tratar problemas do mundo real, alguns descritos abaixo.

Predição de Colaborações: Uma das aplicações mais comuns na literatura consiste em identificar possíveis pares de entidades que ainda não colaboraram entre si em alguma tarefa, mas que de acordo com suas características e da rede como um todo possuem grandes chances de trabalharem em conjunto em um futuro próximo (Barabási et al., 2002; Liben-Nowell e Kleinberg, 2007). Entre as entidades que são representadas em redes de colaborações pode-se citar: autores de artigos científicos em uma rede de coautoria, profissionais em uma rede de contato laboral, entre outras. A predição de links nessas redes tem sido abordada em muitos trabalhos e tem servido para fundamentar muitas técnicas e métodos utilizados em redes sociais de diferentes domínios (Soares, 2012).

Estruturação de Redes Criminosas: Em redes cuja confidencialidade estrutural deve ser preservada, como nas redes terroristas, onde os membros que a compõem ocultam intencionalmente seus contatos para não serem descobertos. Assim, apenas uma parte da rede é conhecida, ficando como responsabilidade da tarefa de predição de links a detecção de relacionamentos que descrevam de maneira mais completa a estrutura dessas redes e, assim, contribuir na resolução de crimes e até na sua prevenção (Carpenter et al., 2002; Krebs, 2002).

Sistemas de Recomendação: Consiste na indicação automática a um usuário de que um objeto pode ser de seu interesse com base tanto nas preferências de dito usuário quanto nas de usuários com características similares às do usuário analisado. Um dos melhores exemplos de sistemas de recomenda- ção é a Amazom.com ${ }^{5}$, que sugere produtos similares aos que o usuário está comprando com base nas opiniões de outros usuários que também adquiriram o produto em questão (Soares, 2012). A predição de links é utilizada para tratar esse problema. Para isso, a rede é modelada como um grafo bipartido ${ }^{6}$ formado pelos conjuntos disjuntos de usuários e itens. Os links preditos indicarão os itens relacionados aos usuários, e assim, poderão ser recomendados a eles (Nkweteyim, 2005; Huang et al., 2005).

\footnotetext{
${ }^{5}$ http://www.amazon.com

${ }^{6} \mathrm{Um}$ grafo bipartido é um grafo cujos vértices podem ser divididos em dois conjuntos disjuntos $A$ e $B$, tais que toda aresta conecta um vértice de $A$ com um vértice de $B$.
} 
Outro exemplo de sistema de recomendação muito popular são os sistemas de sugestão de amizades nas redes sociais online, como Facebook ${ }^{7}$, Google Plus $^{8}$, Orkut ${ }^{9}$, entre outras. Ao realizar a predição de links entre usuários de ditas redes sociais que ainda não possuem vínculos, o sistema poderia sugerir outros usuários que poderiam-se tornar novos amigos.

Propagação de doenças: A eficácia de planos estratégicos para controle e monitoramento da disseminação de doenças e epidemias está intimamente ligada ao bom entendimento de como as redes de contágio funcionam (Soares, 2012). Em uma rede de contágio, os vértices representam indivíduos (infectados ou não) e os links indicam por onde a doença transitou. A análise do histórico da rede junto com a predição de links pode ajudar a revelar padrões de transmissão e os caminhos mais prováveis por onde a doença pode transitar no futuro. Dessa forma, conseguese antecipar ações de controle e impedir a infecção de novos indivíduos (Zanette, 2002; Keeling e Eames, 2005; Christakis e Fowler, 2007).

Personalização de notícias: Algumas das características das redes sociais online que têm atraído a atenção de milhões de usuários são as mudanças de estado, publicação de posts ou outras atividades apresentadas em tempo real feitas pelos usuários de ditas redes. Essas informações são apresentadas de maneira personalizada para cada usuário. Sistemas de personalização de notícias utilizam as conexões de um usuário analisado para obter informações dos usuários que têm relacionamentos fortes com os usuários analisados (Xiang et al., 2010).

\subsection{Desafios e Tendências}

Na literatura existe uma grande variedade de abordagens para resolver o problema da predição de links, embora ainda haja vários pontos que não foram suficientemente explorados. Lü e Zhou (2011) apontam como algumas dessas lacunas a investigação considerando pesos nos links, estruturas multidimensionais e análise temporal.

Referente à questão dos pesos nos links, diferentes pesquisas testam se o uso dos pesos poderia melhorar o desempenho na predição ou não. Embora

\footnotetext{
${ }^{7}$ http://www.facebook.com

${ }^{8}$ http://www.google.com/plus

${ }^{9}$ http://www.orkut.com
} 
o uso de pesos possa parecer relevante para o problema da predição de links tendo em conta que ao usar uma maior quantidade de informação o desempenho na predição também melhorará, diferentes pesquisadores chegaram a resultados controversos. Murata e Moriyasu (2007) sugerem que links com pesos maiores são mais relevantes na predição de relacionamentos, enquanto Lü e Zhou (2010) chegaram à conclusão contrária, isto é, que os links fracos são mais significativos na predição. Outro questionamento diz respeito à maneira de atribuir pesos aos links, isto devido que, dependendo da rede o significado do peso atribuído a um relacionamento pode ser bastante subjetivo.

Redes reais são formadas por links que podem ter múltiplos significados, isto é, são estruturas multidimensionais. Kunegis et al. (2009) identificam, por exemplo, que redes sociais de amizade podem ser compostas por relacionamentos com conotação (sinal) positiva ou negativa (amizade ou inimizade). Leskovec et al. (2010) propuseram um método para predizer links identificando sua conotação positiva ou negativa em redes sociais online. Backstrom e Leskovec (2011) apresentaram a caminhada aleatória supervisionada como método para predição de links considerando os diferentes atributos que podem ter os links de uma rede. Gong et al. (2012) consideram a existência de links sociais, links de atributos, e links mutex, para indicar os links que representam relacionamentos entre vértices, entre atributos dos vértices, e entre vértices mutuamente exclusivos, respectivamente.

A temporalidade é outro fator importante na predição de links. Na análise temporal interessa-se não só em saber quantos links apareceram no futuro mas também quando esses links apareceram. Algumas das propostas com resultados promissores utilizam técnicas baseadas em séries temporais (Potgieter et al., 2007; Sharan, 2008; Soares e Prudencio, 2012) e baseada em eventos (Soares, 2012), mas ainda é necessário entender melhor os efeitos da temporalidade na dinâmica das redes para melhorar o desempenho das técnicas de predição de links.

Além das questões citadas acima, há um problema inerente à tarefa de predição de links, independentemente do método usado na predição: à medida que a rede evolui no tempo, o número de vértices que não se ligam aumenta quadraticamente, enquanto o número de vértices que chegam a se ligar cresce linearmente, de modo que, a rede torna-se esparsa (Rattigan e Jensen, 2005). Assim, a quantidade de instâncias positivas (pares de vértices ligados) e negativas (pares de vértices não ligados) fica muito desbalanceada, o que prejudica 
grandemente a capacidade de generalização dos modelos de predição criados a partir desses dados com distribuição anômala (Soares, 2012). Algumas propostas, como a feita por Lichtenwalter et al. (2010) usam heurísticas para reduzir o número de instâncias negativas (undersampling). Outras propostas tentam aumentar a taxa de acerto dos métodos de predição através do ajuste do viés de acordo com as características do problema, destacando entre elas o aprendizado sensivel ao custo (Pan et al., 2008) e chance constrained (Doppa et al., 2010).

\subsection{Considerações Finais}

Considerando que diferentes sistemas dinâmicos naturais podem ser modelados por meio de redes complexas, diferentes tarefas em torno delas foram identificadas. Assim, a predição de relacionamentos é uma dessas tarefas, tendo uma alta aplicabilidade no mundo atual, já que pode ser usada para solucionar problemas das mais diversas áreas, como biologia, ecologia, marketing, comércio, entre outras (Liben-Nowell e Kleinberg, 2007).

Diferentes propostas tentam resolver eficientemente o problema da predição de links. Segundo Lü e Zhou (2011), essas propostas são divididas em três categorias: os índices baseados na similaridade, os métodos baseados na máxima verosimilhança e os métodos probabilísticos. Assim, entre essas propostas que são tidas como tradicionais, a abordagem baseada na similaridade topológica é a mais difundida, devido a que as informações topológicas são independentes do domínio de aplicação do problema, e podem ser aplicados em qualquer tipo de rede (Soares, 2012).

Mesmo que os índices baseados na similaridade tenham um bom rendimento na predição, eles ainda não exploram outras informações implícitas das redes, as quais são dificilmente detectadas ou, por vezes, não podem ser representadas de maneira simples. Assim, alguns autores propõem abordagens hibridas que, por exemplo, tentam combinar diversos algoritmos de predição em um ensemble (Polikar, 2006); enquanto outros autores utilizam informações externas, como os atributos dos vértices (Gong et al., 2012) ou comunidades das quais os vértices são membros (Zheleva et al., 2008; Soundarajan e Hopcroft, 2012).

As poucas propostas que apresentaram métodos híbridos utilizando as informações das comunidades para predição de links encontraram que, em geral, as informações das comunidades ajudaram a melhorar o desempe- 
nho na predição dos métodos de similaridade estrutural. Porém, os autores dessas propostas não apresentaram uma análise aprofundada de como as informações das comunidades influenciam na tarefa de predição de links.

Assim, este capítulo procurou abordar boa parte do que se tem no estado da arte com relação à tarefa de predição de links, servindo de base para a apresentação da proposta deste trabalho, a qual é inserida na categoria dos métodos híbridos baseados nas informações das estruturas de comunidades para predição de links. 



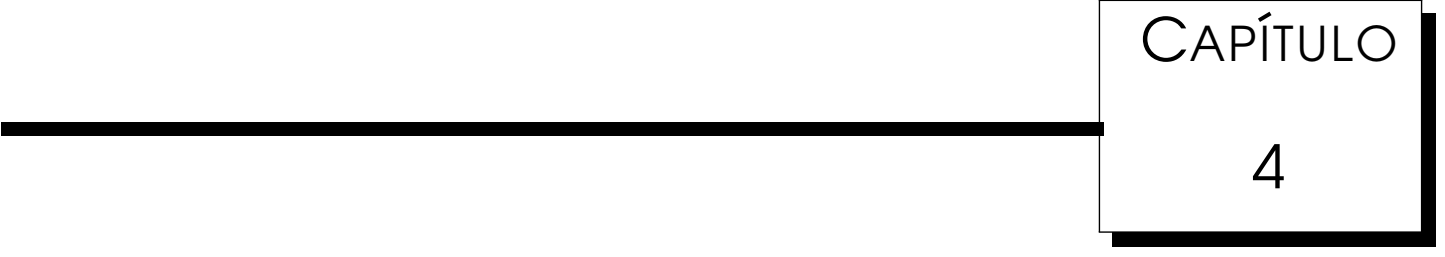 \\ Predição de Links baseada nas Informações das Comunidades}

omo apresentado nos capítulos anteriores, a análise de redes tenta compreender seu processo de formação e evolução. A predição de

links é uma tarefa fundamental nesse processo, pois é responsável por determinar a estrutura da rede, em termos de ligações, no futuro.

A maioria das propostas tradicionais para predição de novos relacionamentos é baseada no uso de informações topológicas das redes. Embora essas propostas tenham apresentado um bom desempenho, recentemente tem aparecido propostas híbridas, as quais, usando mais de uma técnica ou tipo de informação, tentam melhorar o desempenho na predição em relação das propostas tradicionais.

Dentre os métodos híbridos, destacam-se os que utilizam informações externas às usadas pelos métodos tradicionais mas que estão presentes na rede. As informações externas que tem apresentado uma maior destaque são as informações fornecidas pelas estruturas de comunidade das redes (Zheleva et al., 2008; Soundarajan e Hopcroft, 2012).

Neste capítulo são apresentadas duas propostas desenvolvidas durante o mestrado para predição de links. Estas propostas combinam as informações topológicas das redes com as informações de suas estruturas de comunidades. Com essas informações, consegue-se identificar melhor os papeis que cada vértice tem na rede e com isso, quantificar sua real contribuição na predição 
de novos relacionamentos. Antes, contudo, são apresentados os fundamentos teóricos nos quais são baseadas as propostas, bem como a maneira como as informações das comunidades são coletadas e representadas na formulação das duas propostas.

\subsection{Fundamentos Teóricos da Proposta}

As estruturas de comunidades carregam informações valiosas sobre a dinâmica da formação das redes e sobre como os vértices com maior similaridade têm relacionamentos mais fortes tendendo a se agrupar. Por isso, as informações existentes nas estruturas das comunidades devem ser levadas em consideração na tarefa da predição de links.

Com essa intuição, e com a motivação dos resultados obtidos pelos métodos híbridos apresentados na Seção 3.2.4, para formulação da proposta apresentada nesta dissertação, são consideradas duas suposições:

1. O índice $\mathrm{CN}$ considera que todos os vizinhos comuns de um par de vértices analisados, fornecem a mesma contribuição na tarefa de predição. Porém, nas redes reais, cada vizinho comum pode ter um papel diferente, e assim, contribuir de maneira diferente na predição. Identificar tais papeis pode levar a uma melhora do desempenho da predição de novos relacionamentos;

2. As comunidades de uma rede agrupam vértices similares em grupos caracterizados pelas grandes quantidades de relacionamentos entre seus membros, no entanto, os relacionamentos entre vértices de grupos diferentes são menores em quantidade. Usar essa característica das comunidades também pode levar a melhorar o desempenho da tarefa de predição de links.

A primeira suposição tem fundamento na característica da similaridade que têm todos os vizinhos comuns de um par de vértices analisados e que também é aproveitada pelo CN. O CN (Lorrain e White, 1971) é um índice de similaridade estrutural baseado nas informações locais e caracteriza-se por ser simples e ter um ótimo desempenho na predição. A pesquisa realizada por Zhou et al. (2009) apresenta que, nas redes com um alto valor de coeficiente de agrupamento, o índice $\mathrm{CN}$ tem um desempenho comparável ao dos índices de similaridade estrutural baseados em informações globais. 
Como apresentado na Seção 3.2.1, no CN quanto maior for a quantidade de vizinhos comuns que tenha um par de vértices, maior é a chance de se ligarem no futuro. Assim, cada vizinho comum fornece a mesma contribuição na computação da probabilidade de conexão. Porém, as vezes, cada vizinho comum pode ter um papel diferente e, a identificação desses papeis, poderia levar à melhora no desempenho da predição (Liu et al., 2011). Por exemplo, em uma rede social de amizade, os amigos comuns que formam parte do mesmo grupo social de duas pessoas que não se conhecem poderiam ter uma maior contribuição na computação da probabilidade de uma futura amizade entre essas pessoas. No entanto, se os amigos comuns pertencem a diferentes grupos sociais, essa contribuição poderia ser menor.

A segunda suposição tem fundamento na característica das estruturas de comunidades. Experimentos realizados por Feng et al. (2012) em redes reais e sintéticas apresentam que, para redes com uma pobre estrutura de comunidade $^{1}$, os índices de similaridade baseados em informações topológicas têm um desempenho baixo. Entretanto, conforme a estrutura de comunidades das redes vai ficando mais rica, o desempenho desse índices vai melhorando rapidamente.

\subsection{Obtenção das informações das comunidades}

Dado que o foco da proposta apresentada neste capítulo é o uso das informações das estruturas de comunidades, o primeiro ponto a se tratar dirige-se à representação dessas informações. Assim, considerando que as comunidades de uma dada rede analisada são desconhecidas, deve-se executar um algoritmo de detecção de comunidades apropriado. Assim, para formulação da proposta, é necessário o uso de um algoritmo de detecção de comunidades de vértices.

Considerando a rede $G(V, E)$, assume-se que um algoritmo de detecção de comunidades vai identificar $M>1$ comunidades em uma rede. Para cada uma dessas comunidades, é atribuído um rótulo diferente e único: $C_{\alpha}, C_{\beta}, \ldots, C_{M}$. Assim, quando um vértice $x \in V$ pertence a uma comunidade com o rótulo $C$, esse vértice será representado como $x^{C}$. Além disso, se considera que cada

\footnotetext{
${ }^{1}$ A estrutura de comunidade de uma rede é considerada pobre quando as comunidades não têm muita diferença entre elas, existindo poucas ligações entre os vértices das mesmas comunidades ou muitas ligações entre vértices de diferentes comunidades (Brandes et al., 2003). Uma estrutura de comunidades pode ser dita de pobre se tem um baixo valor de modularidade.
} 
vértice pertence unicamente a uma comunidade.

Na Figura 4.1 é apresentado o grafo da Figura 2.1 depois de suas comunidades terem sido detectadas por um dado algoritmo. Tal grafo possui 12 vértices e 19 ligações entre eles. Cada vértice é rotulado com seu respectivo índice utilizado na Figura 2.1. Assim, os vértices do rótulo 1 a 4 pertencem à comunidade de rótulo $C_{\alpha}$ ou comunidade da cor cinza. Os vértices do rótulo 5 até 9 pertencem à comunidade de rótulo $C_{\beta}$ ou comunidade da cor preta. Os vértices do rótulo 10 até 12 pertencem à comunidade de rótulo $C_{\gamma}$ ou comunidade da cor branca.

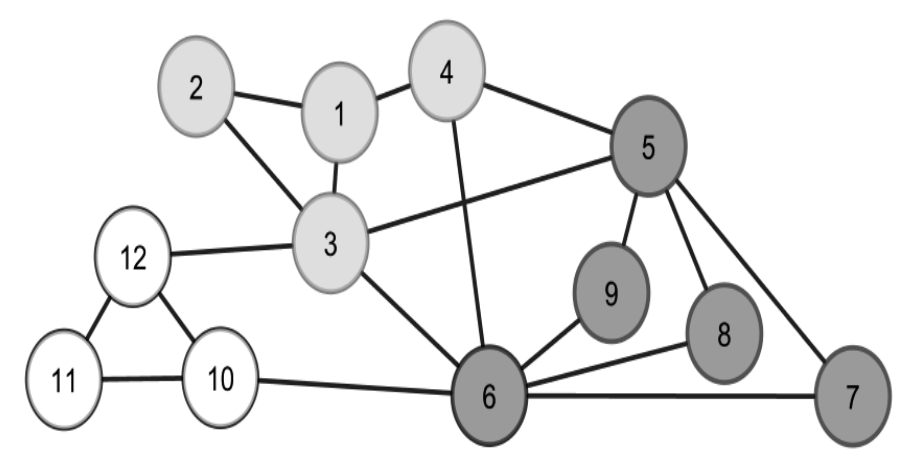

Figura 4.1: Exemplo de uma rede na qual são identificadas três comunidades diferençadas pela cor. Os vértices da mesma cor pertencem à mesma comunidade.

Como se observa na Figura 4.1, cada vértice pertence unicamente a uma comunidade. Dessa maneira, a representação $3^{C_{\alpha}}$ indica que o vértice 3 pertence à comunidade com rotulo $C_{\alpha}$. Da mesma maneira, a representação $8^{C_{\beta}}$ indica que o vértice 8 pertence à comunidade com rótulo $C_{\beta}$.

Além da representação individual de cada vértice para a comunidade à qual pertence, para formulação da proposta desta dissertação tem-se em conta também o conceito de vértices intra-comunidade e vértices inter-comunidades. Os vértices intra-comunidade são os vértices que pertencem à mesma comunidade, ou seja, os vértices que têm o mesmo rótulo de comunidade. Já os vértices inter-comunidades são os vértices que pertencem a diferentes comunidades ou seja, os vértices que têm diferentes rótulos de comunidades. 


\section{3 Índice baseado nas Informações Intra e Inter Co- munidades}

Nesta seção é apresentada a primeira proposta desenvolvida nesta pesquisa. Esta proposta utiliza as informações dos vértices que são vizinhos comuns intra-comunidade e dos vizinhos comuns inter-comunidades de um par de vértices analisados. Com isso, é gerado um novo índice de similaridade para predição de novos relacionamentos.

É importante destacar que esta primeira proposta baseia-se no uso do teorema de Bayes. O teorema de Bayes (Hastie et al., 2009; Russell e Norvig, 2010) é uma abordagem probabilística que descreve as probabilidades condicional e marginal dos eventos $A$ e $B$. Considerando que a probabilidade $a$ priori de $B$ é diferente de zero, a Equação de Bayes é definida como:

$$
P(A \mid B)=\frac{P(B \mid A) \cdot P(A)}{P(B)}
$$

As probabilidades $P(A)$ e $P(B)$ são chamadas de probabilidades a priori de $A$ e $B$, respectivamente. A probabilidade a priori só considera as informações do evento solicitado. $P(A \mid B)$ é chamada probabilidade condicional de $A$ dado que se observa $B$, e também é chamada de probabilidade a posteriori.

Considerando isso, a seguir é descrito o procedimento realizado para dedução do índice para predição de novos relacionamentos correspondente à primeira proposta deste trabalho.

Denota-se por $\Lambda_{x, y}=\Gamma(x) \cap \Gamma(y)$ o conjunto de vizinhos comuns do par de vértices $x$ e $y$. De acordo à Equação de Bayes, tem-se que a probabilidade posterior que o rótulo $C_{\alpha}$ de uma comunidade seja atribuído para o par de vértices $x$ e $y$, dado que conhecemos o conjunto de seus vizinhos comuns, é:

$$
P\left(x^{C_{\alpha}}, y^{C_{\alpha}} \mid \Lambda_{x, y}\right)=\frac{P\left(\Lambda_{x, y} \mid x^{C_{\alpha}}, y^{C_{\alpha}}\right) \cdot P\left(x^{C_{\alpha}}, y^{C_{\alpha}}\right)}{P\left(\Lambda_{x, y}\right)}
$$

De maneira similar, a probabilidade posterior que os rótulos, $C_{\alpha}$ e $C_{\beta}$, de duas comunidades diferentes sejam atribuídos para o par de vértices $x$ e $y$, dado que conhecemos o conjunto de seus vizinhos comuns, é:

$$
P\left(x^{C_{\alpha}}, y^{C_{\beta}} \mid \Lambda_{x, y}\right)=\frac{P\left(\Lambda_{x, y} \mid x^{C_{\alpha}}, y^{C_{\beta}}\right) \cdot P\left(x^{C_{\alpha}}, y^{C_{\beta}}\right)}{P\left(\Lambda_{x, y}\right)}
$$

As Equações 4.2 e 4.3 são usadas para derivar uma proporção que seja útil para medir a probabilidade de conexão de um par de vértices. Essa proporção 
é definida pela Equação 4.4.

$$
s_{x, y}=\frac{P\left(x^{C_{\alpha}}, y^{C_{\alpha}} \mid \Lambda_{x, y}\right)}{P\left(x^{C_{\alpha}}, y^{C_{\beta}} \mid \Lambda_{x, y}\right)}=\frac{P\left(\Lambda_{x, y} \mid x^{C_{\alpha}}, y^{C_{\alpha}}\right) \cdot P\left(x^{C_{\alpha}}, y^{C_{\alpha}}\right)}{P\left(\Lambda_{x, y} \mid x^{C_{\alpha}}, y^{C_{\beta}}\right) \cdot P\left(x^{C_{\alpha}}, y^{C_{\beta}}\right)}
$$

Considerando que $\Lambda_{x, y}=\Lambda_{x, y}^{W} \cup \Lambda_{x, y}^{I}$, onde $\Lambda_{x, y}^{W}=\left\{z \in \Lambda_{x, y} \mid x^{C}, y^{C}, z^{C}\right\}$ é o conjunto dos vizinhos comuns intra-comunidade (Within-community common neighbors - W) e seu complemento $\Lambda_{x, y}^{I}=\Lambda_{x, y} \backslash \Lambda_{x, y}^{W}$, é o conjunto dos vizinhos comuns inter-comunidades (Inter-community common neighbors - I), o qual é definido como a diferença entre o conjunto total de vizinhos comuns com o conjunto dos vizinhos comuns intra-comunidade. Assim, o conjunto $\Lambda_{x, y}^{W}$ é formado pelos vizinhos comuns dos vértices $x$ e $y$ que a sua vez pertencem à mesma comunidade deles. Da mesma maneira, o conjunto $\Lambda_{x, y}^{I}$ é formado pelos vizinhos comuns que podem pertencer à mesma comunidade a qual pertence o vértice $x$, ou à mesma comunidade a qual pertence o vértice $y$, ou qualquer outra comunidade. Claramente, tem-se que $\Lambda_{x, y}^{W} \cap \Lambda_{x, y}^{I}=\varnothing$.

Assim, para estimar a probabilidade de conhecer o conjunto de vizinhos comuns $\Lambda_{x, y}$, dado que $x$ e $y$ pertencem à mesma comunidade de rótulo $C_{\alpha}$, vaise considerar a proporção entre o número de vizinhos comuns pertencentes a mesma comunidade desses vértices e o total de vizinhos comuns existentes. Essa proporção é definida pela Equação 4.5.

$$
P\left(\Lambda_{x, y} \mid x^{C_{\alpha}}, y^{C_{\alpha}}\right)=\frac{\left|\Lambda_{x, y}^{W}\right|}{\left|\Lambda_{x, y}\right|}
$$

De maneira similar, para estimar a probabilidade de conhecer o conjunto de vizinhos comuns $\Lambda_{x, y}$, dado que $x$ e $y$ pertencem a comunidades de rótulos diferentes, $C_{\alpha}$ e $C_{\beta}$, respectivamente, vai-se considerar a proporção entre o número de vizinhos comuns associados ao rótulo de comunidade $C_{\alpha}$, ou $C_{\beta}$, ou qualquer outro rótulo de comunidade $C_{\gamma}$, e o total de vizinhos comuns existentes. Essa proporção é definida pela Equação 4.6.

$$
P\left(\Lambda_{x, y} \mid x^{C_{\alpha}}, y^{C_{\beta}}\right)=\frac{\left|\Lambda_{x, y}^{I}\right|}{\left|\Lambda_{x, y}\right|}
$$

Substituindo as Equações 4.5 e 4.6 na Equação 4.4, a proporção que mede a probabilidade de ligação entre os pares de vértices $x$ e $y$ é definida pela Equação 4.7 .

$$
s_{x, y}=\frac{\left|\Lambda_{x, y}^{W}\right|}{\left|\Lambda_{x, y}^{I}\right|} \cdot \frac{P\left(x^{C_{\alpha}}, y^{C_{\alpha}}\right)}{P\left(x^{C_{\alpha}}, y^{C_{\beta}}\right)}
$$


Lembrando que cada vértice pode pertencer a uma única comunidade, isto é, $y^{C_{\alpha}}=y^{C_{\beta}}$, a computação da proporção $\frac{P\left(x^{C \alpha}, y^{C \alpha}\right)}{P\left(x^{C}, y^{C}\right)}$ pode ser desconsiderada já que tem o valor de 1 . Com isso, a primeira proposta deste trabalho é apresentada na Equação 4.8, a qual define de um novo índice de similaridade nomeado como índice baseado nas informações intra e inter comunidades (Within and Inter Community - WIC).

$$
s_{x, y}^{W I C}=\left\{\begin{array}{cc}
\left|\Lambda_{x, y}^{W}\right|, & \text { se } \Lambda_{x, y}^{W}=\Lambda_{x, y} \quad \mathrm{e} \\
\frac{\left|\Lambda_{x, y}^{W}\right|}{\left|\Lambda_{x, y}^{I}\right|}, & \text { caso contrário }
\end{array}\right.
$$

É importante destacar que, para evitar a divisão por zero, no caso que $\Lambda_{x, y}^{W}=\Lambda_{x, y}$, o índice WIC é definido unicamente como a contagem dos vizinhos comuns intra-comunidade.

Na Tabela 4.1, considerando a rede da Figura 4.1, são apresentados três exemplos da computação do índice WIC para três pares de vértices não ligados. Dessa maneira, se o objetivo é computar a probabilidade da existência de um futuro link entre o par de vértices $(5,6)$, tem-se que seu conjunto total de vizinhos comuns é $\Lambda_{5,6}=\{3,4,7,8,9\}$. A partir desse conjunto, pode-se obter o conjunto de vizinhos comuns intra-comunidades $\Lambda_{5,6}^{W}=\{7,8,9\}$ e o conjunto de vizinhos comuns inter-comunidades $\Lambda_{5,6}^{I}=\{3,4\}$. Conhecendo esses conjuntos e obtendo suas respectivas cardinalidades, deve-se usar a Equação 4.8, a qual define o índice WIC. Assim, se tem como resultado final a pontuação $s_{5,6}^{W I C}=1.5$. O mesmo é realizado para os demais pares de vértices.

Tabela 4.1: Exemplo da computação do índice WIC.

\begin{tabular}{ccccc}
\hline$(x, y)$ & $\Lambda_{x, y}$ & $\Lambda_{x, y}^{W}$ & $\Lambda_{x, y}^{I}$ & $s_{x, y}^{W I C}$ \\
\hline$(3,10)$ & $\Lambda_{3,10}=\{6,12\}$ & $\Lambda_{3,10}^{W}=\{\}$ & $\Lambda_{3,10}^{I}=\{6,12\}$ & $s_{3,10}^{W I C}=0$ \\
$(5,6)$ & $\Lambda_{5,6}=\{3,4,7,8,9\}$ & $\Lambda_{5,6}^{W}=\{7,8,9\}$ & $\Lambda_{5,6}^{I}=\{3,4\}$ & $s_{5,6}^{W I C}=1.5$ \\
$(9,7)$ & $\Lambda_{9,7}=\{5,6\}$ & $\Lambda_{9,7}^{W}=\{5,6\}$ & $\Lambda_{9,7}^{I}=\{\}$ & $s_{9,7}^{W I C}=2$ \\
\hline
\end{tabular}

\subsection{Conjunto de Índices baseados nas Informações Intra-Comunidades}

Nesta seção é apresentada a segunda proposta desenvolvida durante o mestrado. Esta proposta corresponde a um conjunto de índices gerados a partir da reformulação dos índices de similaridade local quando se usam as 
informações dos vizinhos comuns intra-comunidades ao invés do total de vizinhos comuns. A seguir é apresentado o procedimento realizado para formulação do conjunto de índices para predição de links correspondente à segunda proposta deste trabalho.

Considerando que os indices de similaridade estrutural baseados nas informações locais apresentados na Seção 3.2.1, exceto o índice PA, têm como sua base o conjunto de vizinhos comuns, então é possível melhorar seu desempenho se é aproveitada a informação específica dos papeis que esses vizinhos comuns têm.

Os vizinhos comuns intra-comunidade (W) capturam os relacionamentos existentes entre vértices que pertencem à mesma comunidade, isto é, as informações dos vértices que têm uma maior similaridade por compartilharem os mesmos papeis. Por outro lado, os vizinhos comuns inter-comunidade (I) capturam os relacionamentos existentes entre vértices que pertencem a diferentes comunidades.

Dessa maneira, assume-se que os vizinhos comuns intra-comunidade, ou vizinhos $\mathrm{W}$, podem contribuir melhor na probabilidade de conexão de um par de vértices não ligados que os vizinhos inter-comunidades. Com isso, os índices de similaridade estrutural baseados nas informações locais são reformulados usando o conjunto de vizinhos $\mathrm{W}$ de um dado par de vértices $x$ e $y$ $\left(\Lambda_{x, y}^{W}\right)$ ao invés do conjunto total de vizinhos comuns $\left(\Lambda_{x, y}\right)$ desse mesmo par de vértices.

Essa reformulação dos índices de similaridade local formam um conjunto de novos índices, os quais são nomeados como índices da forma W. A seguir é apresentada a reformulação de cada um dos índices de similaridade local, ou seja, as definições de cada índice da forma W.

Vizinhos Comuns da forma W (CN-W): Com base no índice de vizinhos comuns, é definido pela Equação 4.9 .

$$
s_{x, y}^{C N-W}=\left|\Lambda_{x, y}^{W}\right|
$$

Índice de Salton da forma W (Sal-W): Com base no índice de Salton, é definido pela Equação 4.10.

$$
s_{x, y}^{S a l-W}=\frac{\left|\Lambda_{x, y}^{W}\right|}{\sqrt{k_{x} \times k_{y}}}
$$


Índice de Jaccard da forma W (Jac-W): Com base no índice de Jaccard, é definido pela Equação 4.11.

$$
s_{x, y}^{J a c-W}=\frac{\left|\Lambda_{x, y}^{W}\right|}{|\Gamma(x) \cup \Gamma(y)|}
$$

Índice de Adamic-Adar da forma W (AA-W): Com base no índice de AdamicAdar, é definido pela Equação 4.12.

$$
s_{x, y}^{A A-W}=\sum_{z \in \Lambda_{x, y}^{W}} \frac{1}{\log k_{z}}
$$

Índice de alocação de recursos da forma W (RA-W): Com base no índice de alocação de recursos, é definido pela Equação 4.13.

$$
s_{x, y}^{R A-W}=\sum_{z \in \Lambda_{x, y}^{W}} \frac{1}{k_{z}}
$$

Índice de $\mathbf{S} \phi \mathbf{r e n s e n ~ d a ~ f o r m a ~ W ~ ( S o r - W ) : ~ C o m ~ b a s e ~ n o ~ i ́ n d i c e ~ d e ~ S ~} \phi$ rensen, é definido pela Equação 4.14.

$$
s_{x, y}^{S o r-W}=\frac{2\left|\Lambda_{x, y}^{W}\right|}{k_{x}+k_{y}}
$$

Índice do hub promovido da forma W (HPI-W): Com base no índice do hub promovido, é definido pela Equação 4.15.

$$
s_{x, y}^{H P I-W}=\frac{\left.\mid \Lambda_{x, y}^{W}\right) \mid}{\min \left\{k_{x}, k_{y}\right\}}
$$

Índice do hub deprimido da forma W (HDI-W): Com base no índice do hub deprimido, é definido pela Equação 4.16.

$$
s_{x, y}^{H D I-W}=\frac{\left|\Lambda_{x, y}^{W}\right|}{\max \left\{k_{x}, k_{y}\right\}}
$$

Índice de Leicht-Holme-Newman da forma W (LHN-W): Com base no índice de Leicht-Holme-Newman, é definido pela Equação 4.17.

$$
s_{x, y}^{L H N-W}=\frac{\left|\Lambda_{x, y}^{W}\right|}{k_{x} \times k_{y}}
$$




\subsection{Considerações Finais}

Neste capítulo foram apresentadas duas novas propostas para predição de links. Estas propostas pertencem ao grupo de métodos híbridos devido ao uso das informações das comunidades junto com informações topológicas, e assim, obter um melhor desempenho na tarefa de predição de novos relacionamentos.

Na primeira proposta, com base no Teorema de Bayes e considerando a correlação existente entre os vizinhos comuns do par de vértices analisados bem como das comunidades às quais pertencem, foi apresentado um novo índice para predição de links. Esse novo índice, chamado de índice baseado nas informações intra e inter comunidades (WIC), pode ser definido basicamente como a proporção entre a quantidade de vizinhos comuns que pertencem ao mesmo grupo dos vértices analisados e a quantidade de seus vizinhos comuns que pertencem a qualquer grupo.

Usando unicamente a informação dos vizinhos comuns que pertencem à mesma comunidade do par de vértices analisados, foi apresentada a segunda proposta, a qual corresponde a um conjunto de índices chamados de índices da forma W. Cada um dos índices da forma W é uma reformulação dos diferentes índices de similaridade local, e caracterizam-se por utilizar a cardinalidade do conjunto de vizinhos comuns intra-comunidade ao invés da cardinalidade do conjunto total de vizinhos comuns.

Dada a formulação das duas propostas apresentadas, pode-se dizer que, diferentemente das poucas propostas existentes na literatura que utilizam as informações das comunidades, o índice WIC surge como resultado de uma resolução numérica e não simplesmente da observação dos comportamentos dos elementos das comunidades nas redes. Já os índices da forma W surgem como uma derivação do índice WIC. Com isso, o próximo capítulo é focado na apresentação dos resultados obtidos pelo uso do índice WIC e dos índices da forma $\mathrm{W}$ comparando-os com os resultados obtidos pelos índices de similaridade estrutural pertencentes ao estado da arte. 


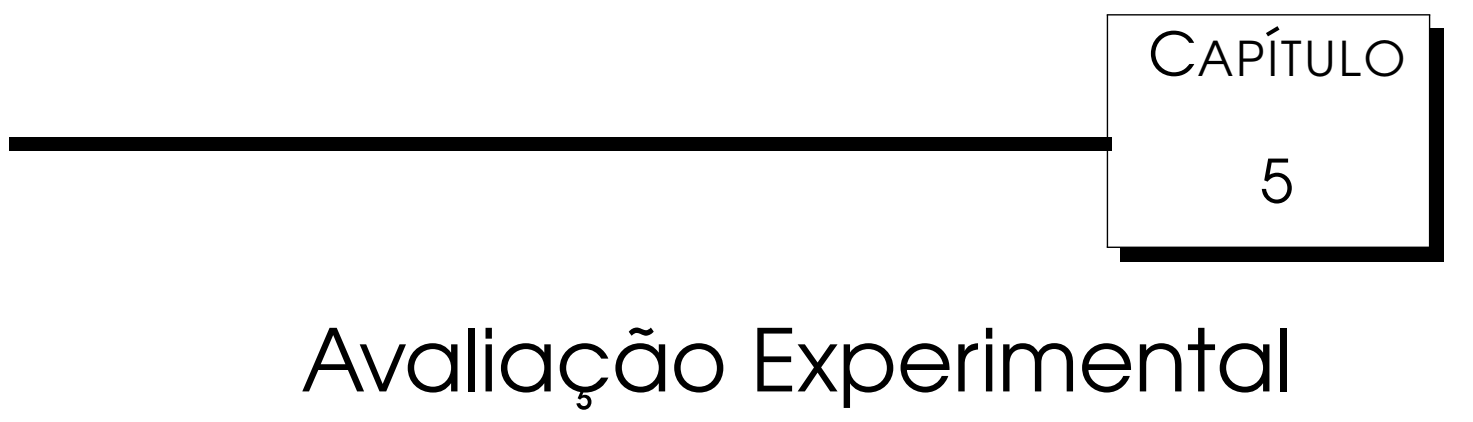

$\mathcal{E}$

ste capítulo apresenta os experimentos realizados para a avaliação dos métodos propostos nesta dissertação e, consequentemente, as discussões sobre os resultados obtidos. Assim, são apresentadas as redes que foram avaliadas, a metodologia de testes usada para obtenção dos resultados, bem como a análise comparativa dos resultados obtidos pelas propostas apresentadas nesta dissertação e pela abordagem tradicional.

\section{1 Redes Adotadas}

Para avaliar o desempenho dos métodos de predição de links, dez redes complexas das quatro categorias existentes foram consideradas: redes de informação, redes tecnológicas, redes biológicas, e redes sociais. As redes que foram adotadas caracterizam-se por serem não direcionadas e apresentarem conexões não ponderadas. A seguir são apresentadas breves descrições de cada uma delas.

1. Airline. Uma rede tecnológica que modela o sistema de transporte aéreo dos Estados Unidos da América, na qual estão presentes 332 aeroportos e 2126 linhas aéreas. Airline é uma rede disponibilizada por Batageli e Mrvar (2006).

2. Power. Uma rede tecnológica que representa a rede de centrais elétricas do oeste dos Estados Unidos de América. Esta rede foi compilada por 
Watts e Strogatz (1998).

3. Router. Uma rede tecnológica que representa uma topologia de rede na qual routers são representados como vértices e as arestas são as conexões entre os routers. Esta rede foi compilada por Spring et al. (2004).

4. Industry-pr. Uma rede de informação, na qual indústrias são relacionadas por co-ocorrência em notícias obtidas da Web entre 03/04/2003 e 30/09/2003. Esta rede foi compilada por Fawcett e Provost (1999).

5. Imdb-prodco. Uma rede de informação de filmes na Internet. Os filmes são ligados se compartilham uma empresa de produção. Esta rede foi compilada por Macskassy e Provost (2007).

6. PoolBlogs. Uma rede de informação, na qual são representadas citações entre blogs políticos registrados em 2005 nos Estados Unidos da América. $\mathrm{Na}$ rede original os links são direcionados, embora neste trabalho são considerados como não direcionados. Esta rede foi compilada por Ackland (2005).

7. Yeast. Uma rede biológica de interação proteína-proteína (PPI). Esta rede foi compilada por von Mering et al. (2002).

8. Football. Uma rede social de relacionamentos entre equipes colegiais de futebol americano durante a temporada do ano 2000. Os vértices são as equipes e as arestas ligam equipes que se enfrentam. Este conjunto foi compilado por Girvan e Newman (2002).

9. Karate. Uma rede social de amizade entre os membros de um clube de karatê em um período de dois anos. Esta rede foi compilada por Zachary (1977).

10. NetScience. Uma rede social de colaboração entre cientistas. Os relacionamentos entre cientistas são definidos quando eles têm publicações em um mesmo tópico de pesquisa. Esta rede foi compilada por (Newman, 2006).

Na Tabela 5.1 são apresentadas as propriedades estruturais básicas das redes adotadas. Nessa tabela, para cada rede, é apresentada sua quantidade de vértices $(|V|)$ e de arestas $(|E|)$, bem como seu respectivo coeficiente de agrupamento global (C), coeficiente de assortatividade (r), e seu grau de heterogeneidade (H). 
Tabela 5.1: Propriedades estruturais básicas de dez redes.

\begin{tabular}{lccccc}
\hline Redes & $|V|$ & $|E|$ & $\mathbf{C}$ & $\mathbf{~}$ & $\mathbf{H}$ \\
\hline Airline & 332 & 2126 & 0.6252 & -0.2079 & 3.4639 \\
Power & 4941 & 6594 & 0.0801 & 0.0034 & 1.4504 \\
Router & 5022 & 6258 & 0.0116 & -0.1384 & 5.5031 \\
Industry-pr & 2189 & 11666 & 0.3297 & 0.1842 & 3.4122 \\
Imdb-prodco & 1441 & 20317 & 0.5843 & 0.3492 & 2.0982 \\
PoolBlogs & 1224 & 16716 & 0.3203 & -0.2211 & 2.9749 \\
Yeast & 2617 & 11855 & 0.2844 & 0.4610 & 3.7284 \\
Football & 115 & 613 & 0.4032 & 0.1624 & 1.0069 \\
Karate & 34 & 78 & 0.5706 & -0.4756 & 1.6933 \\
NetScience & 1461 & 2742 & 0.6937 & 0.4616 & 1.8486 \\
\hline
\end{tabular}

As redes adotadas são de livre acesso e têm sido utilizadas tanto na tarefa de predição de links, bem como em outras tarefas de diferentes trabalhos científicos. Além disso, como observado na Tabela 5.1, essas redes têm uma quantidade considerável de vértices e links e a complexidade de sua estrutura topológica é refletida nos altos valores de coeficiente de agrupamento global e grau de heterogeneidade das redes, bem como o valor negativo que algumas têm no seu coeficiente de assortatividade.

\subsection{Metodologia Experimental}

O principal objetivo dos experimentos realizados e apresentados neste capítulo é mostrar a viabilidade do uso das duas propostas apresentadas neste trabalho dado seu desempenho na predição nas redes adotadas. Para isso, uma série de estratégias, métricas e técnicas foram adotadas.

\subsubsection{Detecção de Diferentes Estruturas de Comunidades}

Para cada rede adotada, foram executados dois algoritmos diferentes para detecção de comunidades: o Fast Modularity (FM), e o WalkTrap (WT), apresentados na Seção 2.2. Além disso, com o objetivo de avaliar o desempenho na predição de nossa proposta quando uma mesma rede tem diferentes agrupamentos, cada algoritmo de detecção de comunidades foi executado sete vezes, com configurações diferentes em cada execução a fim de obter quantidades distintas de comunidades.

A eleição de uma quantidade de sete execuções foi determinada por ser considerada uma quantidade adequada, nem muito alta nem muito baixa, para a 
realização dos experimentos nas dez redes caracterizadas por terem quantidades diferentes de vértices. Assim, para cada rede adotada foram determinadas quatorze estruturas diferentes obtidas por meio de sete execuções diferentes de cada um dos dois algoritmos de detecção de comunidades usado.

Nas Tabelas 5.2 e 5.3 são mostradas, respectivamente, as informações das sete estruturas obtidas usando o algoritmo FM e das sete estruturas obtidas quando o algoritmo WT é usado. Nessas tabelas, para cada rede e para cada uma de suas estruturas de comunidades, são apresentadas: o número total de comunidades obtidas; o tamanho mínimo de uma comunidade, ou seja, o número de vértices pertencentes à comunidade de menor tamanho; o tamanho máximo de uma comunidade, ou seja, o número de vértices pertencentes à maior comunidade; a média dos vértices pertencentes às diferentes comunidades detetadas; e a modularidade $(Q)$ calculada mediante o uso da Equação 2.14. Para cada rede, o valor da modularidade da estrutura mais rica é destacado em negrito.

Das quatorze estruturas obtidas de cada rede, seguindo o procedimento apresentado na Seção 4.2, foram obtidas $M>1$ comunidades, onde cada uma delas apresenta um rótulo diferente e único. Cada vértice $x$ pertencente à comunidade de rótulo $C$ é representado como $x^{C}$. Além disso, cada vértice pode pertencer exclusivamente a uma comunidade, isto é, não são considerados os casos de interseção entre comunidades.

\subsubsection{Subamostragem de Dados}

Em uma rede $G(V, E)$, a distribuição de links existentes e links que poderiam existir no futuro é muito desbalanceada, conforme exposto na Seção 3.4. Dessa maneira, os experimentos seguem a estratégia não supervisionada, apresentada na Seção 3.1.2, mediante o uso de uma validação de subamostragem aleatória. Nessa subamostragem aleatória, o conjunto de links observados $E$ é aleatoriamente dividido em duas partes, conjunto de treino $E^{T}$ e o conjunto de teste ou avaliação $E^{P}$.

Considerando o conceito de proporção de links por vértice, $r=\left\lceil\frac{|E|}{|V|}\right\rceil$, os links formados pelos pares de vértices que tenham um grau maior de $\frac{r}{3}$ são considerados como parte do conjunto de treino e teste. Os links que não satisfazem essa condição são totalmente desconsiderados do processo de subamostragem. Dos links selecionados, os formados por pares de vértices que tenham um grau menor de $2 r$ são considerados diretamente como parte do conjunto de treino $E^{T}$. Enquanto que, dos links formados por pares de vértices que 
Tabela 5.2: Informações das diferentes estruturas de comunidades obtidas usando o algoritmo Fast Modularity para cada rede adotada.

\begin{tabular}{|c|c|c|c|c|c|c|}
\hline Redes & Estrutura & $M$ & Tam mínimo & Tam máximo & Média & $Q$ \\
\hline \multirow{7}{*}{ Airline } & estrutura \# 1 & 32 & 1 & 123 & 10,375 & 0,27 \\
\hline & estrutura \# 2 & 72 & 1 & 114 & 4,611 & 0,261 \\
\hline & estrutura \# 3 & 112 & 1 & 114 & 2,964 & 0,241 \\
\hline & estrutura \# 4 & 152 & 1 & 91 & 2,184 & 0,18 \\
\hline & estrutura \# 5 & 192 & 1 & 91 & 1,729 & 0,113 \\
\hline & estrutura \# 6 & 232 & 1 & 82 & 1,431 & 0,089 \\
\hline & estrutura \# 7 & 272 & 1 & 40 & 1,221 & 0,055 \\
\hline \multirow{7}{*}{ Power } & estrutura \# 1 & 441 & 1 & 224 & 11,204 & 0,435 \\
\hline & estrutura \# 2 & 941 & 1 & 170 & 5,251 & 0,374 \\
\hline & estrutura \# 3 & 1441 & 1 & 136 & 3,429 & 0,319 \\
\hline & estrutura \# 4 & 1941 & 1 & 83 & 2,546 & 0,266 \\
\hline & estrutura \# 5 & 2441 & 1 & 83 & 2,024 & 0,217 \\
\hline & estrutura \# 6 & 2941 & 1 & 83 & 1,68 & 0,169 \\
\hline & estrutura \# 7 & 3441 & 1 & 7 & 1,436 & 0,118 \\
\hline \multirow{7}{*}{ Router } & estrutura \# 1 & 22 & 22 & 1004 & 228,273 & 0,456 \\
\hline & estrutura \# 2 & 622 & 1 & 366 & 8,074 & 0,42 \\
\hline & estrutura \# 3 & 1222 & 1 & 366 & 4,11 & 0,368 \\
\hline & estrutura \# 4 & 1822 & 1 & 366 & 2,756 & 0,307 \\
\hline & estrutura \# 5 & 2422 & 1 & 101 & 2,073 & 0,222 \\
\hline & estrutura \# 6 & 3022 & 1 & 12 & 1,662 & 0,163 \\
\hline & estrutura \# 7 & 3622 & 1 & 5 & 1,387 & 0,112 \\
\hline \multirow{7}{*}{ Industry-pr } & estrutura \# 1 & 189 & 2 & 796 & 11,582 & 0,346 \\
\hline & estrutura \# 2 & 439 & 1 & 564 & 4,986 & 0,336 \\
\hline & estrutura \# 3 & 689 & 1 & 542 & 3,177 & 0,311 \\
\hline & estrutura \# 4 & 939 & 1 & 529 & 2,331 & 0,24 \\
\hline & estrutura \# 5 & 1189 & 1 & 515 & 1,841 & 0,178 \\
\hline & estrutura \# 6 & 1439 & 1 & 429 & 1,521 & 0,155 \\
\hline & estrutura \# 7 & 1689 & 1 & 175 & 1,296 & 0,083 \\
\hline \multirow{7}{*}{ Imdb-prodco } & estrutura \# 1 & 169 & 1 & 272 & 8,476 & $\mathbf{0 , 3 2 8}$ \\
\hline & estrutura \# 2 & 269 & 1 & 272 & 5,337 & 0,303 \\
\hline & estrutura \# 3 & 369 & 1 & 272 & 3,895 & 0,268 \\
\hline & estrutura \# 4 & 469 & 1 & 272 & 3,066 & 0,234 \\
\hline & estrutura \# 5 & 569 & 1 & 272 & 2,528 & 0,202 \\
\hline & estrutura \# 6 & 669 & 1 & 272 & 2,151 & 0,156 \\
\hline & estrutura \# 7 & 769 & 1 & 272 & 1,871 & 0,137 \\
\hline \multirow{7}{*}{ PoolBlogs } & estrutura \# 1 & 23 & 1 & 631 & 51 & $\mathbf{0 , 3 3 8}$ \\
\hline & estrutura \# 2 & 173 & 1 & 553 & 7,034 & 0,333 \\
\hline & estrutura \# 3 & 323 & 1 & 511 & 3,778 & 0,325 \\
\hline & estrutura \# 4 & 473 & 1 & 511 & 2,582 & 0,295 \\
\hline & estrutura \# 5 & 623 & 1 & 511 & 1,965 & 0,203 \\
\hline & estrutura \# 6 & 773 & 1 & 433 & 1,583 & 0,164 \\
\hline & estrutura \# 7 & 923 & 1 & 283 & 1,326 & 0,127 \\
\hline \multirow{7}{*}{ Yeast } & estrutura \# 1 & 117 & 2 & 743 & 22,368 & 0,405 \\
\hline & estrutura \# 2 & 417 & 1 & 607 & 6,276 & 0,393 \\
\hline & estrutura \# 3 & 717 & 1 & 586 & 3,65 & 0,353 \\
\hline & estrutura \# 4 & 1017 & 1 & 575 & 2,573 & 0,29 \\
\hline & estrutura \# 5 & 1317 & 1 & 575 & 1,987 & 0,253 \\
\hline & estrutura \# 6 & 1617 & 1 & 378 & 1,618 & 0,216 \\
\hline & estrutura \# 7 & 1917 & 1 & 177 & 1,365 & 0,162 \\
\hline \multirow{7}{*}{ Football } & estrutura \# 1 & 15 & 1 & 27 & 7,667 & 0,305 \\
\hline & estrutura \# 2 & 25 & 1 & 27 & 4,6 & 0,275 \\
\hline & estrutura \# 3 & 35 & 1 & 27 & 3,286 & 0,242 \\
\hline & estrutura \# 4 & 45 & 1 & 27 & 2,556 & 0,208 \\
\hline & estrutura \# 5 & 55 & 1 & 27 & 2,091 & 0,178 \\
\hline & estrutura \# 6 & 65 & 1 & 27 & 1,769 & 0,149 \\
\hline & estrutura \# 7 & 75 & 1 & 27 & 1,533 & 0,114 \\
\hline \multirow{7}{*}{ Karate } & estrutura \# 1 & 4 & 1 & 17 & 8,5 & 0,292 \\
\hline & estrutura \# 2 & 8 & 1 & 9 & 4,25 & 0,236 \\
\hline & estrutura \# 3 & 12 & 1 & 9 & 2,833 & 0,203 \\
\hline & estrutura \# 4 & 16 & 1 & 7 & 2,125 & 0,16 \\
\hline & estrutura \# 5 & 20 & 1 & 6 & 1,7 & 0,131 \\
\hline & estrutura \# 6 & 24 & 1 & 6 & 1,417 & 0,101 \\
\hline & estrutura \# 7 & 28 & 1 & 6 & 1,214 & 0,063 \\
\hline \multirow{7}{*}{ NetScience } & estrutura \# 1 & 461 & 1 & 86 & 3,169 & 0,354 \\
\hline & estrutura \# 2 & 561 & 1 & 82 & 2,604 & 0,309 \\
\hline & estrutura \# 3 & 661 & 1 & 50 & 2,21 & 0,265 \\
\hline & estrutura \# 4 & 761 & 1 & 50 & 1,92 & 0,22 \\
\hline & estrutura \# 5 & 861 & 1 & 47 & 1,697 & 0,179 \\
\hline & estrutura \# 6 & 961 & 1 & 47 & 1,52 & 0,13 \\
\hline & estrutura \# 7 & 1061 & 1 & 7 & 1,377 & 0,095 \\
\hline
\end{tabular}


Tabela 5.3: Informações das diferentes estruturas de comunidades obtidas usando o algoritmo WalkTrap para cada rede adotada.

\begin{tabular}{|c|c|c|c|c|c|c|}
\hline Redes & Estrutura & $M$ & Tam mínimo & Tam máximo & Média & $Q$ \\
\hline \multirow{7}{*}{ Airline } & estrutura \# 1 & 32 & 1 & 119 & 10,375 & 0,24 \\
\hline & estrutura \# 2 & 72 & 1 & 53 & 4,611 & 0,148 \\
\hline & estrutura \# 3 & 112 & 1 & 48 & 2,964 & 0,137 \\
\hline & estrutura \# 4 & 152 & 1 & 25 & 2,184 & 0,092 \\
\hline & estrutura \# 5 & 192 & 1 & 21 & 1,729 & 0,066 \\
\hline & estrutura \# 6 & 232 & 1 & 14 & 1,431 & 0,037 \\
\hline & estrutura \# 7 & 272 & 1 & 10 & 1,221 & 0,018 \\
\hline \multirow{7}{*}{ Power } & estrutura \# 1 & 441 & 2 & 129 & 11,204 & 0,419 \\
\hline & estrutura \# 2 & 941 & 2 & 34 & 5,251 & 0,358 \\
\hline & estrutura \# 3 & 1441 & 1 & 18 & 3,429 & 0,303 \\
\hline & estrutura \# 4 & 1941 & 1 & 11 & 2,546 & 0,254 \\
\hline & estrutura \# 5 & 2441 & 1 & 10 & 2,024 & 0,208 \\
\hline & estrutura \# 6 & 2941 & 1 & 10 & 1,68 & 0,164 \\
\hline & estrutura \# 7 & 3441 & 1 & 10 & 1,436 & 0,122 \\
\hline \multirow{7}{*}{ Router } & estrutura \# 1 & 22 & 9 & 4274 & 228,273 & 0,304 \\
\hline & estrutura \# 2 & 622 & 2 & 222 & 8,074 & 0,397 \\
\hline & estrutura \# 3 & 1222 & 2 & 93 & 4,11 & 0,337 \\
\hline & estrutura \# 4 & 1822 & 1 & 55 & 2,756 & 0,266 \\
\hline & estrutura \# 5 & 2422 & 1 & 55 & 2,073 & 0,213 \\
\hline & estrutura \# 6 & 3022 & 1 & 55 & 1,662 & 0,162 \\
\hline & estrutura \# 7 & 3622 & 1 & 55 & 1,387 & 0,113 \\
\hline \multirow{7}{*}{ Industry-pr } & estrutura \# 1 & 189 & 2 & 1654 & 11,582 & 0,27 \\
\hline & estrutura \# 2 & 439 & 1 & 860 & 4,986 & 0,338 \\
\hline & estrutura \# 3 & 689 & 1 & 671 & 3,177 & 0,308 \\
\hline & estrutura \# 4 & 939 & 1 & 458 & 2,331 & 0,251 \\
\hline & estrutura \# 5 & 1189 & 1 & 258 & 1,841 & 0,196 \\
\hline & estrutura \# 6 & 1439 & 1 & 72 & 1,521 & 0,122 \\
\hline & estrutura \# 7 & 1689 & 1 & 41 & 1,296 & 0,089 \\
\hline \multirow{7}{*}{ imdb-prodco } & estrutura \# 1 & 169 & 1 & 1126 & 4,935 & 0,251 \\
\hline & estrutura \# 2 & 269 & 1 & 1126 & 4,935 & 0,251 \\
\hline & estrutura \# 3 & 369 & 1 & 1072 & 3,905 & 0,226 \\
\hline & estrutura \# 4 & 469 & 1 & 972 & 3,072 & 0,19 \\
\hline & estrutura \# 5 & 569 & 1 & 872 & 2,533 & 0,152 \\
\hline & estrutura \# 6 & 669 & 1 & 772 & 2,154 & 0,117 \\
\hline & estrutura \# 7 & 769 & 1 & 672 & 1,874 & 0,09 \\
\hline \multirow{7}{*}{ PoolBlogs } & estrutura \# 1 & 23 & 1 & 1200 & 53,217 & 0,242 \\
\hline & estrutura \# 2 & 173 & 1 & 1051 & 7,075 & 0,2 \\
\hline & estrutura \# 3 & 323 & 1 & 901 & 3,789 & 0,175 \\
\hline & estrutura \# 4 & 473 & 1 & 748 & 2,588 & 0,158 \\
\hline & estrutura \# 5 & 623 & 1 & 601 & 1,965 & 0,14 \\
\hline & estrutura \# 6 & 773 & 1 & 451 & 1,583 & 0,082 \\
\hline & estrutura \# 7 & 923 & 1 & 301 & 1,326 & 0,036 \\
\hline \multirow{7}{*}{ Yeast } & estrutura \# 1 & 117 & 2 & 2197 & 22,368 & 0,263 \\
\hline & estrutura \# 2 & 417 & 1 & 250 & 6,276 & 0,359 \\
\hline & estrutura \# 3 & 717 & 1 & 139 & 3,65 & 0,312 \\
\hline & estrutura \# 4 & 1017 & 1 & 139 & 2,573 & 0,278 \\
\hline & estrutura \# 5 & 1317 & 1 & 136 & 1,987 & 0,246 \\
\hline & estrutura \# 6 & 1617 & 1 & 115 & 1,618 & 0,212 \\
\hline & estrutura \# 7 & 1917 & 1 & 106 & 1,365 & 0,167 \\
\hline \multirow{7}{*}{ Football } & estrutura \# 1 & 15 & 1 & 14 & 7,667 & $\mathbf{0 , 3 1 2}$ \\
\hline & estrutura \# 2 & 25 & 1 & 11 & 4,6 & 0,215 \\
\hline & estrutura \# 3 & 35 & 1 & 9 & 3,286 & 0,142 \\
\hline & estrutura \# 4 & 45 & 1 & 6 & 2,556 & 0,1 \\
\hline & estrutura \# 5 & 55 & 1 & 5 & 2,091 & 0,071 \\
\hline & estrutura \# 6 & 65 & 1 & 4 & 1,769 & 0,053 \\
\hline & estrutura \# 7 & 75 & 1 & 4 & 1,533 & 0,04 \\
\hline \multirow{7}{*}{ Karate } & estrutura \# 1 & 4 & 5 & 15 & 8,5 & 0,279 \\
\hline & estrutura \# 2 & 8 & 1 & 9 & 4,25 & 0,199 \\
\hline & estrutura \# 3 & 12 & 1 & 9 & 2,833 & 0,174 \\
\hline & estrutura \# 4 & 16 & 1 & 6 & 2,125 & 0,125 \\
\hline & estrutura \# 5 & 20 & 1 & 5 & 1,7 & 0,085 \\
\hline & estrutura \# 6 & 24 & 1 & 3 & 1,417 & 0,061 \\
\hline & estrutura \# 7 & 28 & 1 & 2 & 1,214 & 0,033 \\
\hline \multirow{7}{*}{ NetScience } & estrutura \# 1 & 461 & 1 & 21 & 3,169 & 0,378 \\
\hline & estrutura \# 2 & 561 & 1 & 21 & 2,604 & 0,332 \\
\hline & estrutura \# 3 & 661 & 1 & 21 & 2,21 & 0,307 \\
\hline & estrutura \# 4 & 761 & 1 & 21 & 1,92 & 0,268 \\
\hline & estrutura \# 5 & 861 & 1 & 21 & 1,697 & 0,248 \\
\hline & estrutura \# 6 & 961 & 1 & 20 & 1,52 & 0,213 \\
\hline & estrutura \# 7 & 1061 & 1 & 20 & 1,377 & 0,19 \\
\hline
\end{tabular}


tenham um grau maior ou igual a $2 r$, um terço deles são aleatoriamente escolhidos como parte do conjunto de treino, $E^{T}$, e o resto formam parte do conjunto de teste, $E^{P}$. Esta metodologia de sub-amostragem aleatória por seleção de links para o conjunto de treino e de teste é baseada em propostas amplamente usadas na literatura (Yin et al., 2010a, 2011; Zhang et al., 2012; Valverde-Rebaza e de Andrade Lopes, 2012b). Esse processo é executado dez vezes obtendo-se dez conjuntos de treino e testes diferentes.

\subsubsection{Experimentação}

Seguindo o processo de detecção das estruturas de comunidades, como apresentado na Seção 5.2.1, para cada rede adotada tem-se quatorze conjuntos de dados diferentes, onde, em cada um deles, um dado vértice é parte de uma estrutura de comunidade diferente. Seguindo o processo de subamostragem aleatória, descrito na Seção 5.2.2, para cada rede adotada tem-se dez conjuntos de dados diferentes, onde, em cada um deles, um dado link pode ser parte do conjunto de treino ou do conjunto de teste. Dessa maneira, para cada uma das redes adotadas, tem-se um total de 140 conjuntos de dados diferentes.

Cada conjunto de dados é armazenado em um arquivo seguindo o formato .net. Na primeira linha do arquivo é especificado o número de vértices da rede $(|V|)$. Em cada uma das seguintes $|V|$ linhas são descritas as informações de cada vértice seguindo o padrão: índice do vértice, nome do vértice, e rótulo da comunidade à qual pertence o vértice. Deve-se considerar que em cada linha é colocada a informação de um vértice só. Depois de listar todos os vértices da rede, na seguinte linha do arquivo é especificado o número de links existentes na rede $(|E|)$. Em cada uma das seguintes $|E|$ linhas são descritas as informações de cada link seguindo o padrão: índice do vértice origem, índice do vértice destino, e peso. Os links são listados na ordem crescente dado pelo índice do vértice de origem seguido pelo índice do vértice de destino.

Considerando que as redes adotadas para experimentação são do tipo não direcionadas, nos arquivos no formato .net, os índices dos vértices origem e destino de um link $e_{x, y}$ correspondem aos índices de destino e origem de um outro link $e_{y, x}$. Mesmo sendo descritos como dois links aparentemente diferentes, eles são considerados como um único link na hora de executar os algoritmos de predição. Outra questão importante a se destacar é que os pesos não são considerados nos algoritmos de predição avaliados, assim é atribuído o valor de 1 como peso para todos os links. 
Assim, para cada um dos 140 conjuntos de dados gerados, foram executados todos os índices de similaridade estrutural baseados nas informações locais e globais, apresentados na Seção 3.2.1, bem como os índices propostos nesta dissertação e que foram apresentados nas Seções 4.3 e 4.4. É importante destacar que, para experimentação, foram escolhidos unicamente os índices de similaridade estrutural devido ao fato de que eles constituem a base teórica das duas propostas apresentadas, bem como pelas questões de viabilidade computacional que sua computação representa.

Dessa maneira, para todos os indices de similaridade estrutural local e de similaridade baseados nas informações das comunidades, utilizou-se informações da vizinhança de até dois passos de distância de cada vértice analisado. Para os indices de similaridade estrutural global considerou-se, para o Katz, como parâmetro de controle dos pesos, $\beta=0,005$ e como tamanho máximo dos caminhos $l=5$, para o RPR, utilizou-se como parâmetro de controle do processo de caminhada $\alpha=0,0001$, e para o SR, utilizou-se a contante $\gamma=0,8$.

\subsubsection{Medida do Desempenho}

Dado que para experimentação foi seguida a abordagem não supervisionada, para avaliar a qualidade das predições adotou-se o uso de duas métricas: a AUC (ver Equação 3.2) e a Precisão (ver Equação 3.3). Com o uso da AUC avalia-se a relação das pontuações entre os links preditos corretamente e aqueles que não foram. Por outro lado, a Precisão mede quantos dos links relevantes preditos por um algoritmo são links preditos corretamente.

Para facilitar a avaliação das predições, os resultados obtidos das métricas AUC e Precisão foram analisados mediante dois tipos de gráficos: histogramas e gráficos de caixas (boxplots). Na Figura 5.1 (a) é apresentado um exemplo do histograma. Nesse tipo de gráficos foram representados os valores da AUC e da Precisão obtidos pelos índices propostos nesta dissertação, isto é, do WIC e dos índices da forma W. Assim, no eixo horizontal são colocados os diferentes números de comunidades de uma rede obtidos por um algoritmo de detecção de comunidades, enquanto, no eixo vertical são colocados os valores obtidos pela AUC e pela Precisão (valores entre 0 e 1). Dessa maneira, um ponto no gráfico indica o valor da métrica obtido na rede avaliada quando ela tem uma dada estrutura de comunidade.

Na Figura 5.1 (b) é apresentado um exemplo de gráfico de caixa (boxplot), usado para representar informações da mediana ( $q 2)$, o quartil inferior $(q 1)$, o quartil superior (q3), o limite inferior $(l i)$ e o limite superior $(l s)$. Estes gráficos 
mostram uma tendência central dada pela mediana ( $(2)$ e uma medida de dispersão dada pela diferença $q 3-q 1$ e os limites $l i$ e $l s$. Nesse tipo de gráficos foram representados as médias das métricas AUC e Precisão obtidos pelos indices propostos nesta dissertação.

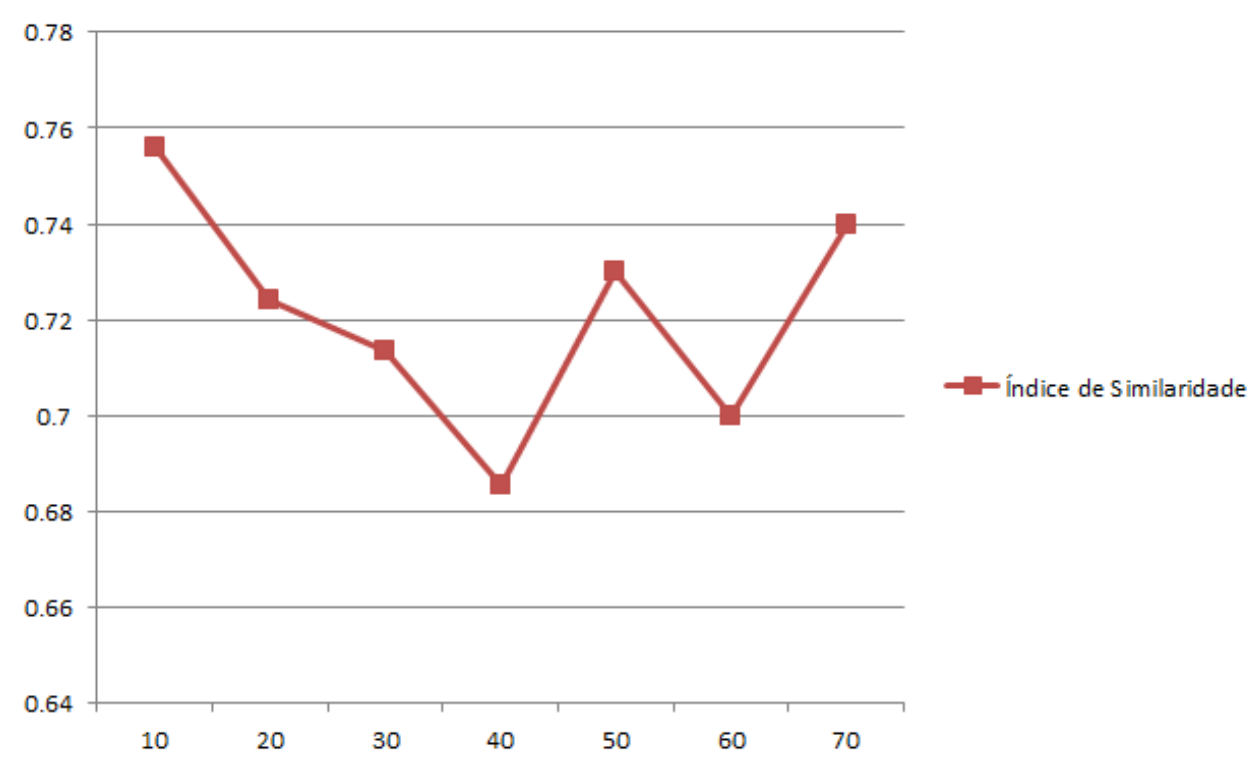

(a)

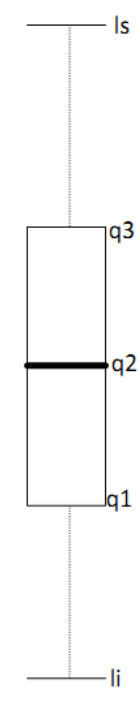

(b)

Figura 5.1: Exemplo da distribuição de dados para analise do resultados obtidos das métricas AUC e Precisão. Em (a) é mostrado um exemplo de histograma. Em (b) é mostrado um exemplo de gráfico de caixa. Os dados representados em (a) e (b) são apenas ilustrativos e não têm relação um com o outro.

Finalmente, para fazer uma análise estatística do desempenho final de todos os preditores avaliados em todos os conjuntos de dados, foi realizado o teste post-hoc proposto por Demsar (2006). Esse teste foi usado para determinar a diferença estatística significativa entre os diferentes preditores avaliando os resultados que eles obtiveram em todas as redes avaliadas. Além disso, o teste post-hoc fornece um ranking dos preditores avaliados, permitindo determinar quais deles têm o melhor desempenho geral. O resultado do teste post-hoc é representado mediante o gráfico da diferença estatística.

A Figura 5.2 mostra um exemplo do gráfico de diferença estatística, no qual a área da diferença crítica ${ }^{1}$ é representada pela linha rotulada com o texto CD (critical diference) e localizada acima do eixo horizontal do gráfico. No eixo horizontal do gráfico são enumeradas as posições que ocuparam os métodos

\footnotetext{
${ }^{1} \mathrm{O}$ desempenho de dois métodos avaliados será significativamente diferente se o valor de suas pontuações (ranking) diferem em pelo menos a diferença crítica.
} 


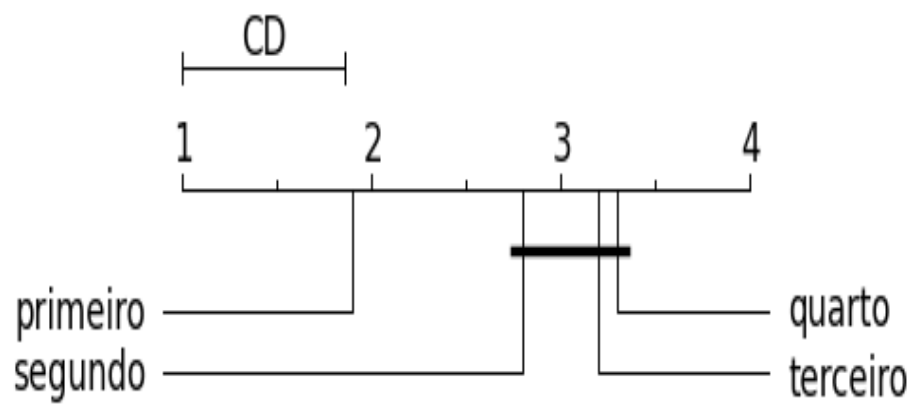

Figura 5.2: Exemplo de um gráfico de diferença estatística usado para representar o ranking do desempenho de diferentes métodos avaliados em diferentes conjuntos de dados.

avaliados (ranking), assim, se são avaliados quatro métodos, então ter-se-á uma enumeração de 1 até 4. Então, sobre esse eixo, de acordo ao seu ranking, são indicados os preditores avaliados com um rótulo correspondente ao seu respectivo nome. No caso da Figura 5.2 os nomes dos preditores avaliados são: primeiro, segundo, terceiro e quarto. Claramente, os preditores mais próximos do valor de 1 são os que têm um melhor desempenho. Também, uma linha em negrito sobre os indicadores dos rótulos dos preditores avaliados é usada para agrupar os preditores que não têm uma diferença estatística significativa.

\subsection{Resultados e Análise}

Nesta seção são descritos os resultados obtidos, seguindo a metodologia experimental apresentada na seção anterior, bem como sua respectiva análise.

\subsubsection{Avaliação do Índice WIC e dos Índices da Forma W}

Com o objetivo de avaliar o desempenho das propostas apresentadas nas Seções 4.3 e 4.4, os resultados da predição foram obtidos seguindo o processo de subamostragem de dados apresentada na Seção 5.2.2 e o processo de experimentação apresentado na Seção 5.2.3.

Dessa maneira, para cada um dos 140 conjuntos de dados obtidos de cada rede adotada, foram calculados a AUC e a Precisão de cada índice avaliado. A partir desses resultados, foram calculados as respectivas médias do desempenho de cada índice. A seguir são apresentados os resultados da média da AUC e Precisão dos índices avaliados, bem como sua respectiva análise. 
Resultados da AUC

Os valores da média da AUC obtida pelo índice WIC, bem como pelos índices da forma $\mathrm{W}$, para as quatorze diferentes estruturas de comunidades detectadas para as dez redes adotadas (sete estruturas detectadas pelo algoritmo FM e sete pelo algoritmo WT), são apresentados nas Figuras 5.3, 5.4, 5.5 e 5.6.

Dos resultados apresentados nas Figuras 5.3, 5.4, 5.5 e 5.6, pode-se observar que, quando as comunidades foram detectadas usando o algoritmo FM, para as redes Airline, Power, Router, Industry-pr, PoolBlogs, e Yeast, o maior valor da AUC obtido pelo índice WIC é encontrado quando se tem a estrutura mais rica da rede, o que corresponde ao maior valor de $Q$, ou seja, quando $M=32, M=441, M=22, M=189, M=23$, e $M=117$, para cada uma dessas redes, respectivamente. Quando as comunidades foram detectadas usando o algoritmo WT, aconteceu o mesmo para as redes Airline (quando $M=32$ ), Imdb-prodco (quando $M=169$ ou $M=269$ ), PoolBlogs (quando $M=23$ ), $\mathrm{e}$ Karate (quando $M=4$ ).

É importante destacar que, nas redes NetScience e PoolBlogs, quando suas comunidades foram detectadas com o algoritmo FM e WT, respectivamente, os maiores valores da AUC obtidos por todos os índices da forma $\mathrm{W}$, foram encontrados nas estruturas mais ricas de cada uma dessas redes. Além disso, independente do algoritmo usado para detecção de comunidades, diferentes índices da forma $\mathrm{W}$ tivessem seu melhor desempenho na estrutura mais rica das diferentes redes avaliadas. Assim, foi recorrente encontrar os índices CNW, AA-W e RA-W tendo seu melhor desempenho de acordo com a AUC na estrutura mais rica das redes Airline, Industry-pr, PoolBlogs e Yeast, quando suas comunidades foram detetadas com o algoritmo FM; e nas redes Airline, Imdb-prodco, PoolBlogs e Karate, quando suas comunidades foram detectadas com o algoritmo WT.

Porém, nem sempre o melhor desempenho dos índices de predição avaliados foi encontrado na estrutura de comunidade mais rica de todas as redes, especificamente quando as estruturas de comunidades foram detectadas pelo algoritmo WT. Na rede Router, o melhor desempenho dos índices WIC, CN-W, HDI-W, Jac-W, LHN-W, Sal-W e Sor-W, em relação à AUC, foram encontrados quando $M=22$, isto é, na terceira melhor estrutura da rede. Na rede Industrypr, só o índice WIC teve seu melhor desempenho de acordo com a AUC na terceira melhor estrutura, isto é, quando $M=189$, logo, todos os índices da forma $\mathrm{W}$ tiveram seu melhor desempenho na estrutura mais pobre $(M=1689)$. Na rede Yeast, tanto o índice WIC como os índices da forma W tiveram seu me- 

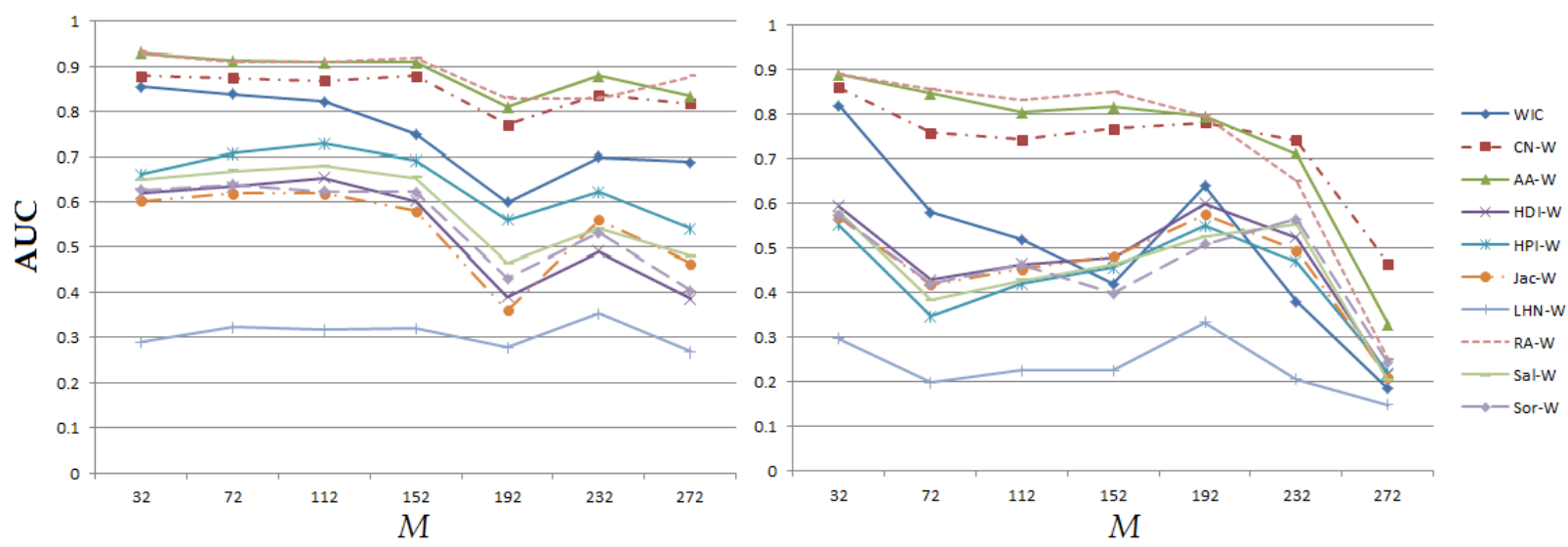

(a)
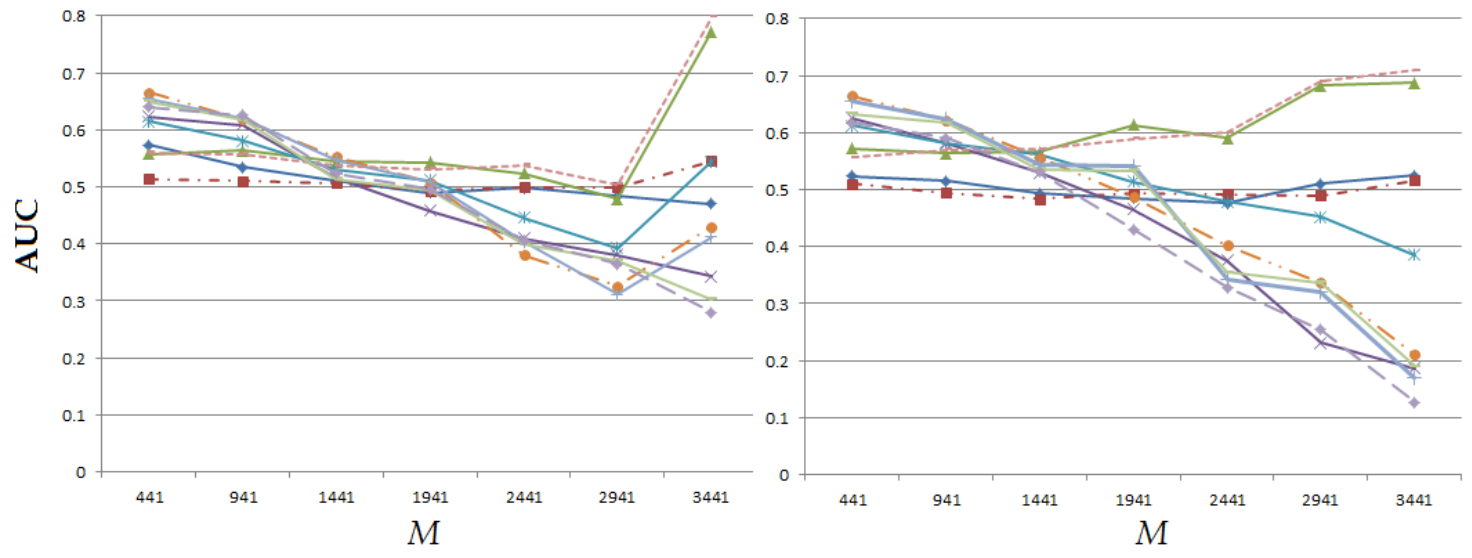

(b)
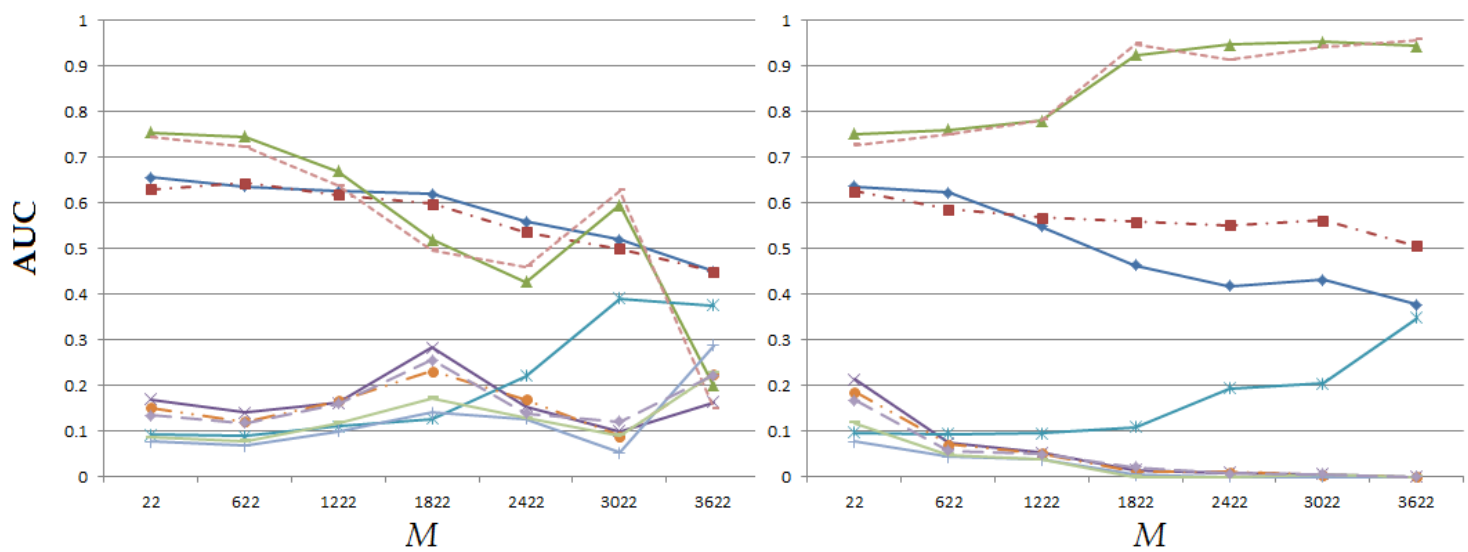

$\longrightarrow$ WIC
$-\square$ CN-W
$\longrightarrow$ AA-W
$\longrightarrow$ HDI-W
$\longrightarrow$ HPI-W
$\longrightarrow$ Jac-W
- LHN-W
- RA-W
$\longrightarrow$ Sal-W
$\longrightarrow$ Sor-W

(c)

Figura 5.3: Resultados da predição de links para as redes adotadas quando se tem estruturas de comunidades diferentes detectadas pelos algoritmos FM (esquerda) e WT (direita). Cada ponto no gráfico indica o valor da média da AUC obtida por um dado índice em uma dada estrutura de comunidade de tamanho $M$ para (a) Airline, (b) Power e (c) Router. 

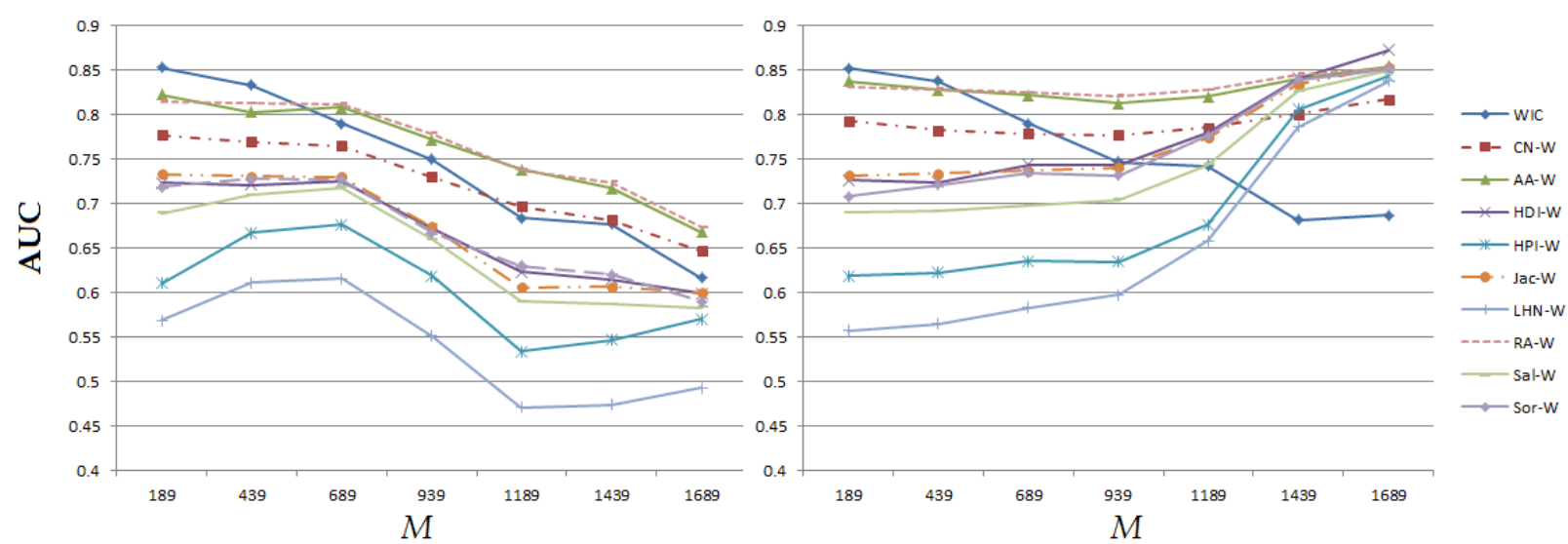

(a)
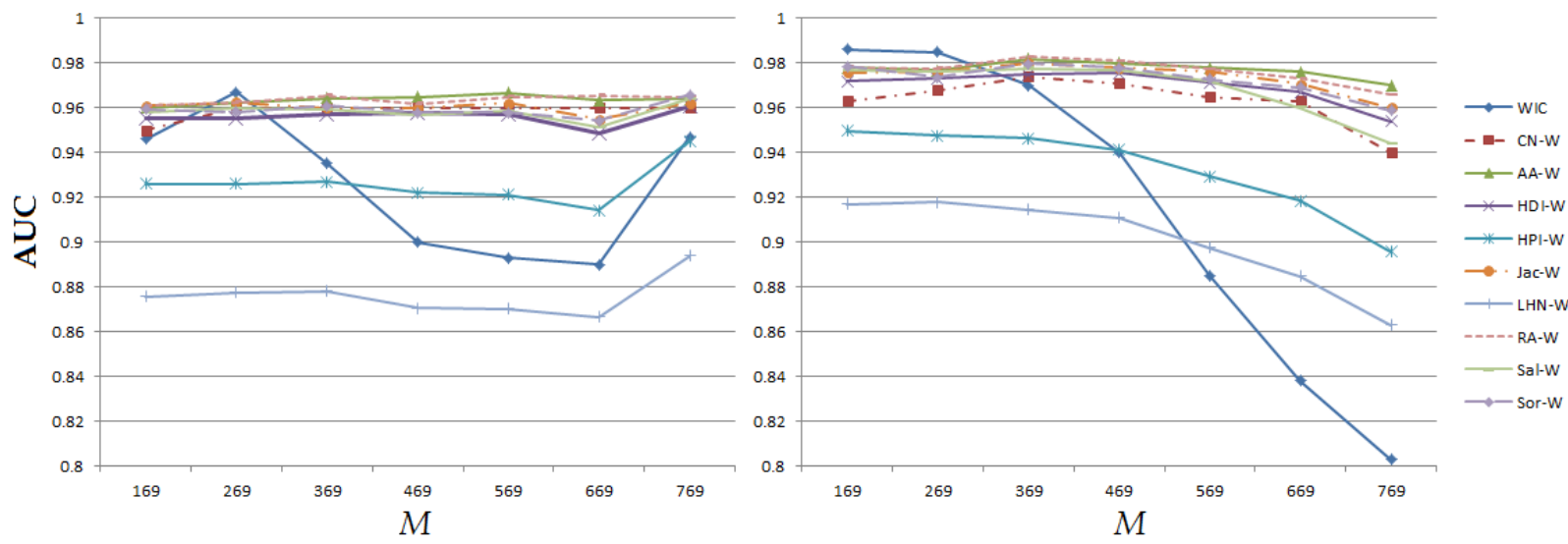

(b)
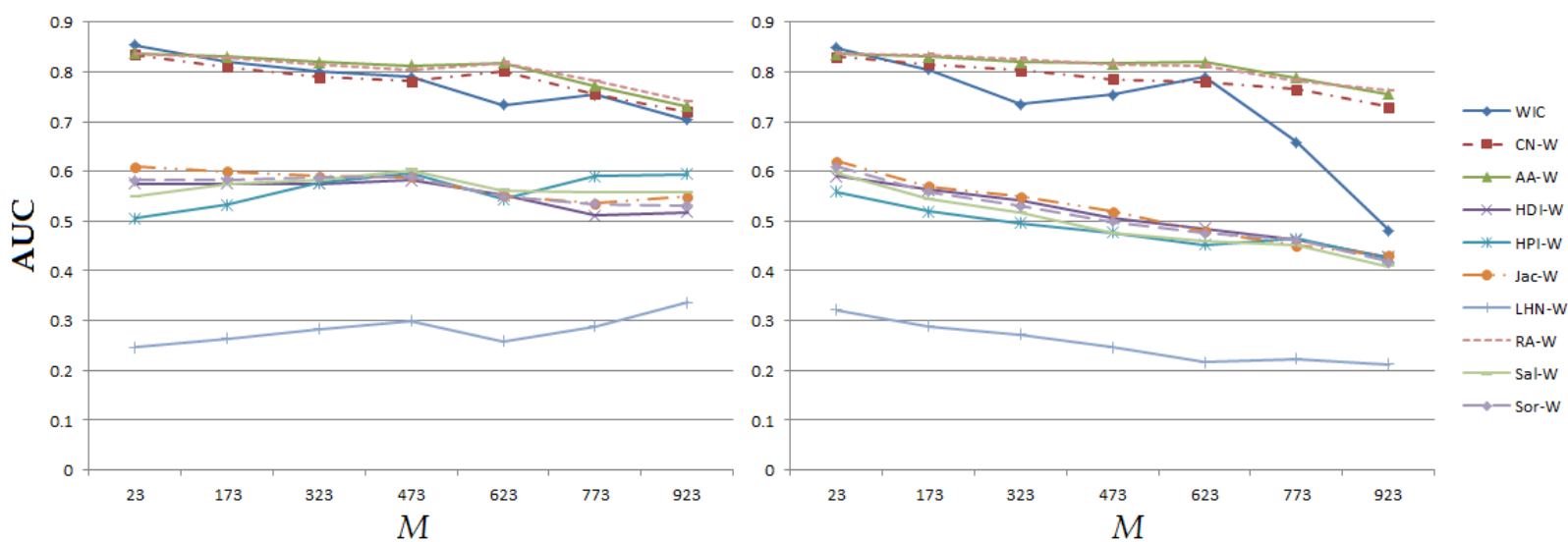

(c)

Figura 5.4: Resultados da predição de links para as redes adotadas quando se tem estruturas de comunidades diferentes detectadas pelos algoritmos FM (esquerda) e WT (direita). Cada ponto no gráfico indica o valor da média da AUC obtida por um dado índice em uma dada estrutura de comunidade de tamanho $M$ para (a) Industry-pr, (b) Imdb-prodco e (c) PoolBlogs. 

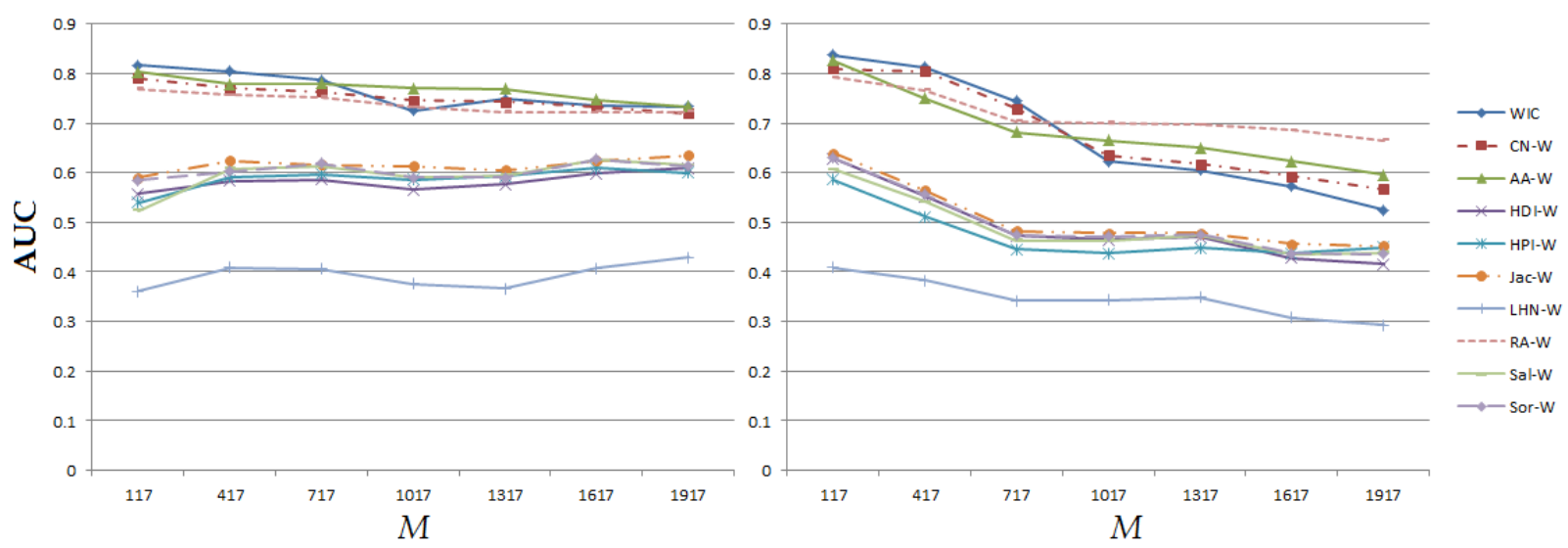

(a)
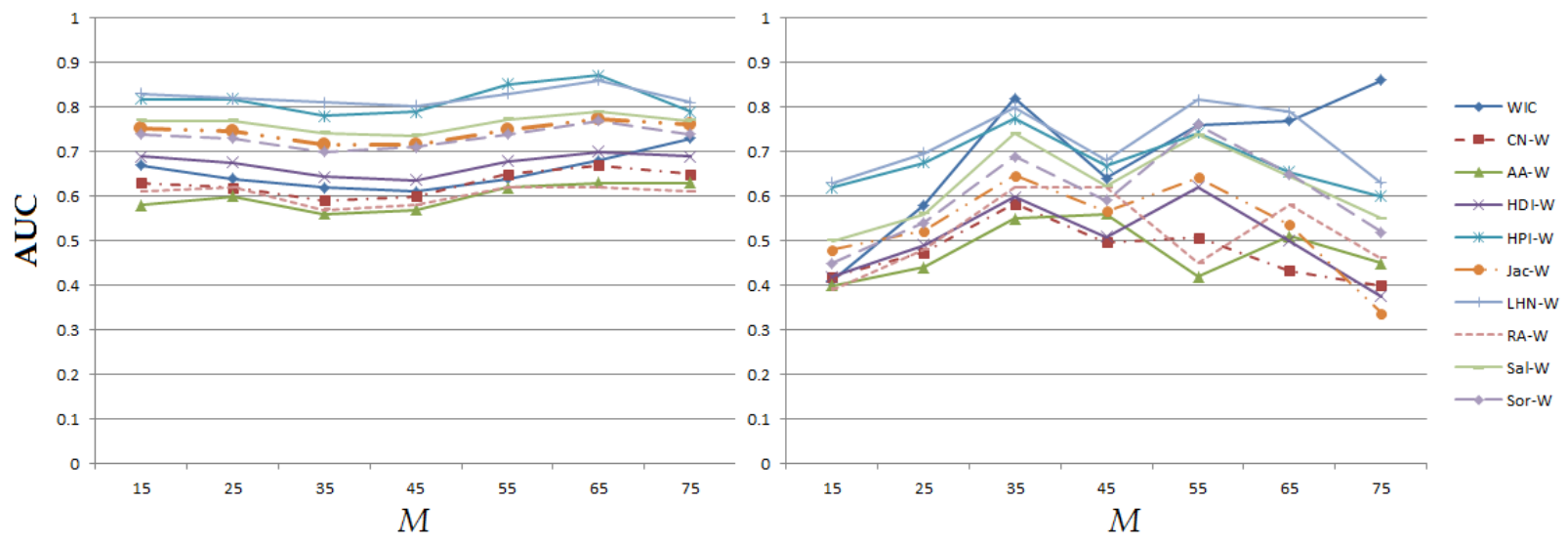

(b)
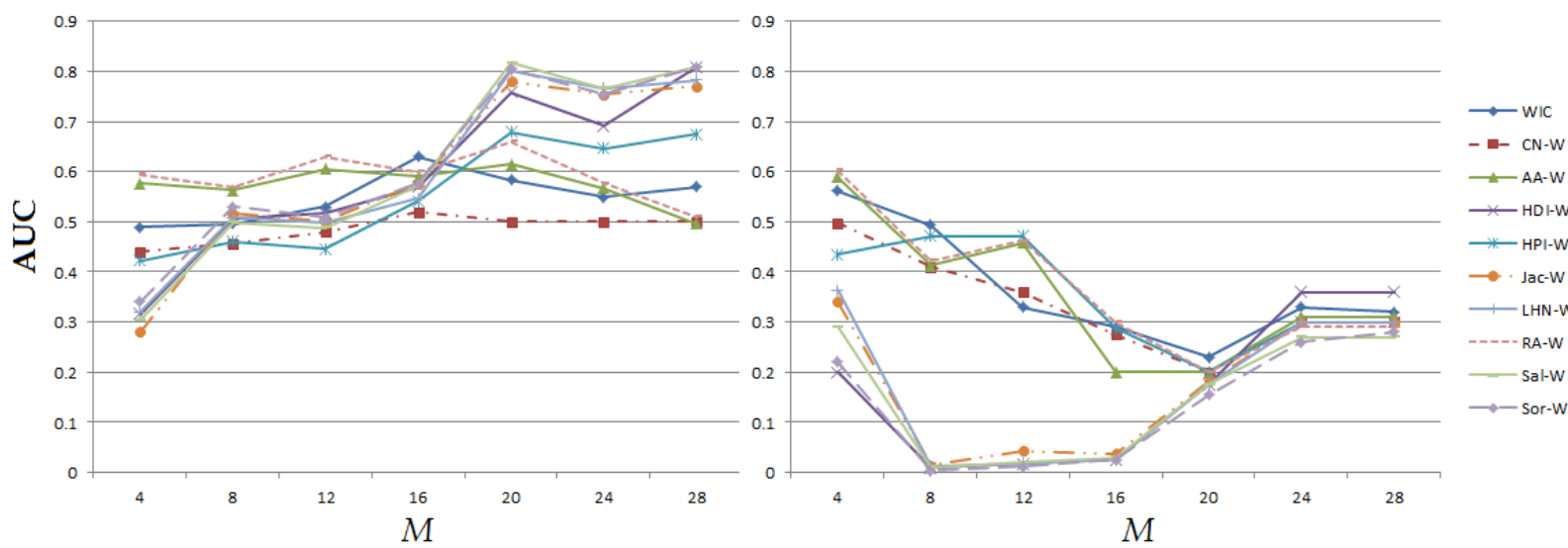

(c)

Figura 5.5: Resultados da predição de links para as redes adotadas quando se tem estruturas de comunidades diferentes detectadas pelos algoritmos FM (esquerda) e WT (direita). Cada ponto no gráfico indica o valor da média da AUC obtida por um dado índice em uma dada estrutura de comunidade de tamanho $M$ para (a) Yeast, (b) Football e (c) Karate. 

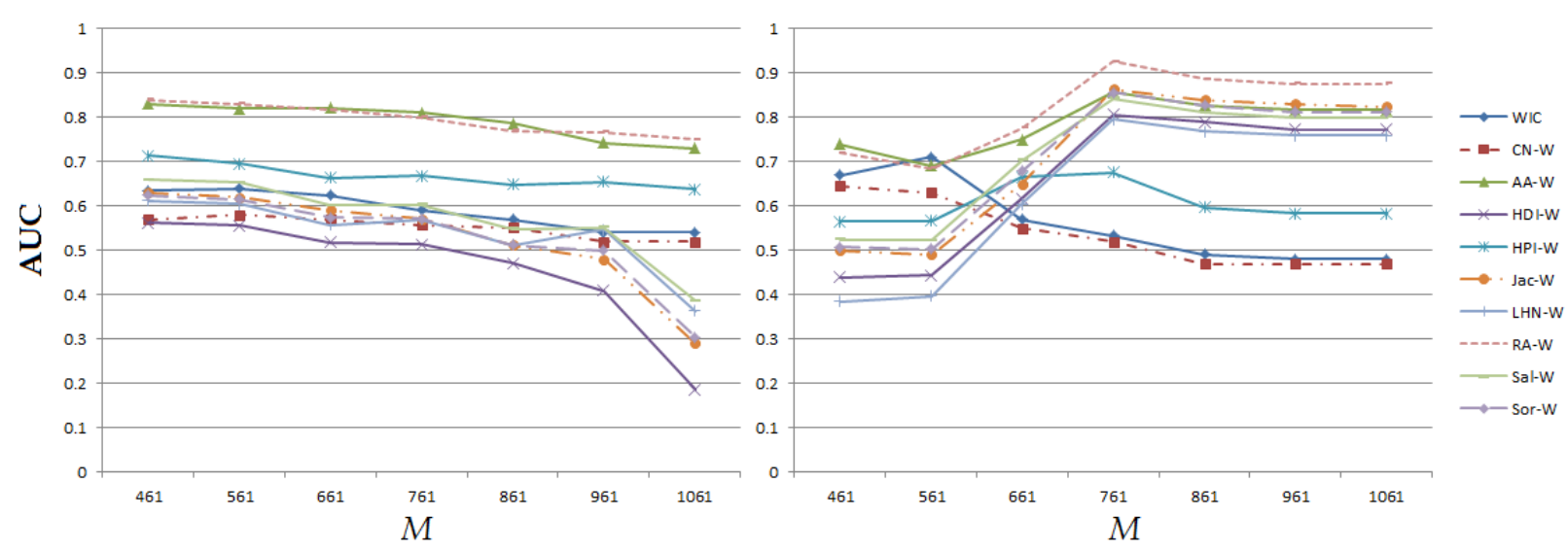

Figura 5.6: Resultados da predição de links para as redes adotadas quando se tem estruturas de comunidades diferentes detectadas pelos algoritmos FM (esquerda) e WT (direita). Cada ponto no gráfico indica o valor da média da AUC obtida por um dado índice em uma dada estrutura de comunidade de tamanho $M$ para NetScience.

lhor desempenho em relação à AUC recém na quarta melhor estrutura, isto é, quando $M=117$. Finalmente, na rede NetScience, o melhor desempenho em relação à AUC, para o índice WIC foi encontrado na segunda melhor estrutura da rede (quando $M=561$ ), enquanto que para todos os índices da forma $\mathrm{W}$, exceto para $\mathrm{CN}-\mathrm{W}$, o melhor desempenho foi encontrado na terceira melhor estrutura (quando $M=761$ ).

Quando as estruturas das redes foram detectadas pelo algoritmo FM, também aconteceu que o melhor desempenho de alguns índices nem sempre foi encontrado na estrutura mais rica das redes Football e Karate. Na rede Football, o melhor desempenho em relação à AUC para os índices WIC e AA-W foi encontrado na estrutura mais pobre, isto é, quando $M=75$, no entanto para o resto dos índices da forma $\mathrm{W}$ foi encontrado na sexta estrutura mais rica (segunda estrutura mais pobre), isto é, quando $M=65$. Na rede Karate, o melhor desempenho em relação à AUC para os índices WIC e CN-W foi encontrado na quarta estrutura mais rica (quando $M=16$ ), no entanto para o resto dos índices da forma $\mathrm{W}$ foi encontrado na quinta estrutura mais rica (quando $M=20$ ).

Além disso, de maneira geral pode-se observar nos resultados apresentados nas Figuras 5.3, 5.4, 5.5 e 5.6, que os valores das médias das AUC para todos os índices avaliados seguem um padrão similar tanto para as estruturas de comunidades descobertas pelo algoritmo FM quanto pelas estruturas de comunidades descobertas pelo WT. Assim, pode-se observar que os índices WIC, CN-W, AA-W, RA-W e Jac-W obtiveram o melhor desempenho em relação à 
AUC. O desempenho do índice WIC caracterizou-se por reduzir algo logo após chegar ao seu valor máximo; o CN-W acompanhou o rendimento do índice WIC mas em geral teve um desempenho mais estável; o AA-W e o RA-W mantiveram um desempenho muito similar, sendo que o RA-W quase sempre superou levemente ao AA-W. O Jac-W sempre se manteve inferior aos quatro índices anteriores mas destacou-se notavelmente dos outros índices da forma W.

\section{Resultados da Precisão}

Nas Figuras 5.7, 5.8, 5.9, e 5.10 são apresentados os resultados correspondentes ao cálculo da Precisão, especificamente a média da Precisão obtida pelo índice WIC e pelos índices da forma W, para as quatorze diferentes estruturas de comunidades detectadas para as dez redes adotadas (sete estruturas detectadas pelo algoritmo FM e sete estruturas detectadas pelo algoritmo WT). Os valores da Precisão, para todas as redes, foram computados considerando o tamanho da lista de links (preditos) relevantes como $10 \%$ do número total de links existentes, isto é, $L=\left\lfloor\frac{\lfloor E\rfloor}{10}\right\rfloor$.

Dos resultados apresentados nas Figuras 5.7, 5.8, 5.9 e 5.10, pode-se observar que, quando as comunidades foram detectadas pelo algoritmo FM, para as redes Airline, Router, Football e NetScience, o maior valor da Precisão obtido pelo índice WIC foi encontrado na estrutura mais rica da rede, o que corresponde ao maior valor de $Q$, isto é, quando $M=32, M=22, M=15$, e $M=461$, respectivamente para cada uma dessas redes. Guando as comunidades foram detectadas usando o algoritmo WT, acontece o mesmo para as redes Airline (quando $M=32$ ), Power (quando $M=441$ ), Imdb-prodco (quando $M=169$ ou quando $M=269$ ), PoolBlogs (quando $M=23$ ) e Yeast (quando $M=417)$.

Dessa forma, é possivel observar que, os maiores valores da Precisão obtidos por todos os índices da forma $\mathrm{W}$, foram encontrados na estrutura mais rica da rede Football, isto é, quando $M=15$. Também, observa-se que os índices $\mathrm{CN}-\mathrm{W}$ e AA-W têm um comportamento em comum. O índice $\mathrm{CN}-\mathrm{W}$ obteve seu melhor desempenho em relação à Precisão na estrutura mais rica das redes PoolBlogs, Football, e NetScience, quando suas comunidades foram detectadas com o algoritmo FM, e nas redes Airline, Power, Imdb-prodco e PoolBlogs, quando suas comunidades foram detectadas com o algoritmo WT. $\mathrm{O}$ mesmo aconteceu para o índice AA-W nas redes Airline e Football, quando suas comunidades foram detectadas pelo algoritmo FM, e nas redes Airline, Router, PoolBlogs, Yeast, Football e Karate, quando suas comunidades foram 

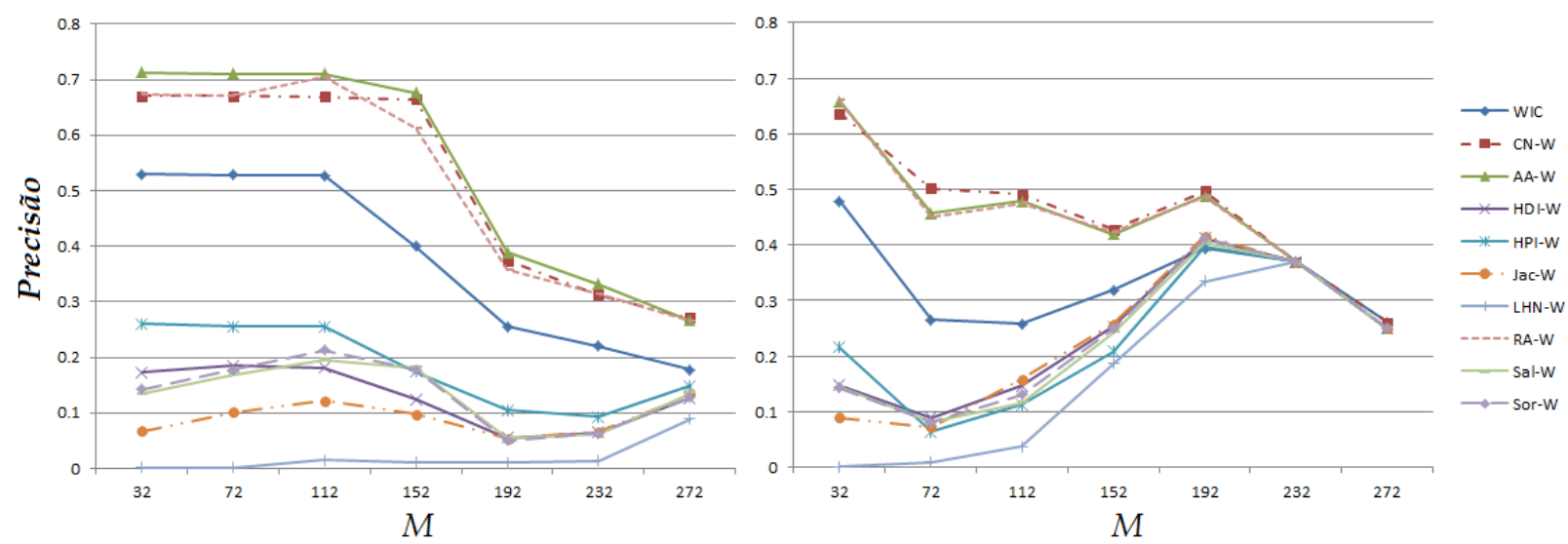

(a)
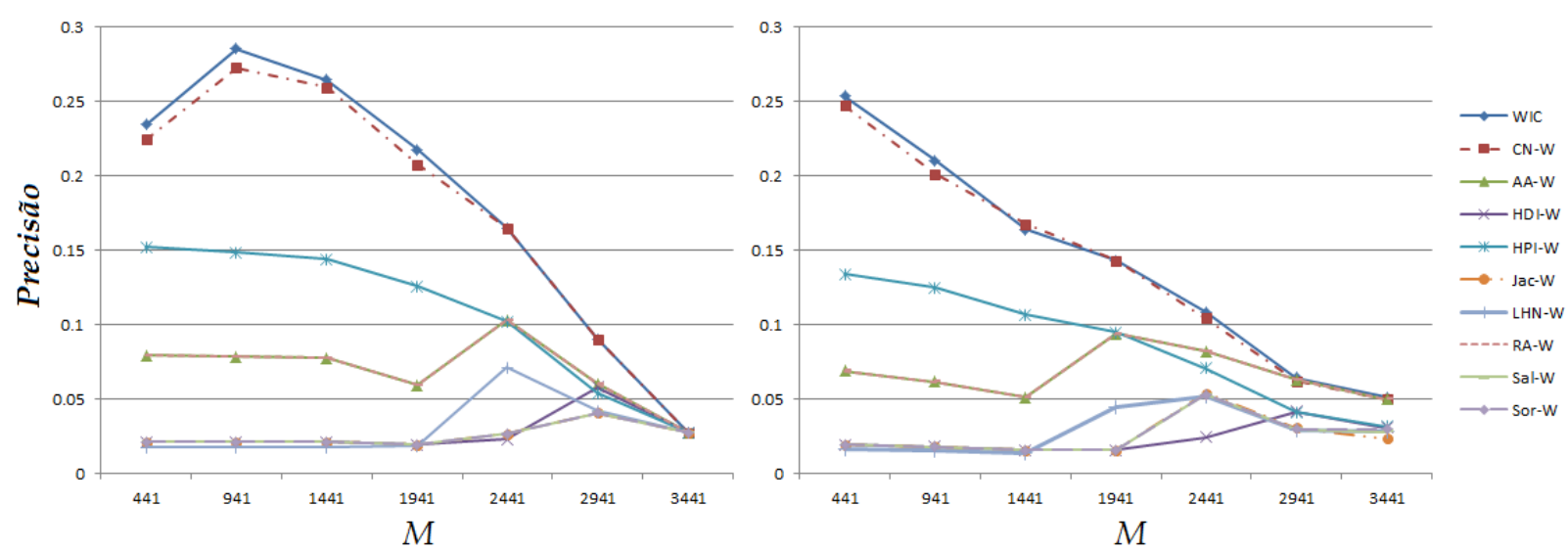

(b)
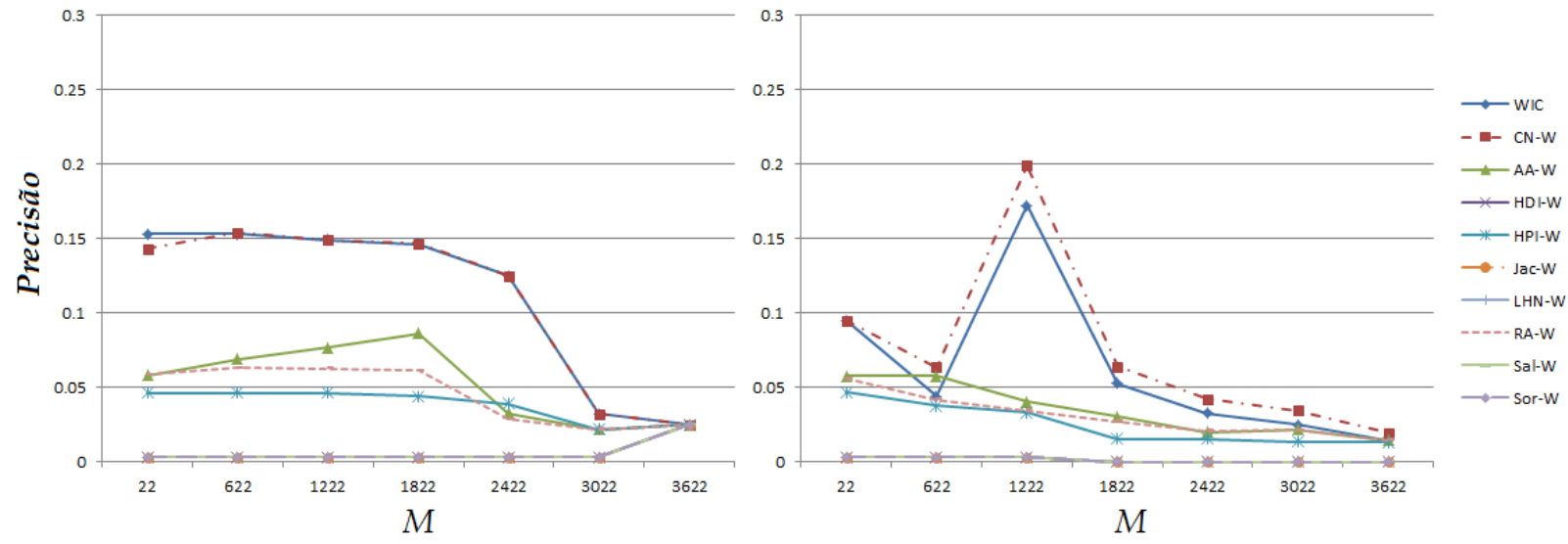

(c)

Figura 5.7: Resultados da predição de links para as redes adotadas quando estruturas de comunidades diferentes foram detectadas pelos algoritmos FM (esquerda) e WT (direita). Cada ponto no gráfico indica o valor da média da Precisão (com $L=10 \%$ do número de links existentes, $|E|$, de cada rede) obtida por um dado índice em uma dada estrutura de comunidade de tamanho $M$ para (a) Airline, (b) Power e (c) Router. 

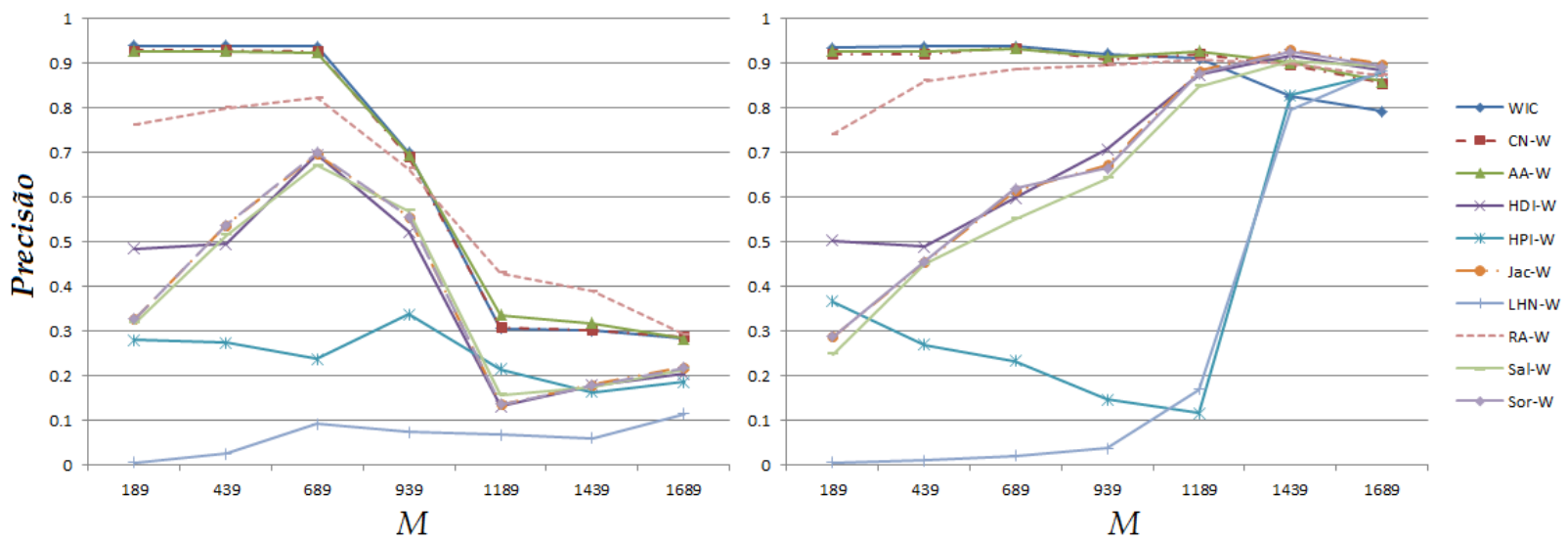

(a)
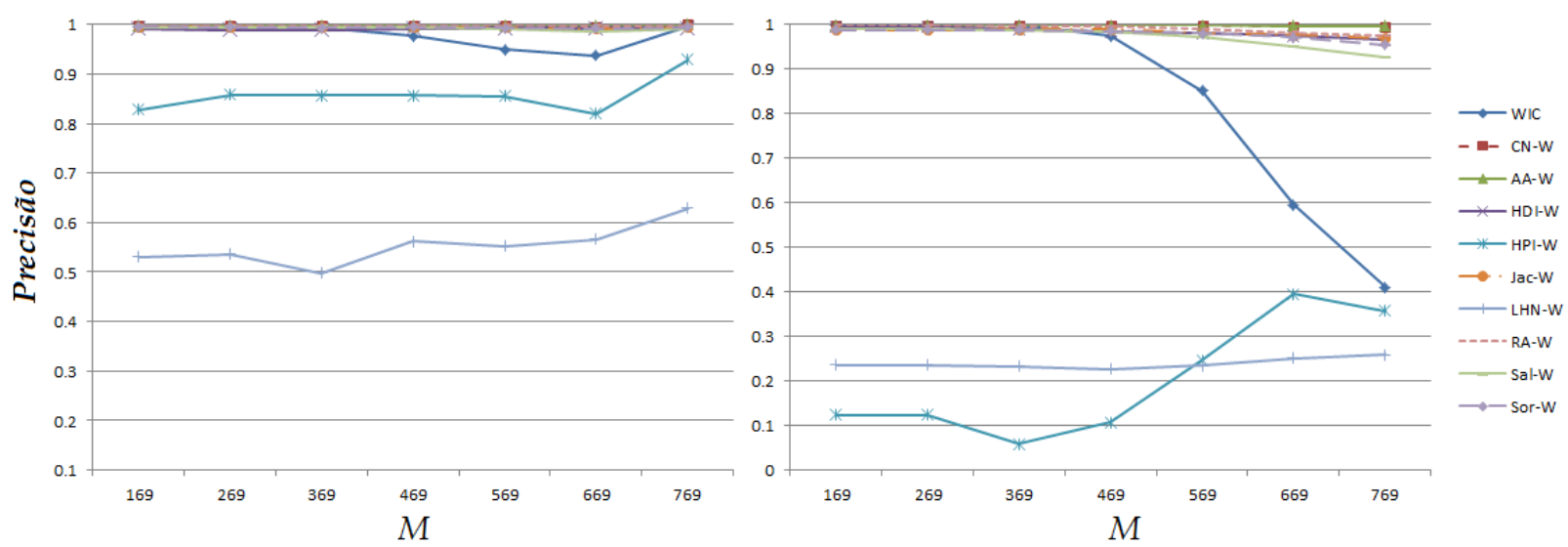

(b)
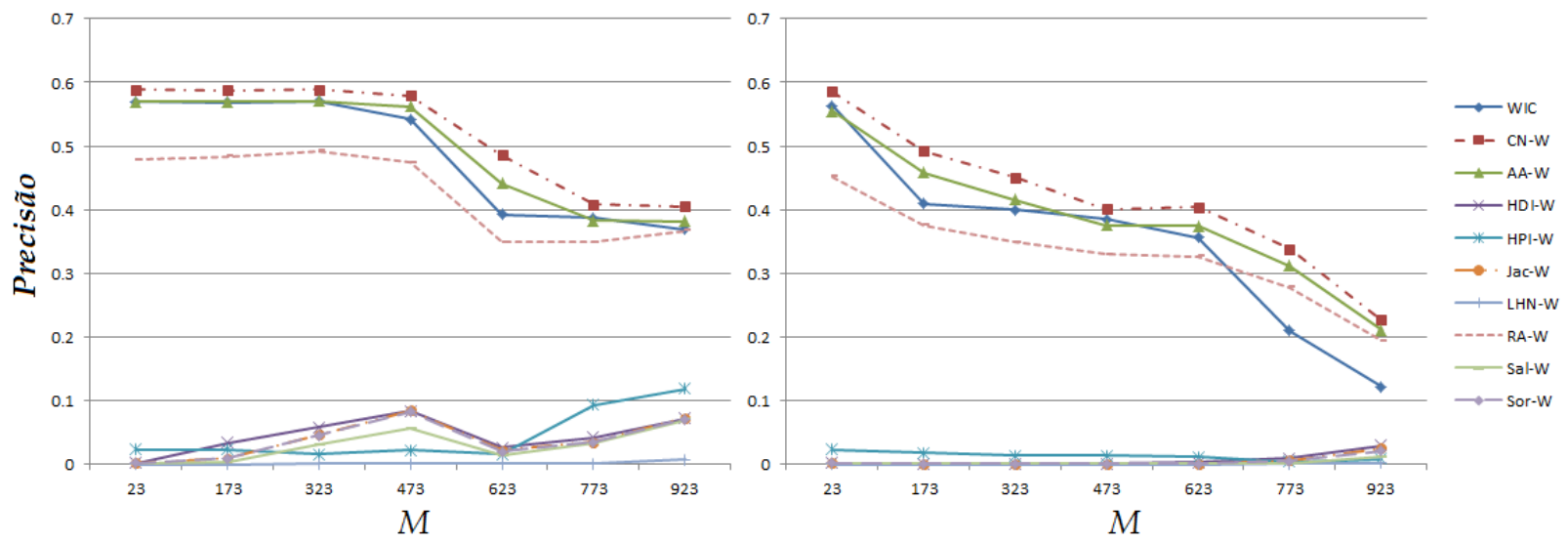

(c)

Figura 5.8: Resultados da predição de links para as redes adotadas quando estruturas de comunidades diferentes foram detectadas pelos algoritmos FM (esquerda) e WT (direita). Cada ponto no gráfico indica o valor da média da Precisão (com $L=10 \%$ do número de links existentes, $|E|$, de cada rede) obtida por um dado índice em uma dada estrutura de comunidade de tamanho $M$ para (a) Industry-pr, (b) Imdb-prodco e (c) PoolBlogs. 

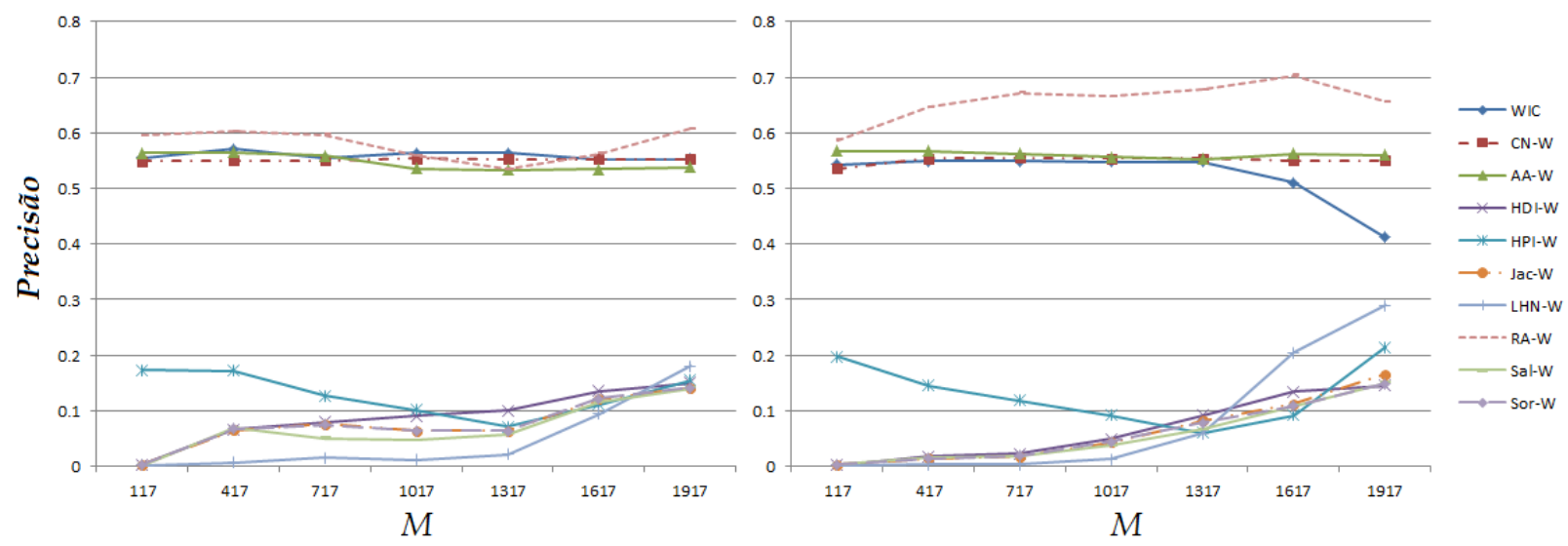

(a)
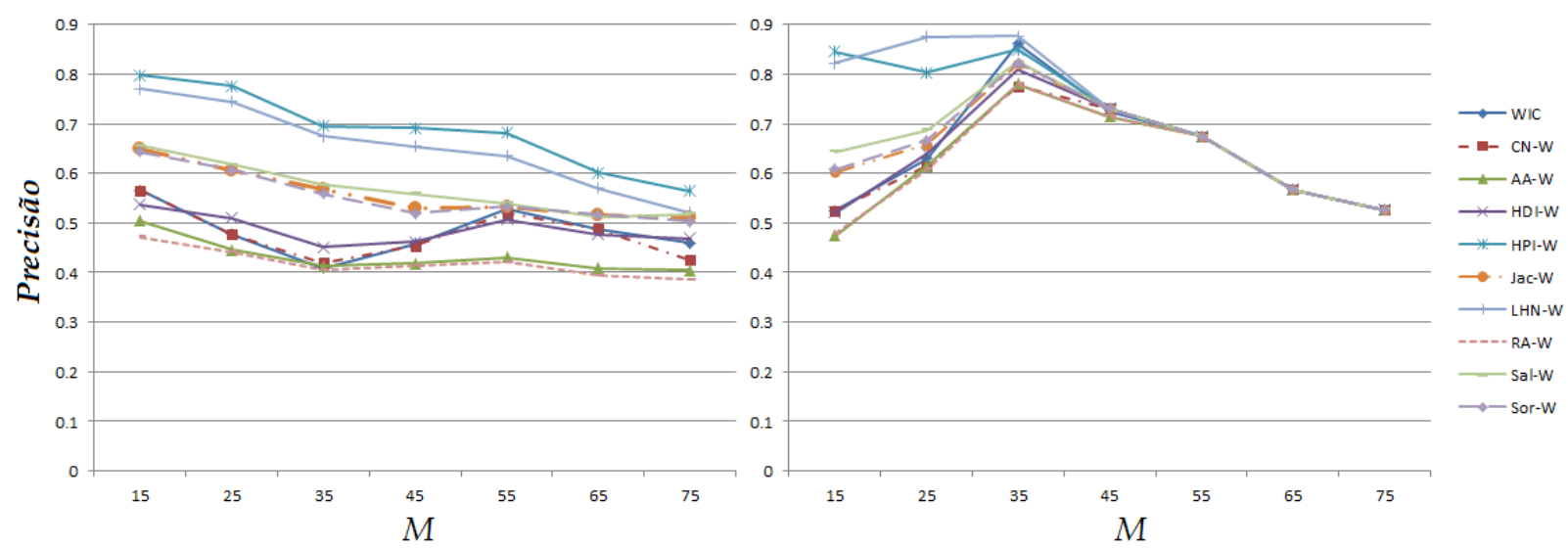

(b)
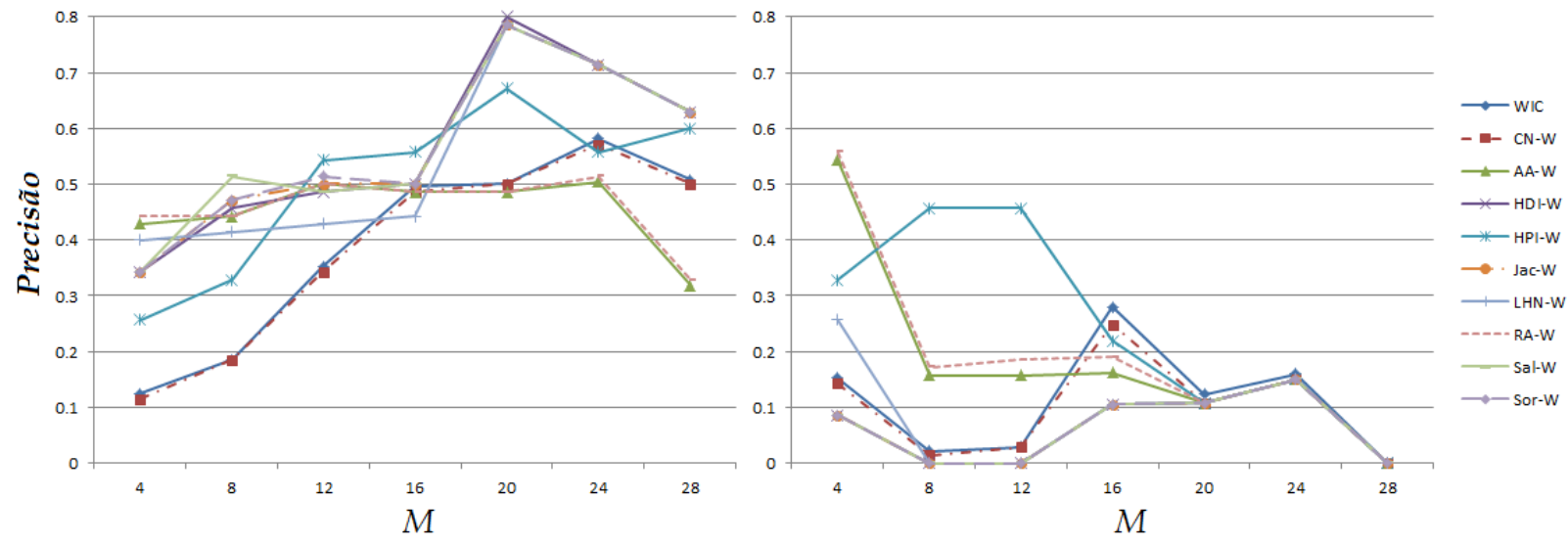

(c)

Figura 5.9: Resultados da predição de links para as redes adotadas quando estruturas de comunidades diferentes foram detectadas pelos algoritmos FM (esquerda) e WT (direita). Cada ponto no gráfico indica o valor da média da Precisão (com $L=10 \%$ do número de links existentes, $|E|$, de cada rede) obtida por um dado índice em uma dada estrutura de comunidade de tamanho $M$ para (a) Yeast, (b) Football e (c) Karate. 

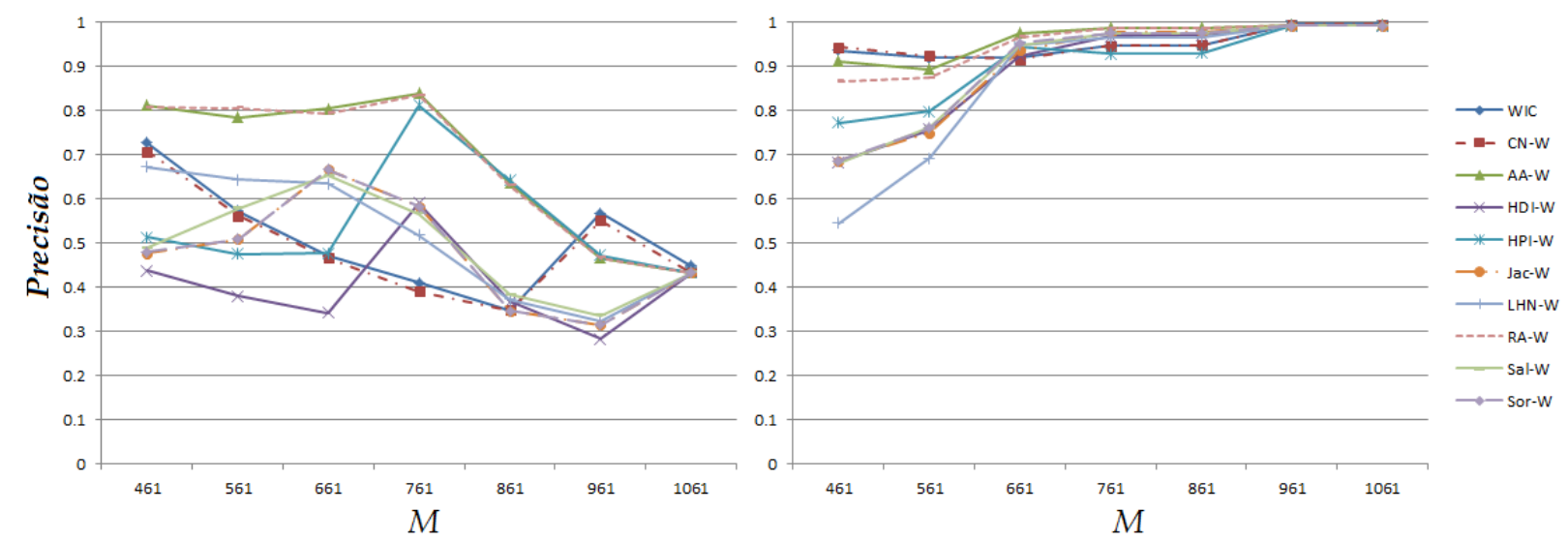

Figura 5.10: Resultados da predição de links para as redes adotadas quando estruturas de comunidades diferentes foram detectadas pelos algoritmos FM (esquerda) e WT (direita). Cada ponto no gráfico indica o valor da média da Precisão (com $L=10 \%$ do número de links existentes, $|E|$, de cada rede) obtida por um dado índice em uma dada estrutura de comunidade de tamanho $M$ para NetScience.

detectadas pelo algoritmo WT.

Porém, da mesma maneira que nos resultados obtidos na análise da AUC, quando se observa os resultados em relação à Precisão, nem sempre o melhor desempenho dos índices avaliados foi encontrado na estrutura de comunidade mais rica de todas as redes, especificamente quando as estruturas de comunidades foram detectadas pelo algoritmo WT. Na rede Football, por exemplo, tanto o índice WIC como todos os índices da forma W encontraram seu melhor desempenho na terceira melhor estrutura, isto é, quando $M=35$. Em outras redes, como Router, Industry-pr e Karate, é recorrente encontrar o melhor desempenho em relação à Precisão dos índices WIC e CN-W na segunda (para Router e Industry-pr) e quarta melhor estrutura dessas redes, isto é, quando $M=1222, M=689$, e $M=16$, respectivamente. Quando as estruturas de comunidades das redes foram detectadas pelo algoritmo FM, o melhor desempenho em relação à Precisão dos índices WIC, CN-W e AA-W, nas redes Router, Industry-pr, Yeast, e PoolBlogs, foi encontrado na segunda (para Router, Industry-pr, e Yeast) e terceira (para PoolBlogs) melhor estrutura dessas redes, isto é, quando $M=622, M=439, M=417$, e $M=323$, respectivamente.

Também, de maneira geral, pode-se observar nos resultados apresentados nas Figuras 5.7, 5.8, 5.9 e 5.10, que os valores das médias da Precisão de todos os índices avaliados são irregulares, isto é, diferentemente dos resultados em relação à AUC, os histogramas da Precisão não seguem um padrão. Assim, para uma dada rede, enquanto a Precisão de um índice vai melhorando 
conforme a estrutura de comunidade vai ficando mais rica, outro índice pode ficar estável, e um outro pode estar caindo dramaticamente, como acontece, por exemplo, nas redes Imdb-prodco, Karate e NetScience. Dessa maneira, observa-se que os índices WIC, CN-W, AA-W, RA-W e HPI-W obtiveram o melhor desempenho em relação à Precisão. Dentre esses índices, observa-se que WIC, CN-W, AA-W e RA-W obtiveram um comportamento similar, isto é, as linhas nos seus respectivos histogramas acompanham-se na maioria das redes, no entanto, o índice HPI-W apareceu sempre abaixo desses quatro índices porém destacando-se dos outros índices da forma W.

\section{Discussão dos Resultados}

Dos resultados apresentados nesta seção, pode-se observar que, tanto para AUC quanto para Precisão, os melhores resultados do índice WIC e dos índices da forma $\mathrm{W}$, na maioria dos casos, foram obtidos na estrutura mais rica de cada rede, ou seja, quando a rede tinha um valor de modularidade alto independentemente da quantidade das comunidades detectadas.

Nos casos onde os melhores resultados não se encontraram na estrutura mais rica da rede, aconteceu que, os melhores resultados, quando avaliouse a AUC, foram encontrados nas redes que mostraram uma estrutura de comunidades mais densa, isto é, nas estruturas que mostraram ter uma maior média de vértices por comunidade. Embora isso, nas redes Football e Karate, caracterizadas por ter um baixo valor de coeficiente de assortatividade (r) e um alto valor de coeficiente de agrupamento global (C), o melhor desempenho dos índices avaliados foi encontrado na estrutura de comunidade mais pobre, porém, com uma média de vértices por comunidade superior a 1.5.

Quando avaliou-se a Precisão, nos casos onde os melhores resultados não se encontravam na estrutura mais rica da rede, aconteceu que, principalmente os índices WIC, CN-W e AA-W tiveram seus melhores resultados em estruturas próximas da mais rica, ou seja, ainda nas estruturas que tinham um alto valor de modularidade.

\subsubsection{Avaliação dos Índices de Similaridade Estrutural e Basea- dos nas Informações das Comunidades}

Com o objetivo de avaliar o desempenho das propostas apresentadas nas Seções 4.3 e 4.4 e dos índices de similaridade estrutural apresentados na Seção 3.2.1, resultados da predição foram obtidos seguindo o processo de su- 
bamostragem de dados apresentada na Seção 5.2.2 e o processo de experimentação apresentado na Seção 5.2.3.

Dessa maneira, para cada um dos 140 conjuntos de dados obtidos de cada rede adotada, foram calculados a AUC e a Precisão para cada índice avaliado. A partir desses resultados, foram calculados as respectivas médias do desempenho de cada índice. A seguir são apresentados os resultados da média da AUC e da Precisão dos índices avaliados, bem como sua respectiva análise.

\section{Resultados da AUC}

Na Tabela 5.4 são apresentados os resultados da média da AUC para todos os índices avaliados, ou seja, para os índices baseados nas informações das comunidades (indice WIC e índices da forma W), bem como para os índices de similaridade estrutural local e global. No caso dos índices baseados nas informações das comunidades, são apresentados dois resultados correspondentes à experimentação realizada sobre as redes quando suas estruturas de comunidades foram detectadas pelos algoritmos FM e WT. Os valores apresentados para cada um desses mesmos índices, correspondem à maior média da AUC obtida na experimentação apresentada na seção anterior, ou seja, dos resultados apresentados nas Figuras 5.3, 5.4, 5.5 e 5.6. Na última coluna da tabela são colocados os valores da média do ranking do desempenho global obtido em cada índice avaliado sobre todas as redes avaliadas.

Dos resultados apresentados na Tabela 5.4, para cada rede avaliada é destacado com a cor negrito o maior valor obtido por um dado índice. Assim, observa-se que, nas redes Imdb-prodco e Yeast, o melhor desempenho foi obtido pelo índice WIC (WT). Na rede PoolBlogs, o melhor desempenho foi obtido pelos índices WIC (FM e WT) e Katz. Na rede Airline, o melhor desempenho foi obtido pelos índices AA, AA-W (FM), RA e RA-W (FM). Na rede Industry-pr, o melhor desempenho foi obtido pelo índice HDI-W (WT). Na rede Karate o melhor desempenho foi obtido pelo índice Sal-W (FM). Na rede Power, o melhor desempenho foi obtido pelo índice RA-W (FM). Nas redes Router e NetScience, o melhor desempenho foi obtido pelo indice RA-W (WT). Na rede Football, o melhor desempenho foi obtido pelo índice SR.

Da Tabela 5.4, pode-se fazer também outras duas observações. A primeira é que, na maioria dos casos, o desempenho do índice WIC (FM e WT) foi superior aos índices de similaridade local e global, bem como em relação à maioria dos índices da forma W. A segunda observação é que, também na maioria dos casos, o desempenho dos índices da forma $\mathrm{W}$ foi superior ao desempenho de 
Tabela 5.4: Resultados da predição correspondentes à AUC das dez redes adotadas. Cada valor representa a média da AUC obtida pelos índices baseados nas informações das comunidades, tanto quando essas informações foram geradas pelo algoritmo FM quanto pelo algoritmo WT, e pelos índices de similaridade estrutural local e global.

\begin{tabular}{|c|c|c|c|c|c|c|c|c|c|c|c|}
\hline & Airline & Power & Router & $\begin{array}{l}\text { Indus- } \\
\text { try-pr }\end{array}$ & $\begin{array}{l}\text { Imdb- } \\
\text { prodco }\end{array}$ & $\begin{array}{l}\text { Pool- } \\
\text { Blogs }\end{array}$ & Yeast & Football & Karate & $\begin{array}{c}\text { Net- } \\
\text { Science }\end{array}$ & $\begin{array}{c}\text { Média do } \\
\text { ranking }\end{array}$ \\
\hline WIC (FM) & 0,86 & 0,57 & 0,66 & 0,85 & 0,97 & 0,85 & 0,82 & 0,73 & 0,63 & 0,65 & 11,85 \\
\hline WIC (WT) & 0,78 & 0,53 & 0,64 & 0,85 & 0,99 & 0,85 & 0,84 & 0,86 & 0,56 & 0,71 & 9,7 \\
\hline $\mathbf{C N}$ & 0,87 & 0,51 & 0,62 & 0,76 & 0,95 & 0,82 & 0,77 & 0,7 & 0,5 & 0,64 & 18,7 \\
\hline CN-W (FM) & 0,88 & 0,55 & 0,64 & 0,78 & 0,96 & 0,84 & 0,79 & 0,67 & 0,52 & 0,58 & 17,05 \\
\hline CN-W (WT) & 0,86 & 0,52 & 0,63 & 0,82 & 0,97 & 0,83 & 0,81 & 0,58 & 0,5 & 0,65 & 16,8 \\
\hline $\mathbf{A A}$ & 0,93 & 0,56 & 0,74 & 0,82 & 0,97 & 0,83 & 0,83 & 0,71 & 0,56 & 0,86 & 11,7 \\
\hline AA-W (FM) & 0,93 & 0,77 & 0,75 & 0,82 & 0,97 & 0,84 & 0,8 & 0,63 & 0,62 & 0,83 & 9,45 \\
\hline AA-W (WT) & 0,89 & 0,69 & 0,95 & 0,85 & 0,98 & 0,84 & 0,83 & 0,56 & 0,59 & 0,86 & 8,55 \\
\hline HDI & 0,69 & 0,64 & 0,2 & 0,72 & 0,97 & 0,61 & 0,61 & 0,6 & 0,34 & 0,61 & 22 \\
\hline HDI-W (FM) & 0,66 & 0,62 & 0,28 & 0,73 & 0,96 & 0,58 & 0,61 & 0,7 & 0,81 & 0,56 & 20,7 \\
\hline HDI-W (WT) & 0,6 & 0,63 & 0,21 & 0,87 & 0,98 & 0,59 & 0,63 & 0,62 & 0,36 & 0,81 & 17,65 \\
\hline HPI & 0,61 & 0,65 & 0,09 & 0,62 & 0,94 & 0,55 & 0,58 & 0,86 & 0,46 & 0,71 & 22,5 \\
\hline HPI-W (FM) & 0,73 & 0,62 & 0,39 & 0,68 & 0,95 & 0,6 & 0,61 & 0,87 & 0,68 & 0,72 & 17,15 \\
\hline HPI-W (WT) & 0,55 & 0,61 & 0,35 & 0,84 & 0,95 & 0,56 & 0,59 & 0,77 & 0,47 & 0,72 & 20,3 \\
\hline Jac & 0,71 & 0,66 & 0,18 & 0,71 & 0,96 & 0,6 & 0,63 & 0,76 & 0,32 & 0,63 & 20,55 \\
\hline Jac-W (FM) & 0,62 & 0,67 & 0,23 & 0,73 & 0,96 & 0,61 & 0,64 & 0,77 & 0,78 & 0,64 & 16,55 \\
\hline Jac-W (WT) & 0,58 & 0,66 & 0,19 & 0,85 & 0,98 & 0,62 & 0,64 & 0,65 & 0,34 & 0,86 & 15,6 \\
\hline LHN & 0,32 & 0,69 & 0,07 & 0,55 & 0,9 & 0,31 & 0,41 & 0,81 & 0,3 & 0,57 & 27,2 \\
\hline LHN-W (FM) & 0,35 & 0,65 & 0,29 & 0,62 & 0,89 & 0,34 & 0,43 & 0,86 & 0,8 & 0,61 & 22,1 \\
\hline LHN-W (WT) & 0,33 & 0,65 & 0,08 & 0,84 & 0,92 & 0,32 & 0,41 & 0,82 & 0,36 & 0,79 & 22,15 \\
\hline $\mathbf{R A}$ & 0,93 & 0,59 & 0,73 & 0,83 & 0,96 & 0,84 & 0,79 & 0,61 & 0,56 & 0,85 & 13,45 \\
\hline RA-W (FM) & 0,93 & 0,8 & 0,74 & 0,82 & 0,97 & 0,84 & 0,77 & 0,62 & 0,66 & 0,86 & 9,4 \\
\hline RA-W (WT) & 0,89 & 0,71 & 0,96 & 0,85 & 0,98 & 0,84 & 0,79 & 0,62 & 0,6 & 0,93 & 7,85 \\
\hline Sal & 0,67 & 0,69 & 0,11 & 0,69 & 0,96 & 0,59 & 0,61 & 0,72 & 0,31 & 0,65 & 22,2 \\
\hline Sal-W (FM) & 0,68 & 0,65 & 0,23 & 0,72 & 0,96 & 0,6 & 0,63 & 0,79 & 0,82 & 0,66 & 16,35 \\
\hline Sal-W (WT) & 0,58 & 0,63 & 0,12 & 0,85 & 0,98 & 0,6 & 0,61 & 0,74 & 0,32 & 0,84 & 18,35 \\
\hline Sor & 0,71 & 0,7 & 0,16 & 0,72 & 0,98 & 0,61 & 0,62 & 0,75 & 0,3 & 0,64 & 18,85 \\
\hline Sor-W (FM) & 0,64 & 0,64 & 0,26 & 0,73 & 0,98 & 0,59 & 0,63 & 0,77 & 0,81 & 0,65 & 16,05 \\
\hline Sor-W (WT) & 0,57 & 0,62 & 0,17 & 0,85 & 0,98 & 0,61 & 0,63 & 0,76 & 0,31 & 0,86 & 17 \\
\hline PA & 0,89 & 0,32 & 0,91 & 0,65 & 0,59 & 0,84 & 0,74 & 0,2 & 0,68 & 0,52 & 19,55 \\
\hline Katz & 0,91 & 0,43 & 0,88 & 0,81 & 0,97 & 0,85 & 0,83 & 0,75 & 0,62 & 0,55 & 13,2 \\
\hline RPR & 0,77 & 0,75 & 0,83 & 0,59 & 0,55 & 0,75 & 0,69 & 0,34 & 0,58 & 0,68 & 17,7 \\
\hline SR & 0,39 & 0,72 & 0,11 & 0,6 & 0,92 & 0,37 & 0,48 & 0,92 & 0,34 & 0,65 & 22,9 \\
\hline
\end{tabular}

suas respectivas formas básicas, isto é, os índices de similaridade local dos quais são baseados.

Assim, dos resultados da AUC foi possivel realizar uma análise do desempenho individual de cada índice, mas não da tendência média nem global de seu desempenho. Para isso, considerando as informações da Tabela 5.4, foram feitas duas análises: a análise das distribuições da AUC, mediante o uso do gráfico de caixas, e a análise da diferença estatística significativa, mediante o uso do gráfico da diferença estatística.

Na Figura 5.11, são apresentados, mediante um gráfico de caixas (boxplots), as distribuições dos resultados da AUC de cada índice avaliado segundo a Tabela 5.4. Assim, para cada índice, foi construído seu respectivo gráfico de caixa, o qual representa a distribuição de seus resultados obtidos nas dez redes avaliadas. Com essa distribuição, pode-se observar a dispersão bem como 
a tendência central de seu desempenho.

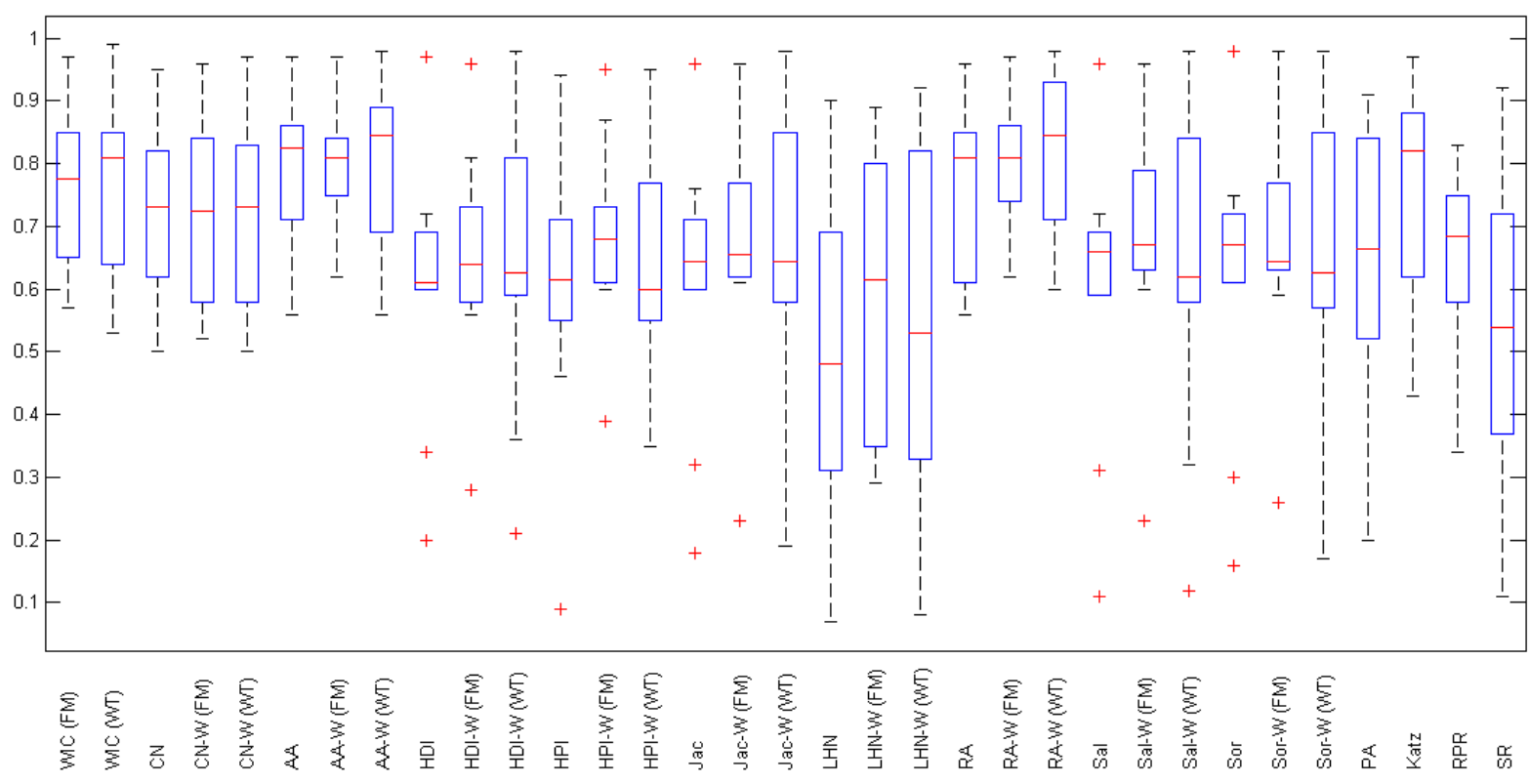

Figura 5.11: Distribuição estatística do desempenho em relação à AUC de todos os índices de predição avaliados. A linha dentro de cada caixa indica a mediana do desempenho nas dez redes avaliadas.

Como descrito na Seção 5.2.4, a linha dentro de cada caixa apresentada na Figura 5.11, representa a mediana da distribuição dos resultados da AUC para cada índice de predição. O tamanho de cada caixa representa a dispersão da distribuição dos resultados de cada índice de predição. Além disso, os pontos assinalados com o simbolo "+" indicam a presença de valores atípicos (outliers). As distribuições dos índices de similaridade baseadas em informações das comunidades são apresentadas tanto quando as estruturas de comunidades das redes foram descobertas com o algoritmo FM quanto pelo algoritmo WT.

Como se pode observar da Figura 5.11, à exceção de AA e RA, todos os outros valores de mediana dos demais índices de similaridade local foram superados pelo valor de mediana da distribuição do desempenho do índice WIC (FM e WT). Essa superioridade do WIC foi manifestada também sobre todos os índices de similaridade global, exceto o Katz. De maneira similar, o índice WIC mostra também uma superioridade sobre todos os índices da forma W, exceto para o AA-W e para o RA-W. Pode-se observar também que, entre os índices de similaridade local, os de melhor desempenho foram o AA e o RA, e o de mais baixo rendimento foi o LHN. Entre os índices de similaridade global, o de melhor desempenho foi o Katz, sendo o de mais baixo rendimento o SR, o qual foi superado por todos os índices de similaridade local, exceto o 
LHN.

Mas a análise do gráfico de caixas ainda não permite dizer qual índice teve, de maneira global, o melhor rendimento na experimentação realizada. Para isso, foi utilizado o teste post-hoc descrito na Seção 5.2.4. Assim, com base nos resultados apresentados na Tabela 5.4, para cada rede avaliada foi gerado um ranking, no qual, cada índice foi colocado em uma posição crescente de acordo ao seu valor de AUC. Esse processo foi realizado para as dez redes adotadas. Depois disso, foi calculada a média do ranking de cada índice, cujo valor foi colocado na última coluna da Tabela 5.4. O valor da média fornece informação do desempenho global de cada índice além das informações necessárias para computar o teste de Friedman e determinar o valor da diferença crítica (Demsar, 2006). Na Figura 5.12 é apresentado o gráfico da diferença estatística contendo unicamente as dez primeiras posições no ranking da média do desempenho em relação à AUC.

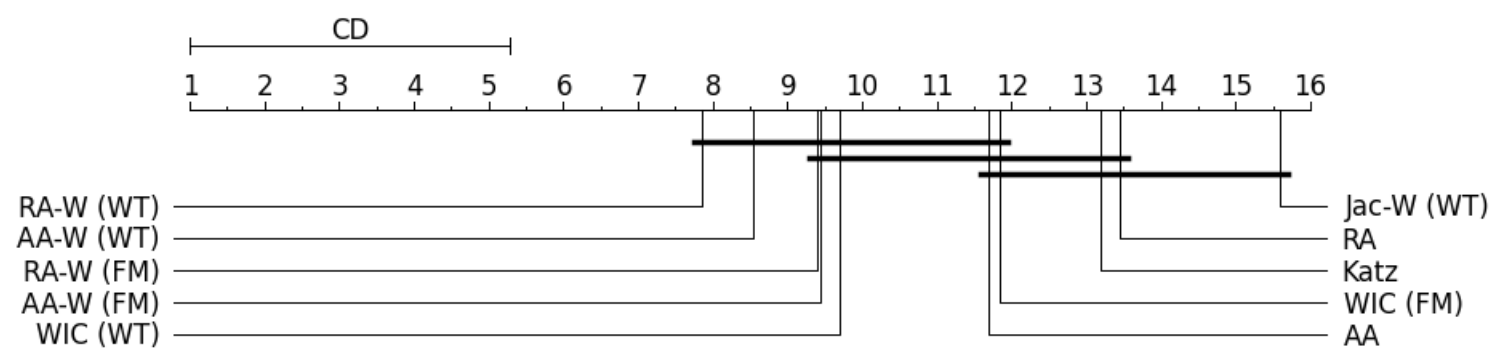

Figura 5.12: Diferença estatística das dez primeiras posições do ranking da média do desempenho em relação à AUC dos índices avaliados sobre as dez redes adotadas. Para os índices de similaridade baseados nas informações das comunidades são considerados os resultados quando são usadas as informações fornecidas pelos algoritmos FM e WT.

Na Figura 5.12, pode-se observar que o valor da diferença crítica é $C D=$ 5.15. Assim, para que dois índices tenham uma diferença estatisticamente significativa no seu desempenho, a média dos seus ranking deve ter uma diferença maior ou igual ao valor de $C D$. Assim, três grupos foram formados: o primeiro constituído pelos índices RA-W (FM e WT), AA-W (FM e WT), WIC (FM e WT) e AA, que ocuparam as sete primeiras posições do ranking; o segundo grupo constituído pelos índices RA-W (FM), AA-W (FM) e WIC (FM e WT), bem como pelos índices AA, RA e Katz; e o terceiro grupo constituído pelos índices WIC (FM), Jac-W (WT), AA, Katz e RA.

Dessa maneira, entre os índices pertencentes a cada um desses três grupos não existe diferença estatisticamente significativa, mas sim entre os índices que não pertencem à interseção desses grupos. Assim, dentre as dez posições 
no ranking do desempenho, os índices RA-W (WT) e AA-W (WT), tiveram uma diferença estatisticamente significativa em relação aos índices Katz, RA e JacW (WT). Da mesma maneira, observou-se também uma diferença estatisticamente significativa entre os índices RA-W (FM), AA-W (FM) e WIC (WT) em relação ao índice Jac-W (WT). Considerando que os índices pertencentes ao primeiro grupo tiveram a melhor média do ranking, tem-se que os índices RA-W (FM e WT) e AA-W (FM e WT) conseguiram o melhor desempenho na predição de links em relação à AUC, seguidos pelos índices WIC (FM e WT) e AA.

\section{Resultados da Precisão}

Na Tabela 5.5 são apresentados os resultados da média da Precisão dos índices avaliados. Além disso, no caso dos índices propostos nesta dissertação, são apresentados dois resultados correspondentes à experimentação feita com informações das estruturas de comunidades detectadas pelos algoritmos FM e WT. Os valores apresentados para cada um desses mesmos índices, correspondem à maior média da Precisão obtida na experimentação apresentada na seção anterior, isto é, dos resultados apresentados nas Figuras 5.7, 5.8, 5.9 e 5.10. Na última coluna da tabela são colocados os valores da média do ranking do desempenho global obtido de cada índice avaliado sobre todas as redes avaliadas.

Dos resultados apresentados na Tabela 5.5, para cada rede avaliada, o maior valor obtido por um dado índice foi destacado em negrito. Assim, observa-se que na rede Industry-pr o melhor desempenho foi obtido pelo índice WIC (FM e WT), entretanto que nas redes Power e NetScience, o melhor desempenho também foi obtido pelo índice WIC quando usou informações das comunidades obtidas pelos algoritmos FM e WT, respectivamente. Nas redes Router e NetScience, o melhor desempenho foi obtido pelo índice CN-W (WT). $\mathrm{Na}$ rede PoolBlogs, o melhor desempenho foi obtido pelos índices CN-W (FM) e Katz. Na rede Karate, o melhor desempenho foi obtido pelo índice HDI-W (FM). $\mathrm{Na}$ rede Football, o melhor desempenho foi obtido pelo índice LHN-W (WT). Na rede Yeast, o melhor desempenho foi obtido pelo índice RA-W (WT). Na rede Airline, o melhor desempenho foi obtido pelo índice AA. Na rede Imdb-prodco o melhor desempenho foi obtido pelos índices WIC (FM e WT), CN, CN-W (FM e WT), AA, AA-W (FM e WT), HDI, HDI-W (WT), Jac-W (FM), RA, RA-W (FM e WT, Sor-W (FM) e Katz.

Também é importante destacar o comportamento particular de boa parte 
Tabela 5.5: Resultados da predição correspondentes à Precisão das dez redes adotadas, com $L=10 \%$ do número de links existentes de cada rede. Cada valor representa a média da Precisão obtida pelos indices baseados nas informações das comunidades, tanto quando essas informações são geradas pelo algoritmo FM quanto pelo algoritmo WT, e pelos índices de similaridade estrutural local e global.

\begin{tabular}{|c|c|c|c|c|c|c|c|c|c|c|c|}
\hline & Airline & Power & Router & $\begin{array}{l}\text { Indus- } \\
\text { try-pr }\end{array}$ & $\begin{array}{l}\text { Imdb- } \\
\text { prodco }\end{array}$ & $\begin{array}{l}\text { Pool- } \\
\text { Blogs }\end{array}$ & Yeast & Football & Karate & $\begin{array}{c}\text { Net- } \\
\text { Science }\end{array}$ & $\begin{array}{c}\text { Média do } \\
\text { ranking }\end{array}$ \\
\hline WIC (FM) & 0,53 & 0,29 & 0,15 & 0,94 & $\mathbf{1}$ & 0,57 & 0,57 & 0,57 & 0,58 & 0,73 & 8,5 \\
\hline WIC (WT) & 0,48 & 0,25 & 0,17 & 0,94 & $\mathbf{1}$ & 0,56 & 0,55 & 0,86 & 0,28 & 1 & 6,65 \\
\hline $\mathbf{C N}$ & 0,91 & 0,07 & 0,09 & 0,92 & $\mathbf{1}$ & 0,58 & 0,54 & 0,53 & 0,3 & 0,91 & 11,25 \\
\hline CN-W (FM) & 0,67 & 0,27 & 0,15 & 0,93 & $\mathbf{1}$ & 0,59 & 0,55 & 0,57 & 0,57 & 0,71 & 8,35 \\
\hline $\mathrm{CN}-\mathrm{W}$ (WT) & 0,64 & 0,25 & 0,2 & 0,93 & $\mathbf{1}$ & 0,58 & 0,56 & 0,78 & 0,25 & 1 & 6,95 \\
\hline $\mathbf{A A}$ & 0,93 & 0,08 & 0,06 & 0,93 & $\mathbf{1}$ & 0,56 & 0,57 & 0,46 & 0,21 & 0,94 & 12 \\
\hline AA-W (FM) & 0,71 & 0,1 & 0,09 & 0,93 & $\mathbf{1}$ & 0,57 & 0,56 & 0,5 & 0,5 & 0,84 & 10,2 \\
\hline AA-W (WT) & 0,66 & 0,09 & 0,06 & 0,93 & 1 & 0,55 & 0,57 & 0,78 & 0,54 & 0,99 & 8,2 \\
\hline HDI & 0,05 & 0,02 & 0 & 0,5 & $\mathbf{1}$ & 0 & 0 & 0,56 & 0,34 & 0,62 & 23,9 \\
\hline HDI-W (FM) & 0,18 & 0,06 & 0 & 0,7 & 0,99 & 0,08 & 0,15 & 0,54 & 0,8 & 0,59 & 20,3 \\
\hline HDI-W (WT) & 0,41 & 0,04 & 0 & 0,92 & 1 & 0,03 & 0,15 & 0,81 & 0,15 & 0,99 & 17,3 \\
\hline HPI & 0,25 & 0,15 & 0,05 & 0,37 & 0,12 & 0,02 & 0,2 & 0,76 & 0,11 & 0,51 & 21,3 \\
\hline HPI-W (FM) & 0,26 & 0,15 & 0,05 & 0,34 & 0,93 & 0,12 & 0,17 & 0,8 & 0,67 & 0,81 & 15,6 \\
\hline HPI-W (WT) & 0,4 & 0,13 & 0,05 & 0,88 & 0,4 & 0,02 & 0,21 & 0,85 & 0,46 & 0,99 & 14,2 \\
\hline Jac & 0,05 & 0,02 & 0 & 0,28 & 0,99 & 0 & 0 & 0,59 & 0,34 & 0,6 & 25,2 \\
\hline Jac-W (FM) & 0,13 & 0,04 & 0 & 0,7 & 1 & 0,08 & 0,14 & 0,65 & 0,79 & 0,67 & 19,15 \\
\hline Jac-W (WT) & 0,42 & 0,05 & 0 & 0,93 & 0,99 & 0,02 & 0,17 & 0,82 & 0,15 & 0,99 & 16,55 \\
\hline LHN & 0 & 0,02 & 0 & 0,01 & 0,24 & 0 & 0 & 0,69 & 0,24 & 0,7 & 27,45 \\
\hline LHN-W (FM) & 0,09 & 0,07 & 0 & 0,11 & 0,63 & 0,01 & 0,18 & 0,77 & 0,79 & 0,67 & 19,7 \\
\hline LHN-W (WT) & 0,37 & 0,05 & 0 & 0,88 & 0,24 & 0 & 0,29 & 0,88 & 0,26 & 0,99 & 18,1 \\
\hline $\mathbf{R A}$ & 0,88 & 0,08 & 0,05 & 0,7 & $\mathbf{1}$ & 0,46 & 0,59 & 0,46 & 0,2 & 0,9 & 14,6 \\
\hline RA-W (FM) & 0,7 & 0,1 & 0,06 & 0,82 & $\mathbf{1}$ & 0,49 & 0,61 & 0,47 & 0,51 & 0,84 & 12 \\
\hline RA-W (WT) & 0,66 & 0,09 & 0,06 & 0,91 & 1 & 0,45 & 0,7 & 0,78 & 0,56 & 0,99 & 9,45 \\
\hline Sal & 0,04 & 0,02 & 0 & 0,23 & 0,99 & 0 & 0 & 0,64 & 0,34 & 0,6 & 24,85 \\
\hline Sal-W (FM) & 0,2 & 0,04 & 0 & 0,67 & 0,99 & 0,07 & 0,14 & 0,66 & 0,79 & 0,65 & 21,1 \\
\hline Sal-W (WT) & 0,37 & 0,05 & 0 & 0,9 & 0,99 & 0,01 & 0,15 & 0,82 & 0,15 & 0,99 & 18,7 \\
\hline Sor & 0,05 & 0,02 & 0 & 0,28 & 0,99 & 0 & 0 & 0,59 & 0,34 & 0,6 & 25,3 \\
\hline Sor-W (FM) & 0,21 & 0,04 & 0 & 0,7 & 1 & 0,08 & 0,14 & 0,64 & 0,79 & 0,67 & 19,5 \\
\hline Sor-W (WT) & 0,41 & 0,05 & 0 & 0,93 & 0,99 & 0,02 & 0,15 & 0,82 & 0,15 & 0,99 & 18,1 \\
\hline PA & 0,84 & 0 & 0,11 & 0,16 & 0,2 & 0,27 & 0,56 & 0 & 0,01 & 0,53 & 22,3 \\
\hline Katz & 0,91 & 0,02 & 0,09 & 0,93 & $\mathbf{1}$ & 0,59 & 0,6 & 0,47 & 0,17 & 0,88 & 13,4 \\
\hline RPR & 0,21 & 0,07 & 0,02 & 0,06 & 0,11 & 0,19 & 0,2 & 0,04 & 0,26 & 0,61 & 22,7 \\
\hline SR & 0 & 0,02 & 0 & 0 & 0,34 & 0 & 0 & 0,76 & 0,23 & 0,55 & 28,25 \\
\hline
\end{tabular}

dos índices avaliados em duas redes. Na rede Router, caracterizada por ter o menor coeficiente de agrupamento global e o maior grau de heterogeneidade, observou-se que o desempenho de todos os índices foi muito pobre (sendo 0.2 o maior valor de Precisão obtido). Assim, observou-se também que, os índices de similaridade local, HDI, Jac, LHN, Sal e Sor, bem como suas respectivas formas $\mathrm{W}$, e o índice de similaridade global, SR, obtiveram um desempenho comum, o qual é 0 , isto é, os primeiros $\left\lfloor\frac{|E|}{10}\right\rfloor$ links preditos por cada um desses indices foram falsos positivos (links que não pertencem ao conjunto de teste). Por outro lado, na rede Imdb-prodco, caracterizada por ter um alto coeficiente de agrupamento global e um baixo grau de heterogeneidade, observou-se que o desempenho da maioria dos índices é muito alto, sendo que os índices WIC (FM e WT), CN, CN-W (FM e WT), AA, AA-W (FM e WT), HDI, HDI (WT), Jac-W 
(FM), RA, RA-W (FM e WT), Sor-W (FM), e Katz, obtiveram o maior desempenho possivel, o qual é 1, isto é, a totalidade dos primeiros $\left\lfloor\frac{|E|}{10}\right\rfloor$ links preditos por cada um desses índices foram verdadeiros positivos (links que pertencem ao conjunto de teste).

Da Tabela 5.5, independentemente que as informações das comunidades, necessárias para os índices propostos nesta dissertação, foram obtidas pelos algoritmos FM ou WT, observou-se que, em boa parte dos casos, o índice WIC obteve um desempenho superior ao dos índices de similaridade local e global, bem como também da maioria dos índices da forma W. Também observouse que na maioria dos casos, os índices da forma $\mathrm{W}$ obtiveram um melhor desempenho que suas respectivas formas básicas.

De maneira similar que na análise da AUC, a partir da Tabela 5.5, foram gerados os gráficos de caixas, para análise da distribuição dos resultados da Precisão, e o gráfico da diferença estatística, para a análise da diferença estatística significativa entre os índices avaliados. Assim, na Figura 5.13, são apresentados, mediante um gráfico de caixas, as distribuições dos resultados da Precisão de cada índice avaliado.

Na Figura 5.13 pode-se observar que, a mediana da distribuição do desempenho do índice WIC (FM) superou todos os índices de similaridade local, tanto que a mediana do WIC (WT) somente foi ligeiramente superada pelo CN e AA. Essa mesma superioridade do WIC (FM e WT) foi também manifestada sobre todos os índices da forma $\mathrm{W}$, exceto para o CN-W, AA-W, e RA-W. Guando comparado com os índices de similaridade global, a mediana do WIC (FM e WT) também foi superior exceto para o Katz. Pode-se observar também que, a mediana do desempenho de todos os índices da forma $\mathrm{W}$ superou à de seus respectivos índices base. Já sobre os índices de similaridade estrutural, entre os de similaridade local, os índices $\mathrm{CN}$ e AA obtiveram a mediana com melhor desempenho e o índice LHN a de mais baixo desempenho, tanto que, entre os índices de similaridade global, o índice Katz obteve o melhor desempenho e o índice SR, mais uma vez, apresentou a mediana com desempenho mais baixo, porém, tão comparável como o de LHN.

Para determinar o índice que obteve, de maneira global, o melhor desempenho na experimentação, foi utilizado o teste post-hoc descrito na Seção 5.2.4. Com a média do ranking de desempenho de cada índice, gerado da mesma maneira que apresentado na análise da AUC, o teste de Friedman foi calculado. Com os resultados desse teste, na Figura 5.14, é apresentado o gráfico da diferença estatística contendo unicamente as dez primeiras posições de 


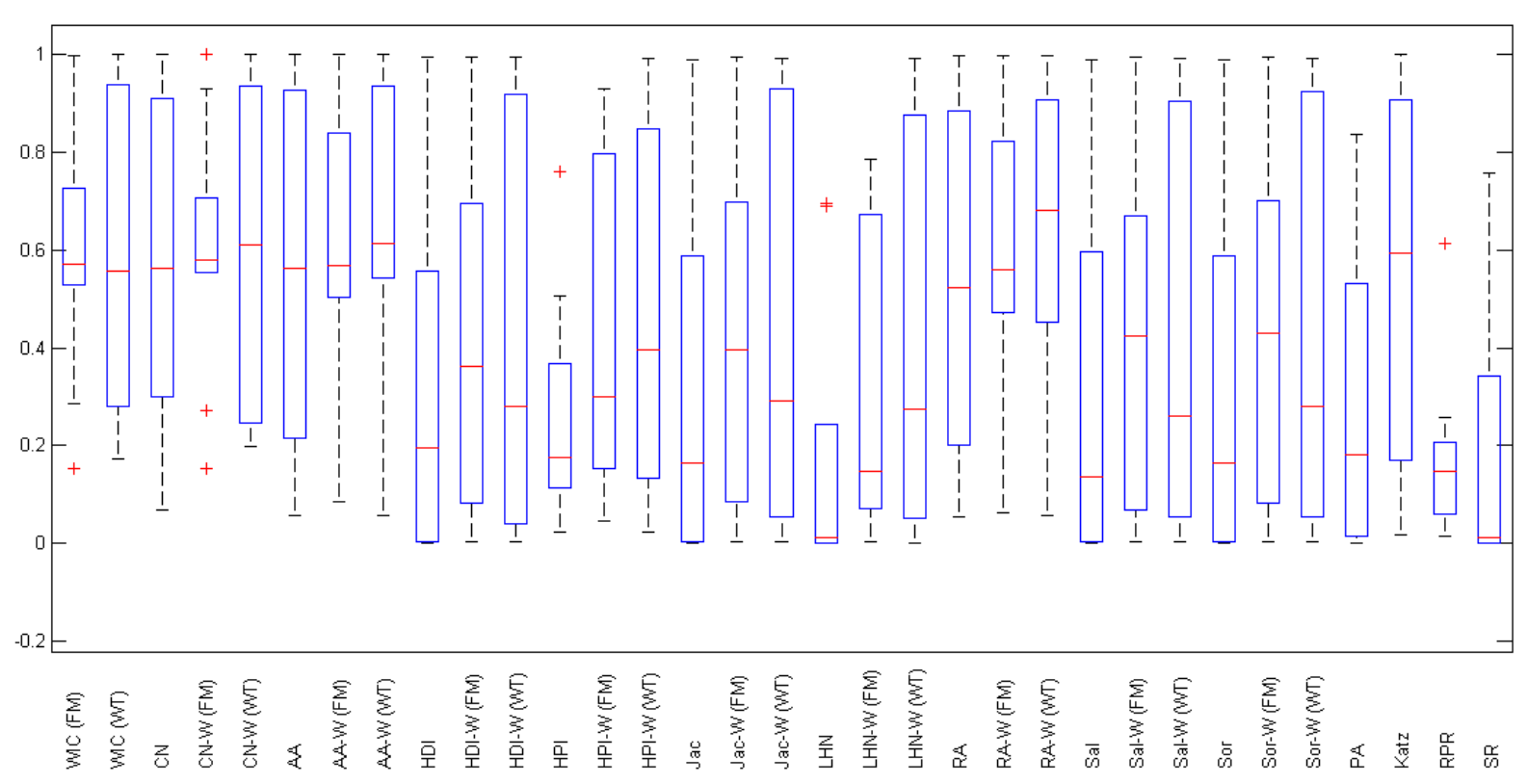

Figura 5.13: Distribuição estatística do desempenho de todos os índices de predição avaliados. A linha dentro de cada caixa indica a mediana do desempenho respeito à Precisão com $L=10 \%$ do número de links existentes, $|E|$, de cada uma das dez redes avaliadas.

acordo ao ranking da média da Precisão.

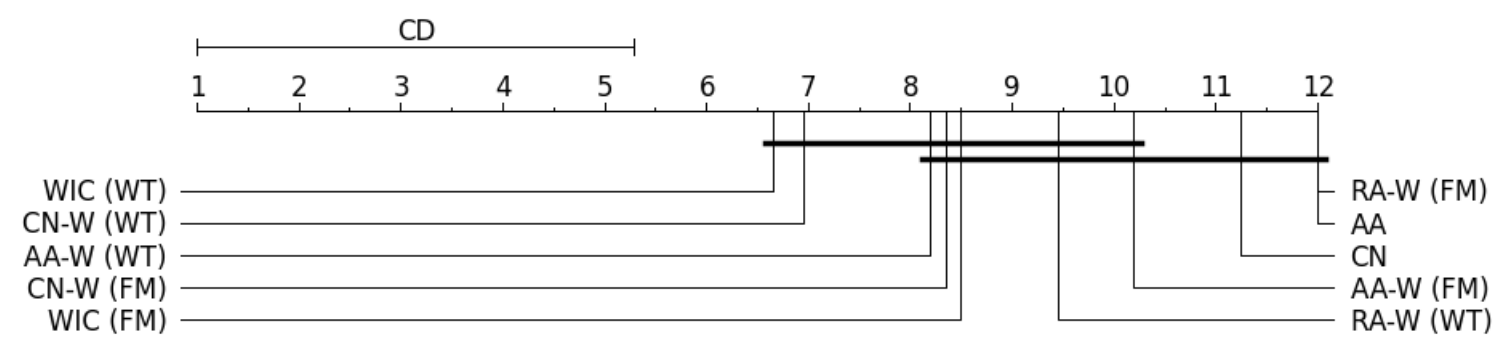

Figura 5.14: Gráfico de diferença estatística mostrando as dez primeiras posições de acordo ao ranking da média do desempenho em relação à Precisão com $L=10 \%$ do número de links existentes, $|E|$, de cada uma das dez redes avaliadas.

Do gráfico de diferença estatística da Figura 5.14, pode-se observar que o valor da diferença crítica é $C D=5.2$, o qual é muito similar ao obtido na análise da AUC. Neste caso, porém, apenas dois grupos foram formados: o primeiro constituído pelas sete primeiras posições ocupadas pelos índices WIC (FM e WT), CN-W (FM e WT), AA-W (FM e WT), e RA-W (WT); e o segundo grupo, constituído pelas sete últimas posições ocupadas pelos índices AA-W (FM e WT), WIC (FM), RA-W (FM e WT), CN, e AA.

O fato do valor da diferença crítica nos resultados da Precisão ser similar 
ao da AUC mesmo quando a quantidade de grupos formados no gráfico de diferença estatística em relação à Precisão for menor, implica que, no caso da análise da Precisão, os índices têm um desempenho muito similar entre eles, isto é, a quantidade de pares de índices que possuem uma diferença estatística significativa vê-se reduzida. Dessa maneira, da Figura 5.14 podese observar unicamente que os índices WIC (WT) e CN-W (WT) tiveram uma diferença estatisticamente significativa em relação aos índices CN, AA, e RA$\mathrm{W}(\mathrm{FM})$.

\section{Discussão dos Resultados}

Guanto a análise da AUC realizada dos resultados apresentados, foi observado um melhor desempenho dos índices de similaridade baseados nas informações das comunidades, propostos nesta dissertação, em relação aos índices de similaridade estrutural pertencentes à abordagem tradicional. Isso foi observado no ranking de desempenho global, no qual, as primeiras posições foram ocupadas pelos índices RA-W, AA-W e WIC tanto quando usaram informações das estruturas de comunidades detectadas pelo algoritmo FM quanto pelo algoritmo WT.

Guanto a análise da Precisão realizada dos resultados apresentados, novamente os índices propostos nesta dissertação obtiveram um melhor desempenho que os índices de similaridade estrutural pertencentes à abordagem tradicional. Assim, no ranking de desempenho global, independentemente do algoritmo de detecção de comunidades usado, os índices WIC, CN-W, RA-W e AA-W ocuparam as primeiras posições. 


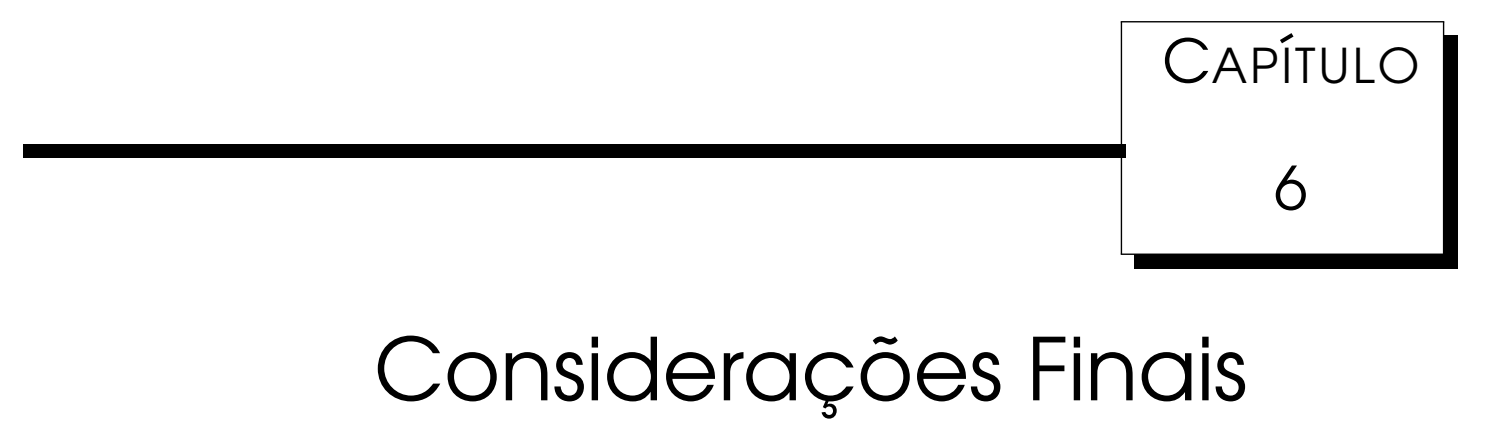

$\mathcal{E}$ ste capítulo apresenta as considerações finais deste trabalho. Assim, são expostas as conclusões e contribuições obtidas pela pesquisa. Em seguida, são discutidas algumas limitações do estudo e, por fim, direcionamentos para trabalhos futuros.

\subsection{Conclusões e Principais Contribuições}

A revisão literária permitiu o entendimento das características e propriedades relacionadas às redes complexas, dentre as quais, a natureza do agrupamento de vértices que compartilham propriedades ou papeis similares, o que serviu como base para realização de um estudo sobre uma das mais importantes tarefa da mineração de links: Predição de Links. As dificuldades e deficiências atuais deste problema levaram à definição dos objetivos e às contribuições deste trabalho.

A partir do levantamento bibliográfico realizado, observou-se que uma das maiores deficiências da área está no fato de que o problema da predição de relacionamentos poucas vezes foi abordado sob o ponto de vista do uso de abordagens híbridas, especificamente aquelas que usam informações das estruturas de comunidades. Grande parte dos trabalhos da literatura fazem uso da definição clássica, na qual utiliza-se unicamente as informações topológicas ou estruturais das redes para extrair características necessárias para predição de novos relacionamentos. 
Além disso, os poucos trabalhos que fazem uso de informações das comunidades observam uma melhoria na qualidade das predições. Porém, estes trabalhos não realizam uma análise aprofundada de como estas informações influenciam na tarefa de predição de links. Estas questões serviram de estímulo para que a presente dissertação realizasse um estudo mais completo na vertente de predição de links baseada nas informações das comunidades.

Assim, para uma dada rede, foi realizada sua modelagem através de sete estruturas de comunidades detectadas pelo algoritmo FM e sete estruturas de comunidades detectadas pelo algoritmo WT. Essas quatorze estruturas de comunidades da rede caracterizaram-se por ter configurações diferentes. Depois disso, seguindo uma estratégia não supervisionada e uma subamostragem aleatória para gerar diferentes conjuntos de treino e teste, índices de similaridade estrutural local e global, bem como os índices de similaridade baseada nas informações das comunidades, propostos nesta dissertação, foram utilizados para predizer novos relacionamentos.

A partir dos resultados obtidos dos experimentos realizados e apresentados no Capítulo 5, da analise tanto da AUC como da Precisão, foi possivel extrair as seguintes conclusões:

- em relação aos índices de similaridade estrutural, correspondentes à abordagem tradicional, comprovou-se que entre os índices de similaridade local destacaram-se o CN, AA e RA, e entre os índices de similaridade global, destacou-se o Katz. Além disso, observou-se que, nas redes com alto valor de coeficiente de agrupamento global, o desempenho dos indices de similaridade local foi comparável ao do Katz. Isto corrobora os resultados apresentados nos diferentes trabalhos existentes na literatura (Zhou et al., 2009; Liben-Nowell e Kleinberg, 2007);

- nas redes que se caracterizaram por ter um alto coeficiente de agrupamento global (maior que 0,3) e um alto grau de heterogeneidade (maior que 1,8$)$, independentemente do algoritmo de detecção de comunidades usado, tem-se que os índices de similaridade baseados nas informações das comunidades, propostos neste trabalho, alcançaram seu melhor desempenho nas estruturas de comunidades mais ricas, isto é, nas estruturas de comunidades que apresentavam uma alta modularidade. Para as redes que não cumprem essas características, observou-se que, na maioria dos casos, esses mesmos índices alcançaram seu melhor desempenho nas estruturas de comunidades que apresentavam um alto nível 
de densidade, isto é, nas estruturas que apresentavam uma maior média de vértices por comunidade;

- em relação aos índices de similaridade baseados nas informações das comunidades, os índices WIC, RA-W, AA-W, e CN-W tiveram um desempenho superior em relação aos outros índices da forma $\mathrm{W}$ e dos índices de similaridade estrutural local e global. Por seu turno, cada índice da forma $\mathrm{W}$ apresentou um melhor desempenho que seu respectivo índice de similaridade estrutural base. Com isso, tem-se que os índices de similaridade baseados nas informações das comunidades, em geral, têm um melhor desempenho na tarefa da predição de links que os indices de similaridade estrutural.

Tendo isso, as principais contribuições deste trabalho foram:

- estudo do uso das informações das comunidades na predição de novos relacionamentos em redes complexas de categorias diferentes. Poucas pesquisas realizaram uma investigação de como a inclusão das informações das comunidades influencia no desempenho da predição de links. Assim, este trabalho abordou o problema a partir de um ponto de vista inovador. Mediante o uso das informações dos vizinhos comuns intracomunidade e inter-comunidades de um par de vértices analisados, foi proposto um novo índice para predição de links, chamado de índice WIC. Também, a partir do uso único das informações intra-comunidades dos vizinhos comuns de um par de vértices analisados, os índices de similaridade estrutural local foram reformulados, assim, foi proposto um conjunto de novos índices chamados de índices da forma $\mathrm{W}$;

- avaliação experimental considerando a existência de diferentes configurações de estruturas de comunidades para uma mesma rede, as quais foram caracterizadas por terem diferentes valores de modularidade bem como comunidades de tamanhos diferentes. Para determinar essas estruturas de comunidades foram utilizados dois algoritmos que seguem abordagens diferentes. Com essa avaliação, foi possivel determinar as condições nas quais os índices de similaridade baseadas nas informações das comunidades, propostos neste trabalho, alcançam seu melhor desempenho, e assim, pode-se aproveitá-los adequadamente na tarefa de predição de links; 
- determinação da justificativa do melhor desempenho dos índices de similaridade baseados nas informações das comunidades em relação aos indices de similaridade estrutural. Dessa maneira, o fato de vértices formarem grupos com outros que compartilham características e/ou papeis, fornece informações importantes para tarefa de predição de links. Em geral, essas informações são mais ricas quando os vértices estão melhor agrupados, ou seja, quando mais alto for o valor da modularidade da estrutura de comunidades de uma rede;

- análise do desempenho atingido por duas métricas sobre dez redes com configurações diferentes e seguindo uma metodologia padrão no contexto da estratégia não supervisionada para predição de links. Além disso, foi realizada uma análise da tendência central bem como da diferença estatística de todos os índices avaliados, tanto dos índices de similaridade estrutural local e global bem como dos índices propostos;

- produção de dois artigos publicados em duas conferências internacionais (Valverde-Rebaza e de Andrade Lopes, 2012a,b). Ditos artigos já foram comentados no Capítulo 1.4.

\subsection{Limitações do Trabalho}

Não foi objetivo deste trabalho abordar todos os aspectos da predição de links, mas apenas em como as informações referentes às estruturas de comunidades podem influenciar positivamente as predições de novos relacionamentos. Para isso, algumas restrições tiveram que ser aplicadas, dentre as quais:

- as informações utilizadas trataram-se apenas de caráter estrutural (topológico), tanto para o cálculo dos índices de similaridade correspondentes à abordagem tradicional como dos índices propostos. Assim, não foram utilizadas informações referentes aos atributos dos vértices como uma fonte extra de informação;

- devido à esparsidade das redes adotadas, nem todos os vértices não ligados puderam ser analisados. Por isso, considerando-se o modelo de mundo pequeno associado à maioria das redes complexas, adotou-se uma heurística para seleção de apenas as díades cujos vértices estão separados até a dois passos de distância; 
- não foram utilizadas as informações referentes aos links como seus pesos ou outro de seus atributos. Assim, no cálculo de todos os índices de predição avaliados considerou-se que todos os links têm o mesmo peso;

- não foram consideradas questões temporais. Assim, a dimensão tempo não foi considerada como fonte de informação no cálculo dos índices avaliados.

\subsection{Trabalhos Futuros}

As limitações deste trabalho nos indicam o que ainda precisa ser feito para ampliar nosso campo de análise. Assim, tem-se o objetivo de dar continuação à pesquisa na predição de links, mas considerando-se as seguintes melhorias:

- comparar a eficácia dos índices propostos com outros métodos híbridos;

- avaliar o desempenho dos índices propostos seguindo uma estratégia supervisionada;

- avaliar o desempenho dos índices propostos considerando a inclusão da dimensão temporal bem como propor uma nova abordagem que aproveite diretamente essas informações junto com as informações das comunidades;

- aplicar os índices propostos em redes sociais de diferentes domínios, como redes sociais de amizade e redes de contato profissional;

- estender os índices propostos para considerar os casos nos quais existe interseção entre grupos de vértices, ou seja, quando um vértice pertence a mais de uma comunidade na mesma rede;

- avaliar mais profundamente os preceitos subjetivos da evolução das redes, especificamente das redes sociais, com o intuito de identificar que comportamentos sociológicos levam aos individuos formar, manter ou terminar relações com outros. 



\section{Referências Bibliográficas}

Ackland, R. (2005). Mapping the US political blogosphere: Are conservative bloggers more prominent? Presentation to BlogTalk Downunder, Sydney. Citado na página 62.

Adamic, L. e Adar, E. (2003). Friends and neighbors on the Web. Social Networks, 25(3):211-230. Citado nas páginas 3 e 35.

Ahn, Y., Bagrow, J., e Lehmann, S. (2010). Link communities reveal multiscale complexity in networks. Nature, 466. Citado nas páginas 24 e 43.

Appel, A. P. e Hruschka Junior, E. R. (2011). Centaurs - a component based framework to mine large graphs. JIDM, 2(1):19-26. Citado na página 27.

Backstrom, L. e Leskovec, J. (2011). Supervised random walks: predicting and recommending links in social networks. In Proceedings of the fourth ACM International Conference on Web Search and Data Mining, WSDM '11, páginas 635-644, New York, NY, USA. ACM. Citado na página 47.

Barabási, A.-L. e Albert, R. (1999). Emergence of scaling in random networks. Science 286, (5439):509-512. Citado nas páginas 2 e 20.

Barabási, A.-L., Jeong, H., Ravasz, E., Néda, Z., Schuberts, A., e Vicsek, T. (2002). Evolution of the social network of scientific collaborations. Physica A, (311):590-614. Citado nas páginas 36 e 45.

Batageli, V. e Mrvar, A. (2006). Pajek datasets, disponible em http://vlado.fmf.uni-lj.si/pub/networks/data/mix/USAir97.net. Data de acesso: 10/02/2012. Citado na página 61 . 
Benchettara, N., Kanawati, R., e Rouveirol, C. (2010). A supervised machine learning link prediction approach for academic collaboration recommendation. In Proceedings of the fourth ACM conference on Recommender systems, RecSys '10, páginas 253-256, New York, NY, USA. ACM. Citado na página 32.

Blondel, V. D., Guillaume, J.-L., Lambiotte, R., e Lefebvre, E. (2008). Fast unfolding of communities in large networks. Journal of Statistical Mechanics: Theory and Experiment, P10008. Citado nas páginas 24 e 43.

Brandes, U., Gaertler, M., e Wagner, D. (2003). Experiments on graph clustering algorithms. In Proceedings of the 11th Annual European Symposium on Algorithms, ESA'03, páginas 568-579. Citado nas páginas 18, 23, e 53.

Bunescu, R. e Mooney, R. J. (2004). Relational markov networks for collective information extraction. In Proceedings of the ICML-04 Workshop on Statistical Relational Learning and its Connections to Other Fields, SRL-2004. Citado na página 2.

Carpenter, T., Karakostas, G., e Shallcross, D. (2002). Practical issues and algorithms for analyzing terrorist networks. In Proceedings of the 2002 Western Multiconference, WMC'02. Citado na página 45.

Christakis, N. A. e Fowler, J. H. (2007). The spread of obesity in a large social network over 32 years. The New England Journal of Medicine, 357(4):370379. Citado nas páginas 11 e 46.

Clauset, A., Moore, C., e Newman, M. E. J. (2008). Hierarchical structure and the prediction of missing links in networks. Nature (London), 453, páginas 98-101. Citado nas páginas 3, 4, e 39.

Clauset, A., Newman, M. E. J., e Moore, C. (2004). Finding community structure in very large networks. Phys. Rev. E, 70. Citado nas páginas 22 e 23.

Cook, D. J. e Holder, L. B. (1994). Substructure discovery using minimum description length and background knowledge. Journal of Artificial Intelligence Research. Citado na página 24.

Costa, L., Rodrigues, F. A., Travieso, G., e Boas, P. R. V. (2007). Characterization of complex networks: A survey of measurements. Advances in Physics, 56:167. Citado nas páginas 2 e 13. 
Davis, A., Gardner, B. B., e Gardner, M. R. (1941). Deep south. University of Chicago Press. Citado na página 29.

Demsar, J. (2006). Statistical comparisons of classifiers over multiple data sets. JMLR, 7:1-30. Citado nas páginas 69 e 85.

Donetti, L. e Muñoz, M. A. (2005). Improved spectral algorithm for the detection of network communities. Modeling Cooperative Behavior in the Social Sciences, 779:104-107. Citado na página 24.

Doppa, J. R., Yu, J., Tadepalli, P., e Getoor, L. (2010). Learning algorithms for link pre- diction based on chance constraints. In Proceedings of the 2010 European Conference on Machine Learning and Knowledge Discovery in Databases: Part I, ECML PKDD’10, páginas 344-360. Citado na página 48.

Dorogovtsev, S. N. e Mendes, J. F. F. (2002). Evolution of networks. In Adv. Phys, páginas 1079-1187. Citado na página 2.

Erdös, P. e Rényi, A. (1959). On random graphs. Publications Mathematicae 6, páginas 290-297. Citado na página 19.

Fararo, T. J. e Sunshine, M. (1964). A study of a biased friendship network. Syracuse University Press. Citado na página 29.

Fawcett, T. e Provost, F. (1999). Activity monitoring: Noticing interesting changes in behavior. In In Proc. of the Fifth ACM SIGKDD Int. Conf. on Knowledge Discovery and Data Mining, páginas 53-62. Citado na página 62.

Feng, X., Zhao, J., e Xu, K. (2012). Link prediction in complex networks: a clustering perspective. Eur. Phys. J. B, 85(1):3. Citado na página 53.

Fortunato, S. (2010). Community detection in graphs. In CoRR, volume abs/0906.0612v2. Citado nas páginas 18 e 22.

Friedman, N., Getoor, L., Koller, D., e Pfeffer, A. (1999). Learning probabilistic relational models. In IJCAI, páginas 1300-1309. Springer-Verlag. Citado na página 41.

Getoor, L. e Diehl, C. P. (2005). Link mining: a survey. ACM SIGKDD Explorations Newsletter, 7(2):3-12. Citado nas páginas 2, 21, 27, e 40.

Getoor, L., Friedman, N., Koller, D., e Taskar, B. (2003). Learning probabilistic models of link structure. J. Mach. Learn. Res., 3:679-707. Citado na página 41. 
Getoor, L. e Taskar, B. (2007). Introduction to Statistical Relational Learning (Adaptive Computation and Machine Learning). The MIT Press. Citado na página 4.

Girvan, M. e Newman, M. E. J. (2002). Community structure in social and biological networks. Proceedings of the National Academy of Sciences, 99(12):7821-7826. Citado nas páginas 2, 18, 20, 24, e 62.

Gong, N. Z., Talwalkar, A., Mackey, L., Huang, L., Shin, E. C. R., Stefanov, E., Shi, E., e Song, D. (2012). Jointly Predicting Links and Inferring Attributes using a Social-Attribute Network (SAN). arXiv:1112.3265v5. Citado nas páginas $4,42,47$, e 48 .

Granovetter, M. S. (1973). The strength of weak ties. The American Journal of Sociology, 78(6):1360-1380. Citado nas páginas 2 e 19.

Gärtner, T. (2002). Exponential and geometric kernels for graphs. In NIPS Workshop on Unreal Data: Principles of Modeling Nonvectorial Data. Citado na página 24.

Han, J. (2009). Mining heterogeneous information networks by exploring the power of links. In Proceedings of the 12th International Conference on Discovery Science, DS '09, páginas 13-30. Citado na página 10.

Han, J., Kamber, M., e Pei, J. (2011). Data Mining: concepts and techniques. Morgan Kaufmann, $3^{\text {a }}$ edição. Citado nas páginas 1 e 33.

Hasan, M. A., Chaoji, V., Salem, S., e Zaki, M. (2006). Link prediction using supervised learning. In Proc. of SDM 06 workshop on Link Analysis, Counterterrorism and Security. Citado na página 32.

Hastie, T., Tibshirani, R., e Friedman, J. (2009). The Elements of Statistical Learning: data mining, inference and prediction, $2 d$ Edition. Springer. Citado na página 55.

Heckerman, D., Meek, C., e Koller, D. (2004a). Probabilistic entity-relationship models, prms, and plate models. In Proceedings of the 21st International Conference on Machine Learning, Banff, Canada. Citado na página 42.

Heckerman, D., Meek, C., e Koller, D. (2004b). Probabilistic models for relational data. Relatório técnico, Microsoft Research. Citado nas páginas 4 e 41 . 
Huang, Z., Li, X., e Chen, H. (2005). Link prediction approach to collaborative filtering. In Proceedings of the 5th ACM IEEE-CS Joint Conference on Digital Libraries, JCDL’05, páginas 141-142. Citado na página 45.

Hummel, R. e Zucker, S. (1983). On the foundations of relaxation labeling processes. IEEE Transactions on Pattern Analysis and Machine Intelligence, páginas 267-287. Citado na página 22.

Jaccard, P. (1901). Étude comparative de la distribution florale dans une portion des Alpes et des Jura. Bulletin del la Société Vaudoise des Sciences Naturelles, 37:547-579. Citado na página 35.

Jeh, G. e Widom, J. (2002). Simrank: a measure of structural-context similarity. In Proceedings of the 8th ACM SIGKDD International Conference on Knowledge Discovery and Data Mining, KDD’02, páginas 538-543. Citado na página 38.

Kahanda, I. e Neville, J. (2009). Using transactional information to predict link strength in online social networks. In ICWSM. Citado na página 3.

Katz, L. (1953). A new status index derived from sociometric analysis. Psychometrika, 18(1):39-43. Citado nas páginas 3 e 37.

Keeling, M. e Eames, K. (2005). Networks and epidemic models. Journal of the Royal Society Interface, 2(4):295-307. Citado na página 46.

King, R. D., Muggleton, S. H., Srinivasan, A., e Sternberg, M. J. E. (1996). Structure-activity relationships derived by machine learning: The use of atoms and their bond connectivities to predict mutagenicity by inductive logic programming. National Academy of Sciences, 93(1):438-442. Citado na página 24.

Kleinberg, J. M. (1999). Authoritative sources in a hyperlinked environment. J. ACM, 46:604-632. Citado na página 22.

Koller, D. e Pfeffer, A. (1998). Probabilistic frame-based systems. In Proceedings of the fifteenth national/tenth conference on Artificial Intelligence/Innovative Applications of Artificial Intelligence, AAAI '98/IAAI '98, páginas 580-587, Menlo Park, CA, USA. American Association for Artificial Intelligence. Citado nas páginas 3 e 40.

Krebs, V. (2002). Mapping networks of terrorist cells. Connections, 24:43-52. Citado nas páginas 3, 39, e 45. 
Kunegis, J., Lommatzsch, A., e Bauckhage, C. (2009). The slashdot zoo: mining a social network with negative edges. In Proceedings of the 18th International Conference on World Wide Web, WWW'09, páginas 741-750. Citado na página 47.

Lafferty, J., McCallum, A., e Pereira, F. (2001). Conditional random fields: Probabilistic models for segmenting and labeling sequence data. In Proceedings of ICMC'01. Citado na página 22.

Leicht, E. A., Holme, P., e Newman, M. E. J. (2006). Vertex similarity in networks. Phys. Rev. E, 73(2):026120. Citado na página 36.

Leskovec, J., Huttenlocher, D., e Kleinberg, J. (2010). Predicting positive and negative links in online social networks. In Proceedings of the 19th International Conference on World Wide Web, WWW'10, páginas 641-650. Citado na página 47.

Liben-Nowell, D. e Kleinberg, J. (2007). The link-prediction problem for social networks. Journal of the American Society for Information Science and Technology, 58(7):1019-1031. Citado nas páginas 2, 3, 24, 28, 29, 36, 45, 48, e 92.

Lichtenwalter, R. N., Lussier, J. T., e Chawla, N. V. (2010). New perspectives and methods in link prediction. In Proceedings of the 16th ACM SIGKDD International Conference on Knowledge Discovery and Data Mining, KDD'10, páginas 243-252. Citado na página 48.

Liu, Z., Zhang, Q.-M., Lü, L., e Zhou, T. (2011). Link prediction in complex networks: a local naïve bayes model. EPL, 96(48007). Citado na página 53.

Lorrain, F. e White, H. (1971). Structural equivalence of individuals in social networks. Journal of Mathematical Sociology, 1:49-80. Citado nas páginas 3 , 34, e 52 .

Lü, L., Jin, C.-H., e Zhou, T. (2009). Similarity index based on local paths for link prediction of complex networks. Phys. Rev. E, 80(4):046122. Citado na página 27.

Lü, L. e Zhou, T. (2010). Link prediction in weighted networks: the role of weak ties. Europhysics Letters, 89. Citado nas páginas 34 e 47. 
Lü, L. e Zhou, T. (2011). Link prediction in complex networks: A survey. Physica A: Statistical Mechanics and its Applications, 390(6):1150-1170. Citado nas páginas $3,24,27,31,33,40,45,46$, e 48.

Lu, Q. e Getoor, L. (2003). Link-based classification. In T. Fawcett, N. Mishra, and N. Mishra (Eds.), Proceedings of the International Conference on Machine Learning (ICML), AAAI Press., páginas 496-503. Citado na página 22.

Maciel, C., Roque, L., e Garcia, A. C. B. (2009). Democratic citizenship community: a social network to promote e-deliberative process. In Proceedings of the 10th Annual International Conference on Digital Government Research: Social Networks: Making Connections between Citizens, Data and Government, dg.o '09, páginas 25-34. Digital Government Society of North America. Citado na página 11.

Macskassy, S. e Provost, F. (2007). Classification in networked data: A toolkit and a univariate case study. J. Mach. Learn, 8:935-983. Citado na página 62.

Mayer, A. (2009). Online social networks in economics. Decis. Support Syst., 47:169-184. Citado na página 11.

McPherson, M., Smith-Lovin, L., e Cook, J. M. (2001). Birds of a feather: Homophily in social networks. Annual Review of Sociology, 27(1):415-444. Citado na página 29.

Mitchell, T. M. (1997). Machine Learning. McGraw-Hill, New York. Citado na página 1.

Moreno, J. L. (1934). Who shall survive? Beacon House. Citado na página 29.

Mossel, E. e Vigoda, E. (2005). Phylogenetic MCMC algorithms are misleading on mixtures of trees. Science (New York, N.Y.), 309(5744):2207-2209. Citado na página 39.

Murata, T. e Moriyasu, S. (2007). Link prediction of social networks based on weighted proximity measures. In Proceedings of the IEEE/WIC/ACM International Conference on Web Intelligence, WI’07, páginas 85-88. Citado nas páginas 34 e 47.

Murata, T. e Moriyasu, S. (2008). Link prediction based on structural properties of online social networks. New Generation Computing, 26(3):245-257. Citado na página 34 . 
Newman, M. E. J. (2001). Clustering and preferential attachment in growing networks. Phys. Rev. E, 64:025102. Citado nas páginas 13, 18, 35, e 36.

Newman, M. E. J. (2003). The structure and function of complex networks. SIAM Review, (45):167-256. Citado nas páginas 2, 13, 19, e 29.

Newman, M. E. J. (2004a). Coauthorship networks and patterns of scientific collaboration. In Proceedings of the National Academy of Science of the Uninted States, volume 101 of PNAS'04, páginas 5200-5205. Citado na página 10.

Newman, M. E. J. (2004b). Fast algorithm for detecting community structure in networks. Phys. Rev. E, 69(6):066133. Citado na página 23.

Newman, M. E. J. (2006). Finding community structure in networks using the eigenvectors of matrices. Phys. Rev. E, 74:036104. Citado na página 62.

Newman, M. E. J. (2010). Networks: an introduction. Oxford University Press. Citado nas páginas 1, 9, 10, 13, 18, 19, e 21.

Newman, M. E. J. e Girvan, M. (2004). Finding and evaluating community structure in networks. Phys. Rev. E, 69(2):026113. Citado na página 22.

Nkweteyim, D. L. (2005). A collaborative filtering approach to predict web pages of interest from navigation patterns of past users within an academic website. Tese de Doutorado, Pittsburgh, PA, USA. AAI3192994. Citado na página 45.

Page, L., Brin, S., Motwani, R., e Winograd, T. (1998). The PageRank citation ranking: Bringing order to the web. Citado nas páginas 22 e 37.

Pan, R., Zhou, Y., Cao, B., Liu, N. N., Lukose, R., Scholz, M., e Yang, Q. (2008). One-class collaborative filtering. In Proceedings of the 8th IEEE International Conference on Data Mining, ICDM’08, páginas 502-511. Citado na página 48.

Polikar, R. (2006). Ensemble based systems in decision making. IEEE Circuits and Systems Magazine, 6(3):21-45. Citado nas páginas 42 e 48.

Pons, P. e Latapy, M. (2006). Computing communities in large networks using random walks. J. Graph Algorithms Appl,, 10(2):191-218. Citado na página 23. 
Pons, P. e Latapy, M. (2011). Post-processing hierarchical community structures: Quality improvements and multi-scale view. Theor. Comput. Sci., 412:892-900. Citado na página 40.

Poole, D. (1993). Probabilistic horn abduction and bayesian networks. Artif. Intell., 64:81-129. Citado nas páginas 3 e 40.

Potgieter, A., April, K. A., Cooke, R. J. E., e Osunmakinde, I. O. (2007). Temporality in Link Prediction: Understanding Social Complexity. Sprouts: Working Papers on Information Systems, 9(7). Citado nas páginas 3, 40, e 47.

Powers, D. M. W. (2011). Evaluation: From Precision, Recall and F-Factor to ROC, Informedness, Markedness \& Correlation. Journal of Machine Learning Technologies, 2(1):37-63. Citado na página 33.

Rapoport, A. (1957). Contribution to the theory of random and biased nets. Bulletin of Mathematical Biophysics, (19):257-277. Citado na página 29.

Rattigan, M. J. e Jensen, D. (2005). The case for anomalous link discovery. SIGKDD Explor. Newsl., 7:41-47. Citado na página 47.

Ravasz, E., Somera, A. L., Mongru, D. A., Oltvai, Z. N., e Barabási, A. L. (2002). Hierarchical Organization of Modularity in Metabolic Networks. Science, 297(5586):1551-1555. Citado na página 36.

Redner, S. (2008). Networks: Teasing out the missing links. Nature, 453(7191):47-48. Citado nas páginas 3 e 39.

Rosvall, M. e Bergstrom, C. (2008). Maps of information flow reveal community structure in complex networks. In Proceedings of the National Academy of Science of the Uninted States, volume 105 of PNAS'08, páginas 1118-1123. Citado nas páginas 24 e 43.

Russell, S. e Norvig, P. (2010). Artificial Intelligence: A Modern Approach, 3rd Edition. Prentice Hall. Citado na página 55.

Sales-Pardo, M., Guimerà, R., Moreira, A., e Núñez-Amaral, L. A. (2007). Extracting the hierarchical organization of complex systems. In Proc. Natl. Acad. Sci., number 15224. Citado nas páginas 3 e 38.

Salton, G. e McGill, M. J. (1986). Introduction to Modern Information Retrieval. McGraw-Hill, Inc., New York, NY, USA. Citado na página 35. 
Sharan, U. (2008). Temporal-relational classifiers for prediction in evolving domains. In In Proceedings of the IEEE International Conference on Data Mining. Citado na página 47.

Soares, P. (2012). Predição de links em redes sociais com uso de informações temporais. Dissertação de Mestrado, Universidade Federal de Pernambuco, Recife, Brasil. Citado nas páginas 10, 12, 13, 20, 29, 45, 46, 47, e 48.

Soares, P. e Prudencio, R. (2012). Time series based link prediction. In Proceedings of the 2012 International Joint Conference on Neural Networks, IJCNN'12, páginas 784-790. Citado na página 47.

Solomonoff, R. e Rapoport, A. (1951). Connectivity of random nets. Bulletin of Mathe- matical Biology, (13):107-117. Citado na página 19.

Soundarajan, S. e Hopcroft, J. (2012). Using Community Information to Improve the Precision of Link Prediction Methods. WWW'12, páginas 607-608. Citado nas páginas $4,42,43,44,48$, e 51 .

$\mathrm{S} \phi$ rensen, T. (1948). A method of establishing groups of equal amplitude in plant sociology based on similarity of species content, and its application to analyses of the vegetation. Danish commons. Biol. Skr. 5, (4). Citado na página 35.

Spring, N., Mahajan, R., Wetherall, D., e Anderson, T. (2004). Measuring ISP topologies with rocketfuel. Networking, IEEE/ACM Transactions on, 12(1):2 - 16. Citado na página 62.

Swamynathan, G., Wilson, C., Boe, B., Almeroth, K., e Zhao, B. Y. (2008). Do social networks improve e-commerce?: a study on social marketplaces. In Proceedings of the first workshop on Online social networks, WOSN '08, páginas 1-6, New York, NY, USA. ACM. Citado na página 11.

Tang, J., Wang, T., Wang, J., e Wei, D. (2009). Efficient social network approximate analysis on blogosphere based on network structure characteristics. In Proceedings of the 3rd Workshop on Social Network Mining and Analysis, SNA-KDD '09, páginas 7:1-7:8, New York, NY, USA. ACM. Citado na página 11.

Taskar, B., Abbeel, P., e Koller, D. (2002). Discriminative probabilistic models for relational data. In Proceedings of the Eighteenth Conference Annual 
Conference on Uncertainty in Artificial Intelligence (UAI-02), páginas 485-489, San Francisco, CA. Morgan Kaufmann. Citado na página 41.

Taskar, B., Segal, E., e Koller., D. (2001). Probabilistic classification and clustering in relational data. In Proceedings of the Seventeenth International Joint Conference on Artificial Intelligence, páginas 870-878. Citado na página 41.

Valverde-Rebaza, J. e de Andrade Lopes, A. (2012a). Link prediction in complex networks based on cluster information. In Advances in Artificial Intelligence, SBIA 2012, 21 th Brazilian Symposium on Artificial Intelligence, volume 7589 of Lecture Notes in Computer Science, páginas 92-101. Springer. Citado nas páginas 4,7 , e 94 .

Valverde-Rebaza, J. e de Andrade Lopes, A. (2012b). Structural Link Prediction Using Community Information on Twitter. In Proceedings of the 2012 Fourth International Conference on Computational Aspects of Social Networks, CASON 2012, páginas 132-137. Citado nas páginas 4, 7, 67, e 94.

von Mering, C., Krause, R., Snel, B., Cornell, M., Oliver, S. G., Fields, S., e Bork, P. (2002). Comparative assessment of large-scale data sets of proteinprotein interactions. Nature, 417(6887):399-403. Citado na página 62.

Wang, C., Satuluri, V., e Parthasarathy, S. (2007). Local probabilistic models for link prediction. In Proceedings of the 2007 Seventh IEEE International Conference on Data Mining, páginas 322-331, Washington, DC, USA. IEEE Computer Society. Citado nas páginas 2 e 40.

Washio, T., De Raedt, L., e Kok, J. N. (2004). Advances in mining graphs, trees and sequences: Preface. Fundam. Inf., 66:.5-.8. Citado nas páginas 1 e 2.

Wasserman, S. e Faust, K. (1994). Social network analysis: Methods and applications. Cambridge University Press. Citado nas páginas 10 e 15 .

Watts, D. e Strogatz, S. (1998). Collective dynamics of small-world networks. Nature 393, (6684):440-442. Citado nas páginas 16, 20, e 62.

Xiang, R., Neville, J., e Rogati, M. (2010). Modeling relationship strength in online social networks. In Proceedings of the 19th international conference on World wide web, WWW '10, páginas 981-990, New York, NY, USA. ACM. Citado nas páginas 11 e 46. 
Yin, D., Hong, L., e Davison, B. D. (2011). Structural link analysis and prediction in microblogs. In Proceedings. of the 20th ACM International Conference on Information and Knowledge Management, CIKM '11, páginas 1163-1168. Citado na página 67.

Yin, Z., Gupta, M., Weninger, T., e Han, J. (2010a). Linkrec: a unified framework for link recommendation with user attributes and graph structure. In Proceedings of the 19th International Conference on World Wide Web. Citado na página 67.

Yin, Z., Gupta, M., Weninger, T., e Han, J. (2010b). A unified framework for link recommendation using random walks. In Proceedings of the 2010 International Conference on Advances in Social Networks Analysis and Mining, ASONAM'10, páginas 152-159. Citado na página 29.

Yoshida, K., Motoda, H., e Indurkhya, N. (1994). Graph based induction as a unified learning framework. Journal of Applied Intelligence, 4(3):297-316. Citado na página 24.

Yu, P. S., Han, J., e Faloutsos, C. (2010). Link Mining: Models, Algorithms, and Applications. Springer Publishing Company, Incorporated, $1^{\text {a }}$ edição. Citado na página 40.

Zachary, W. W. (1977). An information flow model for conflict and fission in small groups. Journal of Anthropological Research, 33(4):452-473. Citado na página 62.

Zanette, D. (2002). Dynamics of rumor propagation on small-world networks. Physical Review E, 65, 041908. Citado na página 46.

Zhang, Q.-M., Lü, L., Wang, W.-Q., Zhu, Y.-X., e Zhou, T. (2012). Potential theory for directed networks. CoRR, abs/1202.2709. Citado na página 67.

Zheleva, E., Getoor, L., Golbeck, J., e Kuter, U. (2008). Using friendship ties and family circles for link prediction. In Proceedings of the 2nd International Conference on Advances in Social Network Mining and Analysis, SNAKDD'08, páginas 97-113. Citado nas páginas 4, 42, 43, 48, e 51.

Zhou, T., Lü, L., e Zhang, Y.-C. (2009). Predicting missing links via local information. The European Physical Journal B, 71:623. Citado nas páginas $3,4,27,32,35,36,52$, e 92 . 